LA-UR-01-4561

Approved for public release: distribution is unlimited.

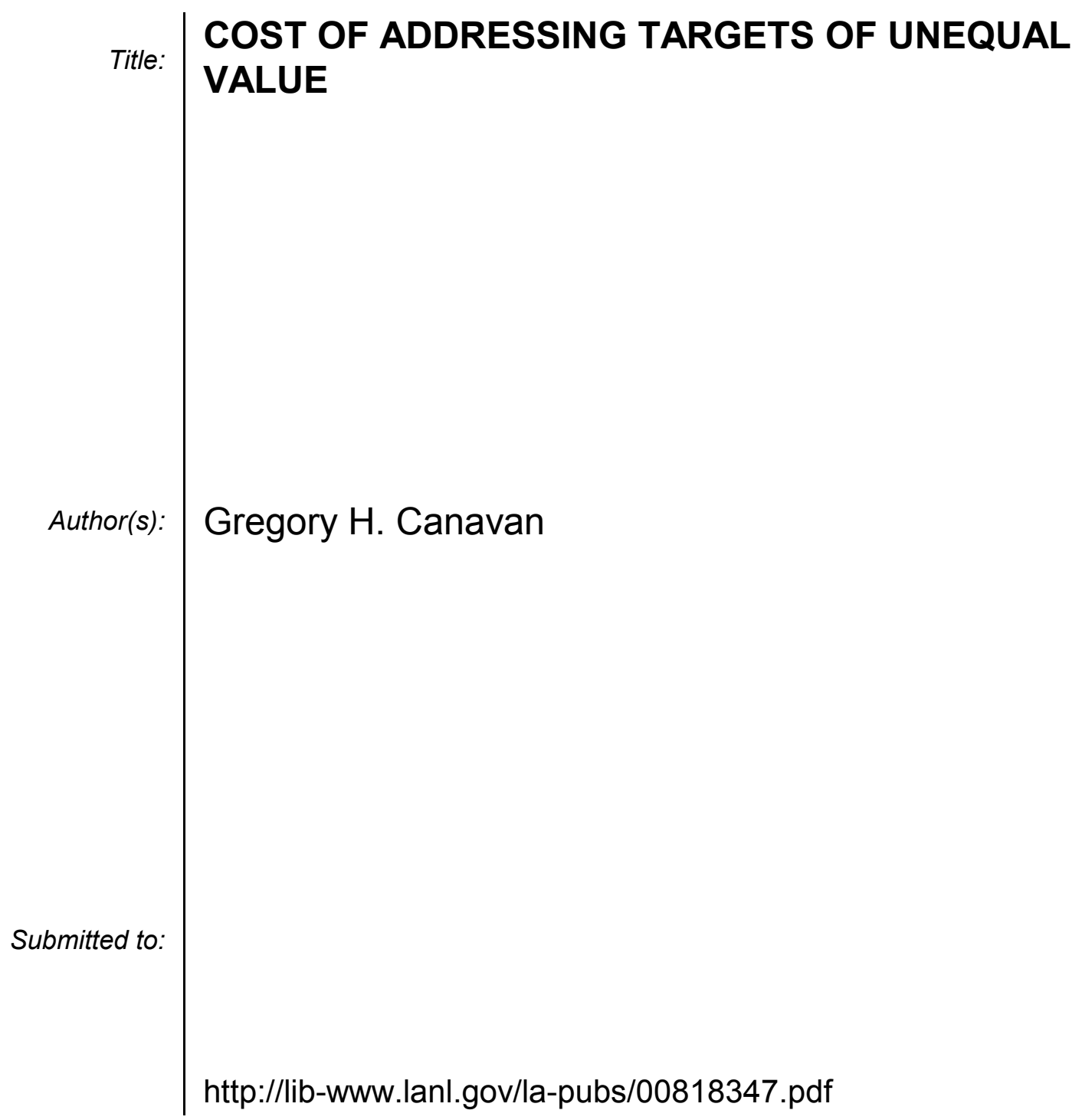

Los Alamos National Laboratory, an affirmative action/equal opportunity employer, is operated by the University of California for the U.S. Department of Energy under contract W-7405-ENG-36. By acceptance of this article, the publisher recognizes that the U.S. Government retains a nonexclusive, royaltyfree license to publish or reproduce the published form of this contribution, or to allow others to do so, for U.S. Government purposes. Los Alamos National Laboratory requests that the publisher identify this article as work performed under the auspices of the U.S. Department of Energy. Los Alamos National Laboratory strongly supports academic freedom and a researcher's right to publish; as an institution, however, the Laboratory does not endorse the viewpoint of a publication or guarantee its technical correctness. 


\title{
COST OF ADDRESSING TARGETS OF UNEQUAL VALUE
}

\author{
Gregory H. Canavan
}

First strike costs are generalized to include higher value targets. As the number of weapons decreases, second strikes shift to high value targets. An increased preference for damaging high value targets or a decreased preference for preventing damage to one's own decrease first strike costs and stability. Defenses reduce second strikes, first strike costs, and the number of weapons delivered on the first striker's high value targets.

Introduction. The formalism for evaluating first strike costs and incentives for military targeting generalize to include higher value targets. That introduces two new allocations to the usual allocation between missiles and military targets, but they can be performed analytically. As the number of weapons on each side decreases, the optimal fraction of second strike weapons allocated to military values falls. The shift to high value targets is more pronounced below about 1,000 weapons for nominal parameters. Below 500 weapons the first striker's cost of action drops below its cost of inaction. A strike would induce a second strike of about 250 weapons on high value targets. An increase in the first striker's preference for damage to the other's high value targets increases or a decrease in its preference for preventing damage to its own high value targets decreases first strike costs and stability margins.

Including defenses complicates allocations slightly. The main effect is increased attrition of second strikes, particularly at larger defenses, which makes it possible to significantly reduce damage to high value targets. At 1,000 weapons, by 300 to 400 interceptors the first striker's costs are reduced to $30 \%$ below that of inaction and the number of weapons delivered on the first striker's high value targets is reduced to about 100 .

Exchanges are modeled and optimized with generalizations of previous work. ${ }^{1}$ Side U has $\mathrm{M}$ vulnerable missiles with $\mathrm{m}$ warheads each and $\mathrm{N}$ survivable missiles with $\mathrm{n}$ warheads for a total of $\mathrm{W}=\mathrm{mM}+\mathrm{nN}$ warheads. Side $\mathrm{P}$, whose forces and costs are denoted by primes, has $\mathrm{M}^{\prime}$ vulnerable missiles with m' warheads each and N' survivable missiles with n' warheads for a total of $\mathrm{W}^{\prime}=\mathrm{m}^{\prime} \mathrm{M}^{\prime}+\mathrm{n}^{\prime} \mathrm{N}^{\prime}$ warheads. If $\mathrm{U}$ strikes first, it delivers a fraction $\mathrm{f}$ of its $\mathrm{W}$ weapons on P's vulnerable missiles and the remaining $1-\mathrm{f}$ in a first strike on value targets of magnitude

$$
\mathrm{F}=(1-\mathrm{f}) \mathrm{W} \text {. }
$$


The counter force strike of an average of $r=f W / M$ ' warheads on each vulnerable missile, which gives them a survival probability Q' determined by the weapons' kill probability is $\mathrm{p}=1-\mathrm{q}$. If $[r]$ is the integer part of $r$, a fraction $r-[r]$ of the missiles are struck by $[r]+1$ weapons and a fraction $[\mathrm{r}]+1-\mathrm{r}$ are struck by $[\mathrm{r}]$, whereby

$$
Q^{\prime}=(r-[r]) q^{([r]+1)}+([r]+1-r) q^{[r]}=(1-p(r-[r])) q^{[r]},
$$

Prime's launched second strike is

$$
\mathrm{S}^{\prime}=\mathrm{Q}^{\prime} \mathrm{m}^{\prime} \mathrm{M}^{\prime}+\text { n'N', }
$$

which is delivered on value, as residual weapons are taken to have no value. Unprime's second strike and primes first strike are obtained by conjugating (interchanging primed and unprimed terms) in Eqns. (1) to (3).

Costs. First and second strikes are converted into costs through exponential approximations to the value of the targets destroyed. It is assumed that $\mathrm{U}$ has $1 / \mathrm{k}$ and $\mathrm{P}$ has $1 / \mathrm{k}$ ' military value target and that $\mathrm{U}$ has $1 / \mathrm{v}$ and $\mathrm{P}$ has $1 / \mathrm{v}$ ' higher value targets. $\mathrm{U}$ divides its first strike between P's military and higher value targets, allocating a fraction $\mathrm{h}$ to the former and $1-\mathrm{h}$ to the latter, which produces first strike costs of

$$
\begin{aligned}
& \mathrm{C}_{1 \mathrm{mo}}=\mathrm{Le}^{-\mathrm{k}^{\prime} \mathrm{hF}}, \\
& \mathrm{C}_{1 \mathrm{vo}}=\mathrm{Ve}^{-\mathrm{v}^{\prime}(1-\mathrm{h}) \mathrm{F}},
\end{aligned}
$$

where $\mathrm{C}_{1 \mathrm{mo}}$ is the cost to $\mathrm{U}$ of its incomplete damage to $\mathrm{P}$ 's military value and $\mathrm{C}_{1 \mathrm{vo}}$ is the cost to $\mathrm{U}$ of its incomplete damage to P's higher value targets. $\mathrm{L}$ is U's preference for attacking P's military targets relative to preventing damage to its own. Thus, V/L indicates U's preference for attacking P's higher value targets relative to that for attacking military targets.

$\mathrm{P}$ also divides its second strike between U's military and higher value targets, allocating a fraction $\mathrm{g}$ to the former and $1-\mathrm{g}$ to the latter, which produces costs to first striker $\mathrm{U}$ of

$$
\begin{aligned}
& \mathrm{C}_{1 \mathrm{~ms}}=1-\mathrm{e}^{-\mathrm{kg}^{\prime} \mathrm{S}^{\prime},} \\
& \mathrm{C}_{1 \mathrm{vs}}=\mathrm{K}\left(1-\mathrm{e}^{-\mathrm{v}\left(1-\mathrm{g}^{\prime}\right) \mathrm{S}^{\prime}}\right),
\end{aligned}
$$

where $\mathrm{C}_{1 \mathrm{~ms}}$ is the cost to U of P's damage to U's military targets and $\mathrm{C}_{1 \mathrm{vs}}$ is the cost of P's damage to U's higher value targets. $\mathrm{K}$ is the priority $\mathrm{U}$ assigns to damage on its higher value targets relative to that given to damage on its military targets. U's cost for striking first is

$$
\begin{aligned}
\mathrm{C}_{1} & =\mathrm{C}_{1 \mathrm{~m}}+\mathrm{C}_{1 \mathrm{v}}=\mathrm{C}_{1 \mathrm{~ms}}+\mathrm{C}_{1 \mathrm{mo}}+\mathrm{C}_{1 \mathrm{vs}}+\mathrm{C}_{1 \mathrm{vo}} \\
& =\left(1-\mathrm{e}^{-\mathrm{kg}^{\prime} \mathrm{S}^{\prime}}\right)+\mathrm{Le}^{-\mathrm{k}^{\prime} \mathrm{hF}} \\
& +\mathrm{K}\left(1-\mathrm{e}^{-\mathrm{v}\left(1-\mathrm{g}^{\prime}\right) \mathrm{S}^{\prime}}\right)+\mathrm{Ve}^{-\mathrm{v}^{\prime}(1-\mathrm{h}) \mathrm{F}},
\end{aligned}
$$


The first two terms are the cost of damage to $\mathrm{U}$ and incomplete damage to P's military targets, which are included in previous analyses. The last two are the corresponding costs of damage to $\mathrm{U}$ and incomplete damage to P's higher value targets, which are new. Thus, for $\mathrm{K}$ and $\mathrm{V}$ small, the analysis reproduces previous results, while for $\mathrm{K}$ and $\mathrm{V}$ large it should migrate to a stability analysis based on high value rather than military targets. From the form of the damage functions implicit in Eq. (8) it follows that for $\mathrm{K}$ and $\mathrm{V}>1$ and $\mathrm{v}^{\prime}<\mathrm{k}$ ', $\mathrm{U}$ sees an incentive to preferentially strike high value targets.

Allocations. $\mathrm{U}$ chooses $\mathrm{f}$ and $\mathrm{h}$ to minimize $\mathrm{C}_{1}$. When higher value targets are included, $\mathrm{P}$ can also choose $\mathrm{g}$ to maximize $\mathrm{C}_{1}$. Thus, there are two optimizations. $\mathrm{U}$ attempts to minimize $\mathrm{C}_{1}$ through appropriate choice of $\mathrm{f}$ and $\mathrm{h}$, while for every choice, $\mathrm{P}$ chooses $\mathrm{g}$ to maximize $\mathrm{U}$ 's $\mathrm{C}_{1}$. It is useful to treat this joint optimization in two steps. In the first, $\mathrm{g}$ is varied exogenously, optimizing $\mathrm{f}$ and $\mathrm{h}$ for each value of $\mathrm{g}$. In the second, all three are optimized for each value of force levels.

Equal forces and target structures. Assume unprime and prime have $1 / \mathrm{k}=1 / \mathrm{k}^{\prime}=1,000$ military, $1 / \mathrm{v}=1 / \mathrm{v}^{\prime}=100$ high value targets, $\mathrm{M}=\mathrm{N}=500$ missiles, and $\mathrm{m}=\mathrm{n}=2$ warheads per missiles and parameters $\mathrm{L}=0.5$ and $\mathrm{K}=\mathrm{V}=1$, i.e., a modest preference for high value targets and roughly equal preferences for striking and protecting high value targets. For those parameters, $\mathrm{h} \approx 0.7$ for all values of $\mathrm{g}$, while $\mathrm{U}$ 's allocation to missiles $\mathrm{f}$ increases roughly linearly to 0.4 as $g$ increases from 0 to 1 .

Figure 1 shows how the various components of cost vary with $\mathrm{g}$. $\mathrm{C}_{1 \mathrm{~ms}}$ increases with $\mathrm{g}$ from about 0.2 to 0.6 with diminishing returns; $\mathrm{C}_{1 \mathrm{mo}}$ increases slightly with $\mathrm{g}$ to 0.2 ; the overall $\mathrm{C}_{1 \mathrm{~m}}$ increases with $\mathrm{C}_{1 \mathrm{~ms}}$ to about 0.8 . Conversely, $\mathrm{C}_{1 \mathrm{vs}}$ is roughly constant at small $\mathrm{g}$, but falls at large $\mathrm{g}$, and $\mathrm{C}_{1 \mathrm{vo}}$ is small throughout, $\mathrm{so}_{1 \mathrm{v}}$ falls with $\mathrm{C}_{1 \mathrm{vs}}$ at larger $\mathrm{g}$. The total $\mathrm{C}_{1}$ increases with $\mathrm{C}_{1 \mathrm{~ms}}$ at small $\mathrm{g}$ and falls with $\mathrm{C}_{1 \mathrm{vs}}$ at large $\mathrm{g}$, so it. has a maximum of $\approx 1.7$ at $\mathrm{g} \approx 0.7$, which is value of $\mathrm{g}$ that $\mathrm{P}$ would choose to maximize U's cost of striking first. Note that this maximum value of 1.7 is larger than $\mathrm{L}+\mathrm{V}=0.5+1=1.5$, which is $\mathrm{U}$ 's cost of inaction.

Although inappropriate, a choice of $g<0.35$ by $P$, i.e., a second strike primarily on high value targets, would produce a $\mathrm{U}$ cost of first strike less than that of inaction, i.e, it would produce an incentive to strike. A strike totally on military targets, $g=1$, would produce a first strike cost about equal to the cost of inaction. Thus, the proper admixture of higher value targets can stabilize configurations that would be unstable if targeting was confined to military targets. 
Figure 2 shows the impact of reduced forces $M=N=250$ with $m=n=2$. The cost of damage to military targets again increases with $\mathrm{g}$, but the reduction in forces causes $\mathrm{C}_{1 \mathrm{v}}$ to drop more rapidly, which shifts the optimum value of $g$ to 0.5 and reduces the maximum in $\mathrm{C}_{1}$ to about 1.6. As the number of missiles falls, the optimum continues to shift to smaller g. Reducing force levels at constant cost parameters shifts targeting from military to high value targets.

Optimum allocations. Since the total first and second strikes are determined by the allocation $\mathrm{f}$, the secondary allocations $\mathrm{g}$ and $\mathrm{h}$ can be determined by differentiating the costs of Eq. (8) with respect to them. The partial derivative of $C_{1}$ with respect to g' determines the optimal allocation

$$
\mathrm{g}^{\prime}=\left(\mathrm{v}+\left(1 / \mathrm{S}^{\prime}\right) \ln (\mathrm{k} / \mathrm{Kv})\right) /(\mathrm{k}+\mathrm{v}),
$$

and that with respect to $h$ determines

$$
\mathrm{h}=\left(\mathrm{v}^{\prime}+(1 / \mathrm{F}) \ln \left(\mathrm{Lk} \mathrm{k}^{\prime} \mathrm{Vv}^{\prime}\right)\right) /\left(\mathrm{k}^{\prime}+\mathrm{v}^{\prime}\right),
$$

which are shown in Fig. 3 as functions of total force level $\mathrm{W}$ as the number of doublet $\mathrm{U}$ and $\mathrm{P}$ vulnerable and survivable missiles are reduced equally. U's allocation to missiles, $\mathrm{f}$, is roughly constant at 0.25 . U's allocation of its first strike to military targets, $h$, and P's restrike on military targets, $\mathrm{g}$, fall from about 0.75 at $\mathrm{W}=2,000$ to 0.55 at 500 , after which they fall rapidly to zero by 300 . Thus, below about 1,000 weapons, second strikes shift rapidly to high value targets.

Figure 4 shows the total number of weapons allocated to high value targets in first and second strikes as functions of the total number of weapons available. At 2,000 weapons they are about 400 and 300 weapons, or about 20 and $15 \%$ of the total, respectively. By $\mathrm{W}=500$ they are 300 and 225, reflecting the shift to high value shown in Fig. 3. For smaller values they fall rapidly, but constitute most of the remaining weapons.

Figure 5 shows the resulting costs. The cost for damage to value changes little, but the cost for damage to military targets falls from about 0.75 to 0.5 , so the total cost falls below the cost of inaction by about 600 weapons even when they are targeted optimally between military and high value targets. Figure 6 provides more detail on the variation of component costs. $\mathrm{C}_{1 \mathrm{~m}}$ only falls about $30 \%$, but its components vary more: $\mathrm{C}_{1 \mathrm{~ms}}$ falls $100 \% ; \mathrm{C}_{1 \mathrm{mo}}$ increases a like amount. Similarly, $\mathrm{C}_{1 \mathrm{vs}}$ and $\mathrm{C}_{1 \text { vo }}$ vary about $50 \%$, but $\mathrm{C}_{1 \mathrm{v}}$ varies little. Modest changes in aggregate costs are the result of larger changes in components - particularly at small forces.

Sensitivity to cost parameters. Sensitivity to $\mathrm{L}$ is understood from preveious analyses of purely military target structures. Sensitivity to V, which reflects U's preference for damage to 
P's high value targets is straightforward. The calculations are done for the small force $\mathrm{W}=400$, because Eq. (10) indicates that for large forces, $h \sim v^{\prime} /\left(k^{\prime}+v^{\prime}\right)=1 / k^{\prime} /\left(1 / k^{\prime}+1 / v^{\prime}\right)$, i.e., that $U$ targets military targets in proportion to their fraction of the total. For small forces, the allocation is more complex. There,as $\mathrm{V}$ increases, $\mathrm{h}$ falls from unity at $\mathrm{V}=0$ to 0 at $\mathrm{V} \approx 1$. Figure 7 shows that has little impact on military or high value target costs for $\mathrm{V}<1$. However, $\mathrm{C}_{1}$ increases with $\mathrm{V}$ for any first strike and allocations, so the cost of inaction $\mathrm{L}+\mathrm{V}$ increases linearly with $\mathrm{V}$, crossing $\mathrm{C}_{1}$ at $\mathrm{V} \approx 1$. Thus, small $\mathrm{V}$, i.e, little preference for damage to the other's high value targets, leads to inaction, while large $\mathrm{V}$, i.e, preference for damaging high value targets, could lead to strikes.

Figure 8 shows the strike allocations as functions of K, which is U's preference for avoiding damage to it own high value targets. The allocation to missiles is again about 0.25 , increasing slightly for very small or large $\mathrm{K}$, which produces corresponding increases in the weapons per missile $\mathrm{r}$ and decreases in their survival probability $\mathrm{Q}$ ' there. $\mathrm{h}$ is about 0.55 , falling slightly at extreme $\mathrm{K}$. $\mathrm{g}$ falls from about 0.8 to 0.4 as $\mathrm{K}$ increases from 0.25 to 2.3 .

Figure 9 shows the variation of component costs caused by these variations in allocations. Costs due to military targets fall slightly at small $\mathrm{K}$. Costs for high value targets increase roughly in proportion to K--largely due to the cost of damage to U's value, which is proportional to K. Since $\mathrm{K}$ does not enter the cost of inaction, it remains fixed at $\mathrm{L}+\mathrm{V}=1.5$. Thus, small $\mathrm{K}$ make the cost of action smaller than that of inaction, and large K make it larger. Said another way, a low concern for one's own high value targets reduces stability margin, and a large concern increases it.

Defenses primarily reduce second strikes in this analysis. Adding a term $-\mathrm{I}$, where I is the number of $U$ interceptors, does not change the optimal value of $h$. It changes the denominator of the first term in Eq. (9) to S' - I, which decreases g'. It also changes the second strike in the iterative solution for the allocation $\mathrm{f}$. Figure 10 shows the allocations as functions of I. $\mathrm{f}$ increases from 0.25 to 0.5 at $\mathrm{I}=350$, where it becomes efficient to increase the weapons on each vulnerable missile $\mathrm{M}$ from $\mathrm{r}=1$ to 2 , which decreases $\mathrm{Q}$ ' from 0.2 to 0.04 . That decreases $\mathrm{h}$ discontinuously; $\mathrm{g}$ falls throughout for the reason discussed above.

Figure 11 shows the resulting costs. The cost to $\mathrm{U}$ for military targets falls to $\mathrm{I}=300$; the cost for high value targets falls for larger I. The total cost decreases throughout, falling below the cost of inaction at about $\mathrm{I}=100$. Figure 12 shows the weapons delivered on high value targets in 
first and second strikes. At small I, the top curve is the first strike, F; the second is the second strike, S; the third is the weapons on P's value in U's first strike; and the fourth is P's weapons on U's high value targets in its second strike. $\mathrm{F}$ is about 750 until it becomes effective to shift additional weapons to missiles at $\mathrm{I}=350$. The second strike $\mathrm{S}$ falls throughout with survivability and interceptor losses. U's first strike on high value remains relatively constant at 330 to 310 weapons. P's strike on value remains roughly constant to $I=350$, where it falls more sharply due to reduced prelaunch survivability under increased weapons per missile. Of these trends, perhaps the most useful is U's incentive to do additional damage limiting with its defenses, which can significantly reduce the damage to its high value targets.

Summary and conclusions. The formalism developed for addressing first strike costs and incentives used for the analysis of military targeting generalizes in a natural and efficient way to include higher value targets. This introduces two new allocations in addition to the allocation between missiles and military targets discussed in earlier analyses. They are the allocation of the first strike between military and high value targets and the allocation of the second strike between the first striker's military and high value targets. The new allocations can be performed analytically, given the iterative solution of the allocation of the first strike between missiles and value. As the number of weapons on each side decreases, the optimal fraction of second strike weapons allocated to military values falls. This implies a shift of targeting towards high value targests that becomes sharper below about 1,000 weapons for nominal conditions. Below 500 weapons the first striker's cost of action drops below its cost of inaction. A strike there would induce a second strike of about 250 weapons on high value targets. As the first striker's preference for damage to the other's high value targets increases, or its preference for preventing damage to its own high value targets decreases, first strike costs and stability margins are reduced.

When defenses are included, allocations are complicated slightly, but the main effect is the increased attrition and of second strikes, particularly at larger defenses. That makes it possible to significantly reducing damage to high value targets. At a level of 1,000 weapons, the first striker's costs are strongly reduced by $>300$ interceptors. By 400 interceptors the first striker's cost is reduced to $30 \%$ below that of inaction and the number of weapons delivered on the first striker's high value targets is reduced to about 100. To fully evaluate the impact of these results on stability it is necessary to examine the other sides' first strike costs as well. 


\section{References}

${ }^{1}$ G. Canavan, "Decision Analysis of Bi- and Tri-Lateral Engagements," Roundtable on Stability, US State Department, IDA, November 2000; Los Alamos National Laboratory Report LA-UR-00-5737, November 2000. 


\section{targeting}

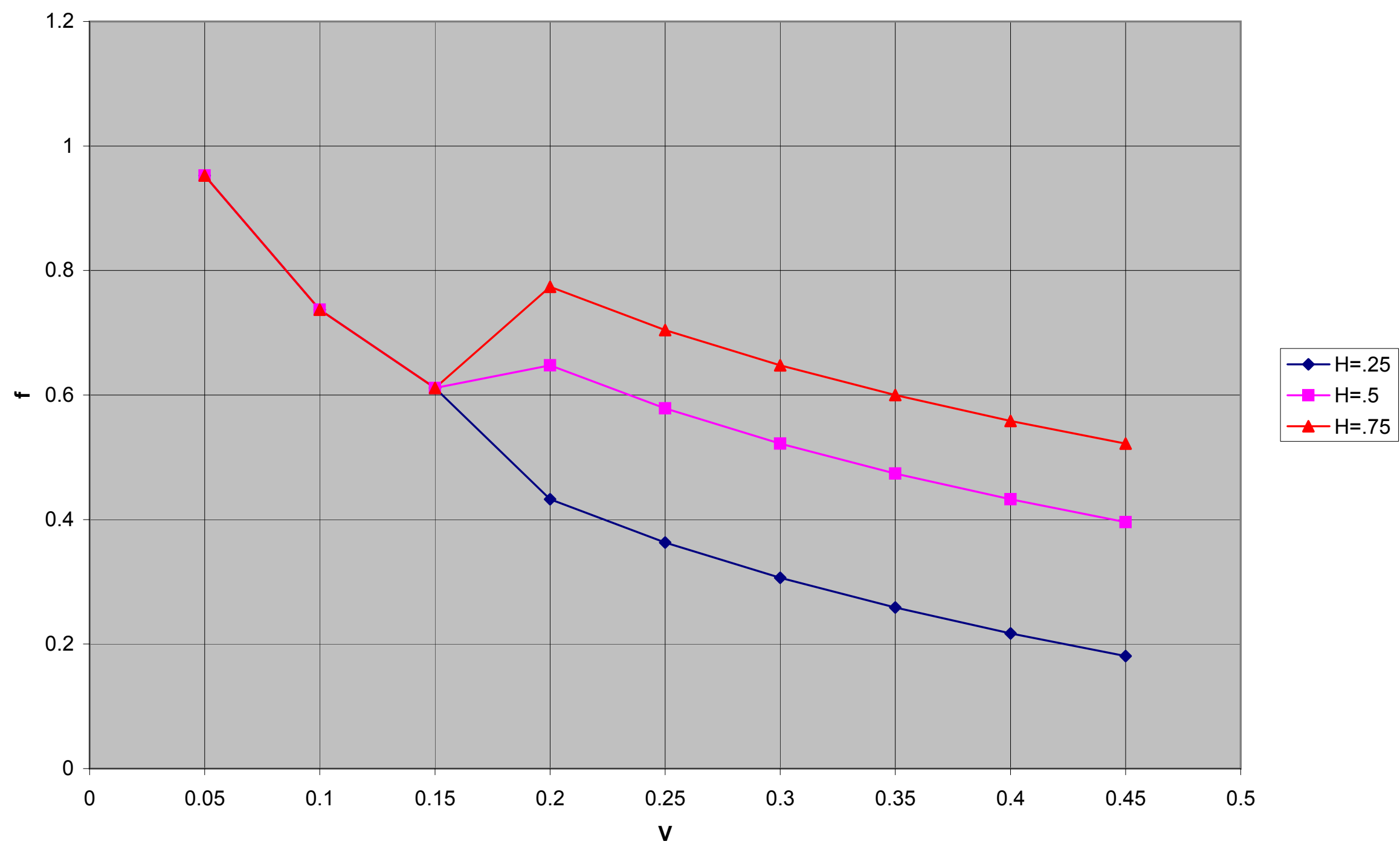


C1-L-V

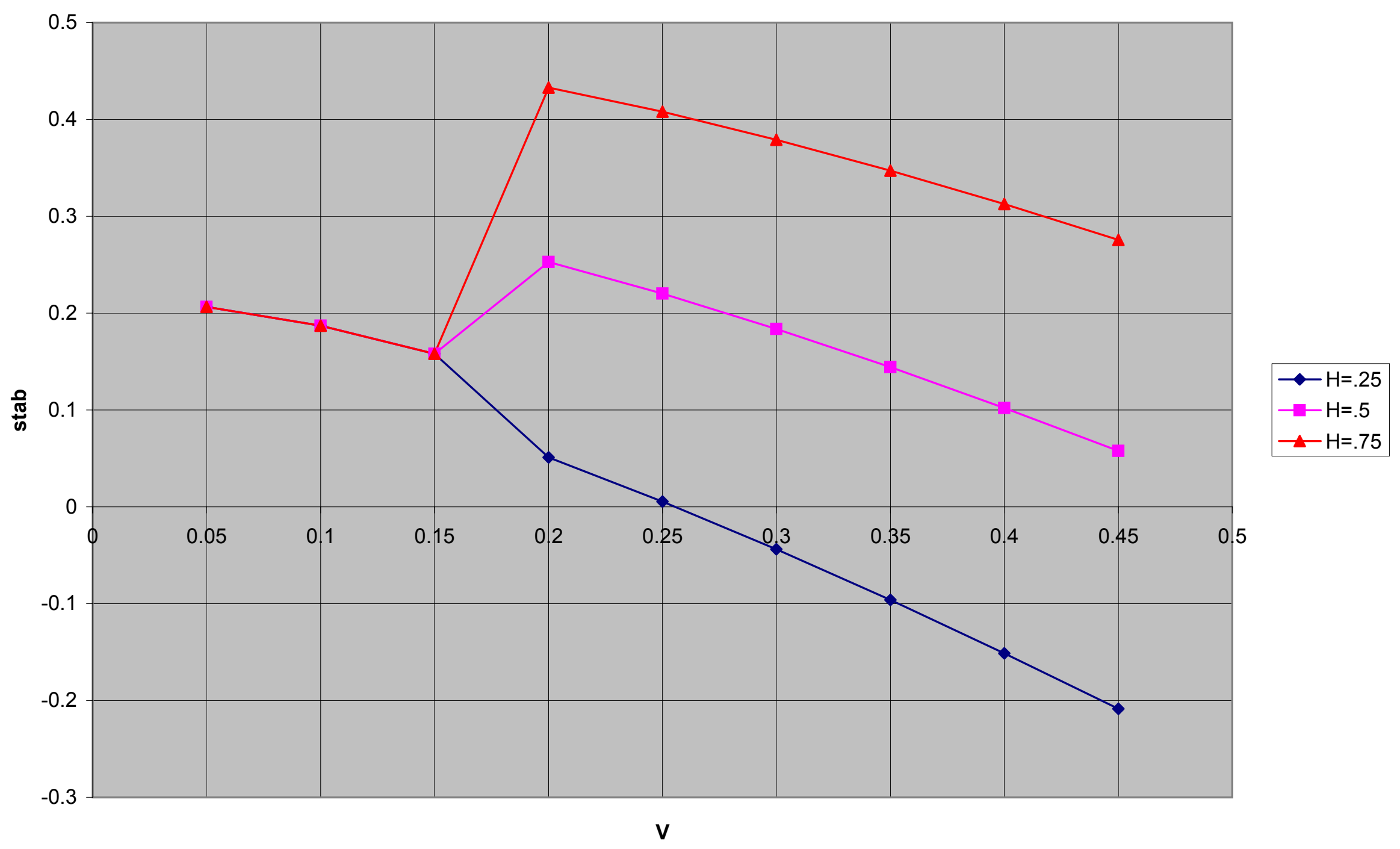


damage vs $\mathrm{V} ; \mathrm{H}=\mathbf{0 . 2 5}$

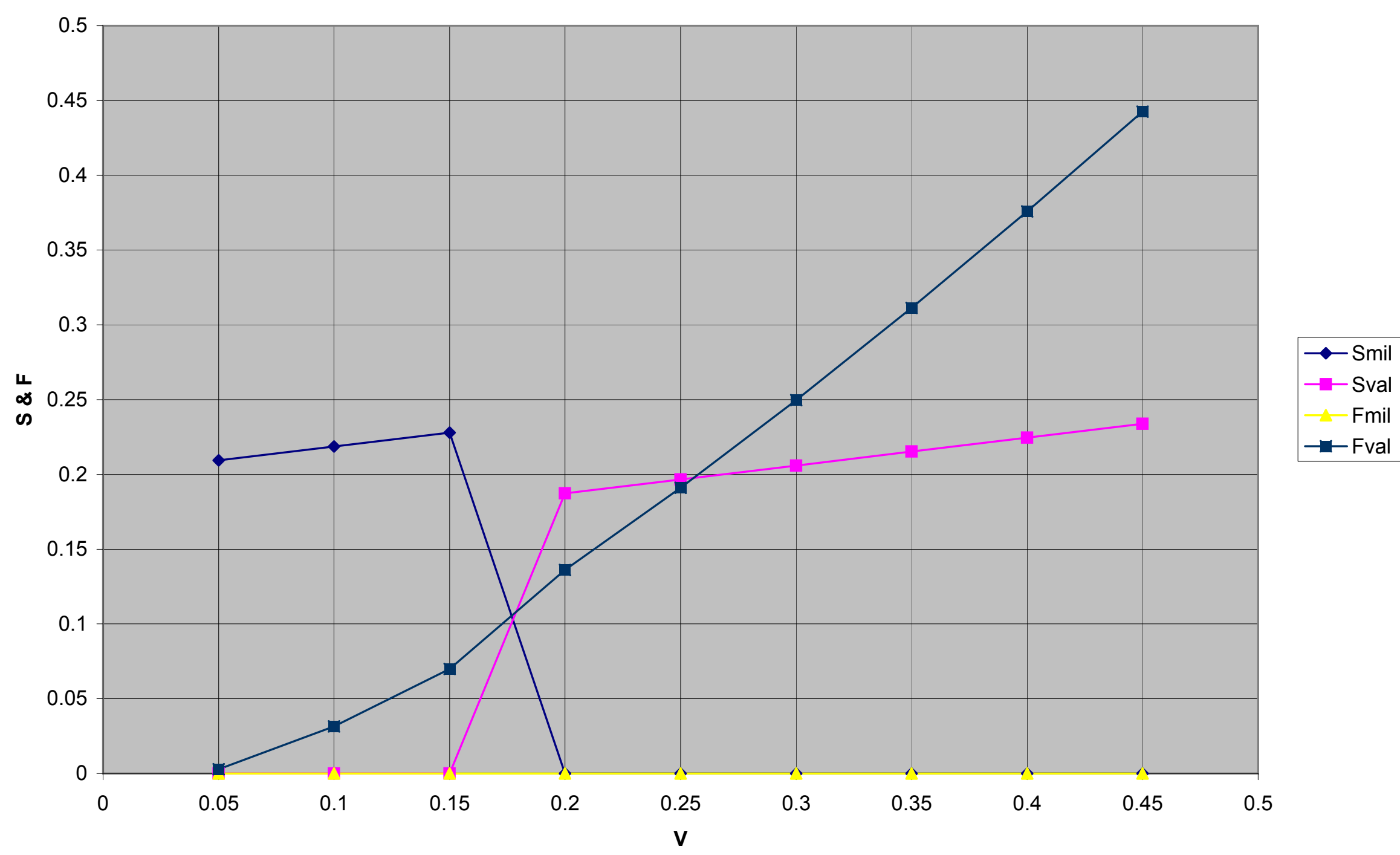


$C 2-L-V$ vs V

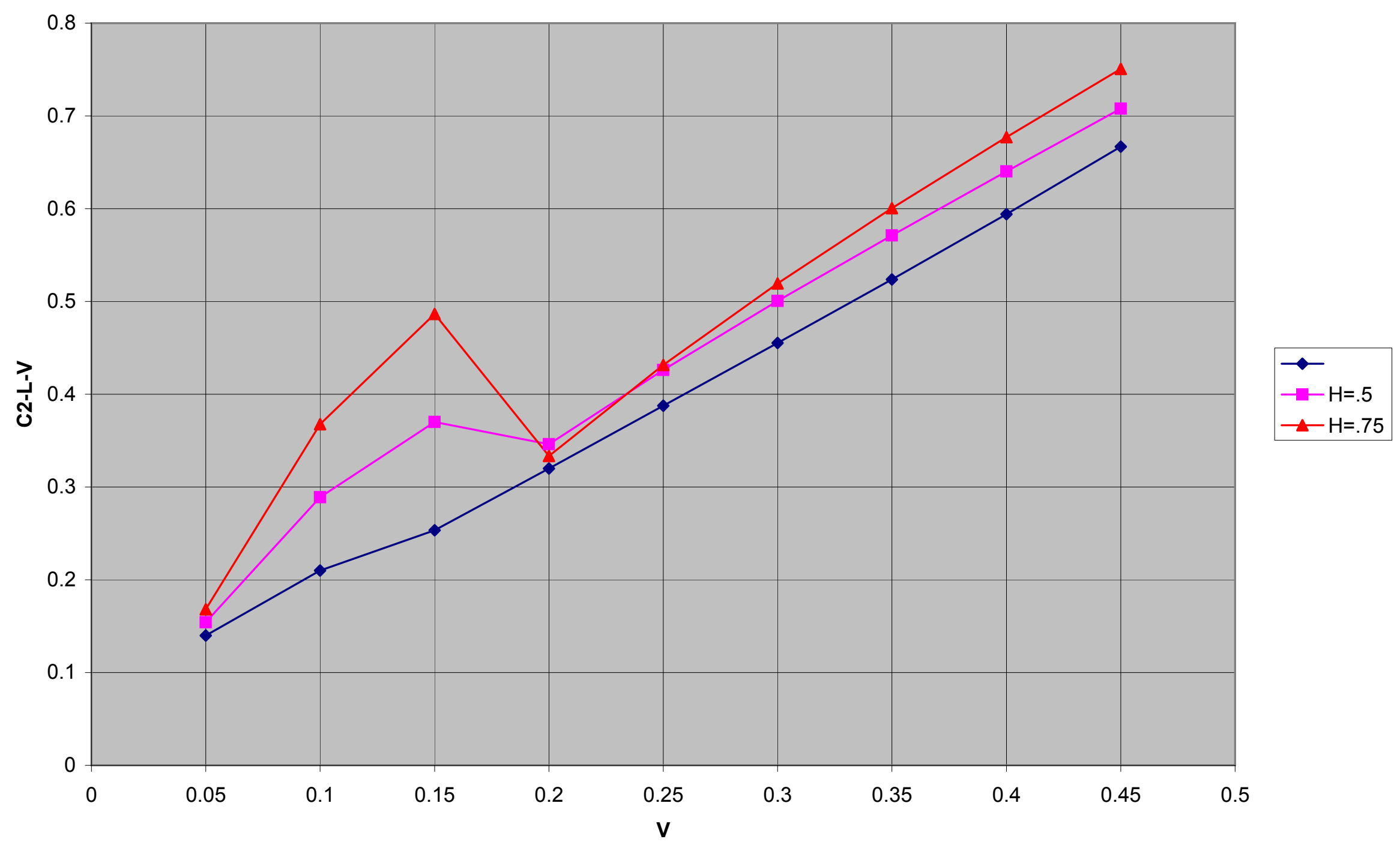


$0.003 \quad 0.60 .0010 .002 \quad 0 \quad 0.2 \quad 6 E-04 \quad 0.25$

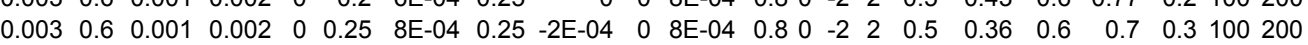

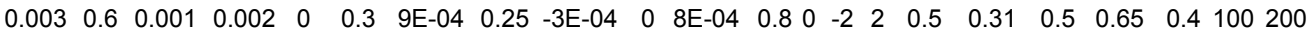
$\begin{array}{lllllllllllllllllllllll}0.003 & 0.6 & 0.001 & 0.002 & 0 & 0.35 & 0.001 & 0.25 & -5 \mathrm{E}-04 & 0 & 8 \mathrm{E}-04 & 0.8 & 0 & -2 & 2 & 0.5 & 0.26 & 0.5 & 0.6 & 0.4 & 100 & 200\end{array}$

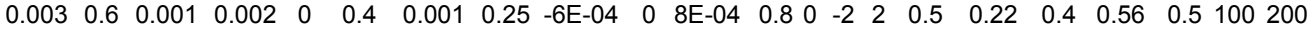

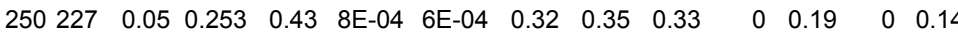

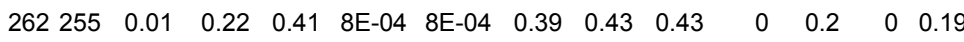

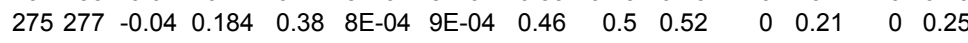

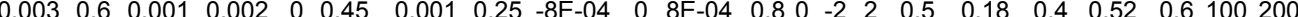

L k v-Lk $h$ Voth Hterm Hself Lk-Vv g Gterm $p$ q Inq $\mathrm{m}$ M/W f

$\begin{array}{llllllllllllllllll}0.003 & 0.6 & 0.001 & 0.002 & 0 & 0.05 & 2 \mathrm{E}-04 & 0.5 & 5 \mathrm{E}-04 & 1 & 0.001 & 0.8 & 0 & -2 & 2 & 0.5 & 0.95\end{array}$ $\begin{array}{lllllrllllllllllll}0.003 & 0.6 & 0.001 & 0.002 & 0 & 0.1 & 3 \mathrm{E}-04 & 0.5 & 3 \mathrm{E}-04 & 1 & 0.001 & 0.8 & 0 & -2 & 2 & 0.5 & 0.74\end{array}$ $\begin{array}{lllllllllllllllll}0.003 & 0.6 & 0.001 & 0.002 & 0 & 0.15 & 5 \mathrm{E}-04 & 0.5 & 2 \mathrm{E}-04 & 1 & 0.001 & 0.8 & 0 & -2 & 2 & 0.5 & 0.61\end{array}$ $\begin{array}{lllllllllllllllll}0.003 & 0.6 & 0.001 & 0.002 & 0 & 0.2 & 6 \mathrm{E}-04 & 0.5 & 0 & 0 & 0.002 & 0.8 & 0 & -2 & 2 & 0.5 & 0.65\end{array}$ $\begin{array}{lllllllllllllllll}0.003 & 0.6 & 0.001 & 0.002 & 0 & 0.25 & 8 \mathrm{E}-04 & 0.5 & -2 \mathrm{E}-04 & 0 & 0.002 & 0.8 & 0 & -2 & 2 & 0.5 & 0.58\end{array}$ $\begin{array}{lllllllllllllllllll}0.003 & 0.6 & 0.001 & 0.002 & 0 & 0.3 & 9 \mathrm{E}-04 & 0.5 & -3 \mathrm{E}-04 & 0 & 0.002 & 0.8 & 0 & -2 & 2 & 0.5 & 0.52\end{array}$ $\begin{array}{llllllllllllllllll}0.003 & 0.6 & 0.001 & 0.002 & 0 & 0.35 & 0.001 & 0.5 & -5 \mathrm{E}-04 & 0 & 0.002 & 0.8 & 0 & -2 & 2 & 0.5 & 0.47\end{array}$ $\begin{array}{lllllllllllllllll}0.003 & 0.6 & 0.001 & 0.002 & 0 & 0.4 & 0.001 & 0.5 & -6 \mathrm{E}-04 & 0 & 0.002 & 0.8 & 0 & -2 & 2 & 0.5 & 0.43\end{array}$ $\begin{array}{lllllllllllllllll}0.003 & 0.6 & 0.001 & 0.002 & 0 & 0.45 & 0.001 & 0.5 & -8 \mathrm{E}-04 & 0 & 0.002 & 0.8 & 0 & -2 & 2 & 0.5 & 0.4\end{array}$ $v \quad L \quad k \quad v-L k \quad h$ Voth Hterm Hself Lk-Vv g Gterm $p$ q Inq $m$ M/W f

$\begin{array}{lllllllllllllllll}0.003 & 0.6 & 0.001 & 0.002 & 0 & 0.05 & 2 \mathrm{E}-04 & 0.75 & 5 \mathrm{E}-04 & 1 & 0.001 & 0.8 & 0 & -2 & 2 & 0.5 & 0.95\end{array}$ $\begin{array}{lllllrlllllllllllll}0.003 & 0.6 & 0.001 & 0.002 & 0 & 0.1 & 3 \mathrm{E}-04 & 0.75 & 3 \mathrm{E}-04 & 1 & 0.001 & 0.8 & 0 & -2 & 2 & 0.5 & 0.74\end{array}$

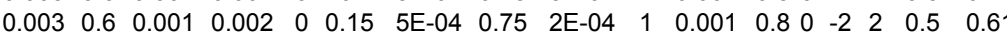

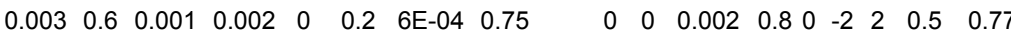

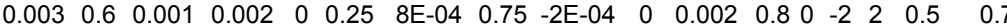
$\begin{array}{llllllllllllllllll}0.003 & 0.6 & 0.001 & 0.002 & 0 & 0.3 & 9 \mathrm{E}-04 & 0.75 & -3 \mathrm{E}-04 & 0 & 0.002 & 0.8 & 0 & -2 & 2 & 0.5 & 0.65\end{array}$ $\begin{array}{lllllllllllllllll}0.003 & 0.6 & 0.001 & 0.002 & 0 & 0.35 & 0.001 & 0.75 & -5 E-04 & 0 & 0.002 & 0.8 & 0 & -2 & 2 & 0.5 & 0.6\end{array}$ $\begin{array}{lllllllllllllllll}0.003 & 0.6 & 0.001 & 0.002 & 0 & 0.4 & 0.001 & 0.75 & -6 \mathrm{E}-04 & 0 & 0.002 & 0.8 & 0 & -2 & 2 & 0.5 & 0.56\end{array}$

$\begin{array}{lllllllllllllllllll}0.003 & 0.6 & 0.001 & 0.002 & 0 & 0.45 & 0.001 & 0.75 & -8 \mathrm{E}-04 & 0 & 0.002 & 0.8 & 0 & -2 & 2 & 0.5 & 0.52\end{array}$
Q $\quad \mathrm{M} \mathrm{nN} \mathrm{S}$

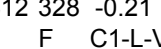

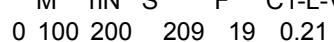
$\begin{array}{lllll}0.1 & 100200 & 219 & 105 & 0.19\end{array}$

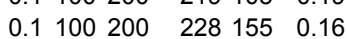
$\begin{array}{llllll}0.1 & 100 & 200 & 225 & 141 & 0.25\end{array}$ $\begin{array}{llllll}0.2 & 100 & 200 & 231 & 169 & 0.22\end{array}$ $0.2100200 \quad 237191 \quad 0.18$ $0.2100200 \quad 243210 \quad 0.14$ $0.2100200 \quad 250227 \quad 0.1$ $0.3100200 \quad 256242 \quad 0.06$ Q $\mathrm{M}$ nN S F C1-L-V

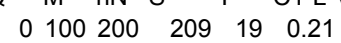
$\begin{array}{lllll}0.1 & 100200 & 219 & 105 & 0.19\end{array}$ $0.1100200228155 \quad 0.16$ $\begin{array}{llllll}0.1 & 100 & 200 & 217 & 90 & 0.43\end{array}$ $\begin{array}{llllll}0.1 & 100 & 200 & 221 & 118 & 0.41\end{array}$ $\begin{array}{llllll}0.1 & 100 & 200 & 225 & 141 & 0.38\end{array}$ $\begin{array}{llllll}0.1 & 100 & 200 & 229 & 160 & 0.35\end{array}$ $\begin{array}{llllll}0.2 & 100 & 200 & 233 & 177 & 0.31\end{array}$

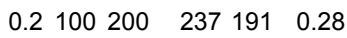
C1-L-V

\begin{abstract}
G2 H2 C2-L-V
\end{abstract}
0.002 6E- $04 \quad 0.15$

$\begin{array}{lll}0.002 & 6 \mathrm{E}-04 & 0.29\end{array}$

$\begin{array}{lll}0.002 & 6 \mathrm{E}-04 & 0.37\end{array}$

$\begin{array}{lll}0.002 & 6 \mathrm{E}-04 & 0.35\end{array}$

$0.002 \quad 8 \mathrm{E}-04 \quad 0.43$

$\begin{array}{lll}0.002 & 9 \mathrm{E}-04 & 0.5\end{array}$

$\begin{array}{lll}0.002 & 0.001 & 0.57\end{array}$

$\begin{array}{lll}0.002 & 0.001 & 0.64\end{array}$

$\begin{array}{lll}0.002 & 0.001 & 0.71\end{array}$

G2 H2 C2-L-V

$\begin{array}{lll}0.002 & 6 \mathrm{E}-04 & 0.17\end{array}$

$\begin{array}{lll}0.002 & 6 \mathrm{E}-04 & 0.37\end{array}$

$0.002 \quad 6 \mathrm{E}-04 \quad 0.49$

$\begin{array}{lll}0.002 & 6 \mathrm{E}-04 & 0.33\end{array}$

$0.002 \quad 8 \mathrm{E}-04 \quad 0.43$

0.002 9E-04 0.52

$\begin{array}{lll}0.002 & 0.001 & 0.6\end{array}$

$\begin{array}{lll}0.002 & 0.001 & 0.68\end{array}$

$\begin{array}{lll}0.002 & 0.001 & 0.75\end{array}$

C2-L-V 
cost vs f

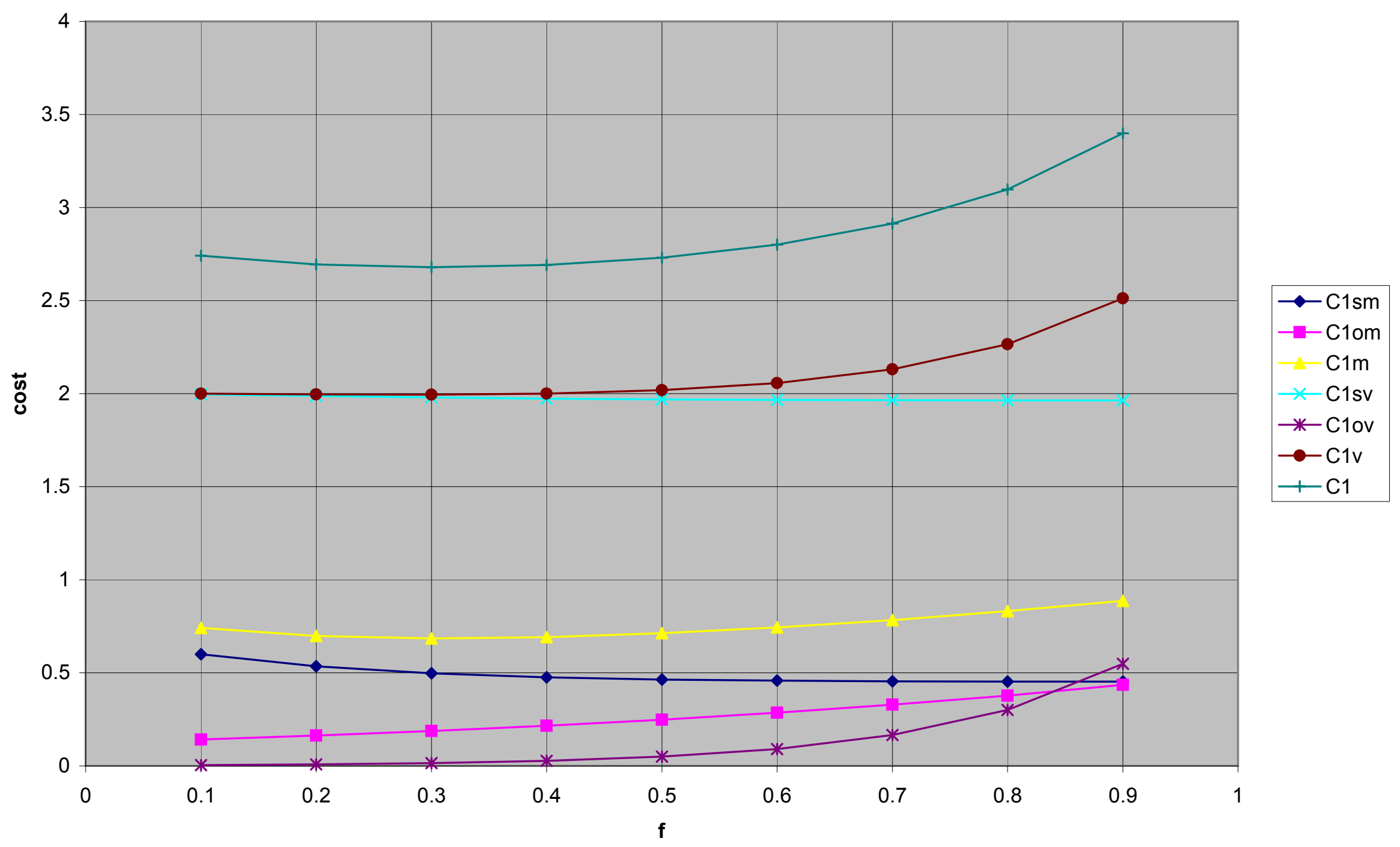


cost vs $\mathbf{g}$

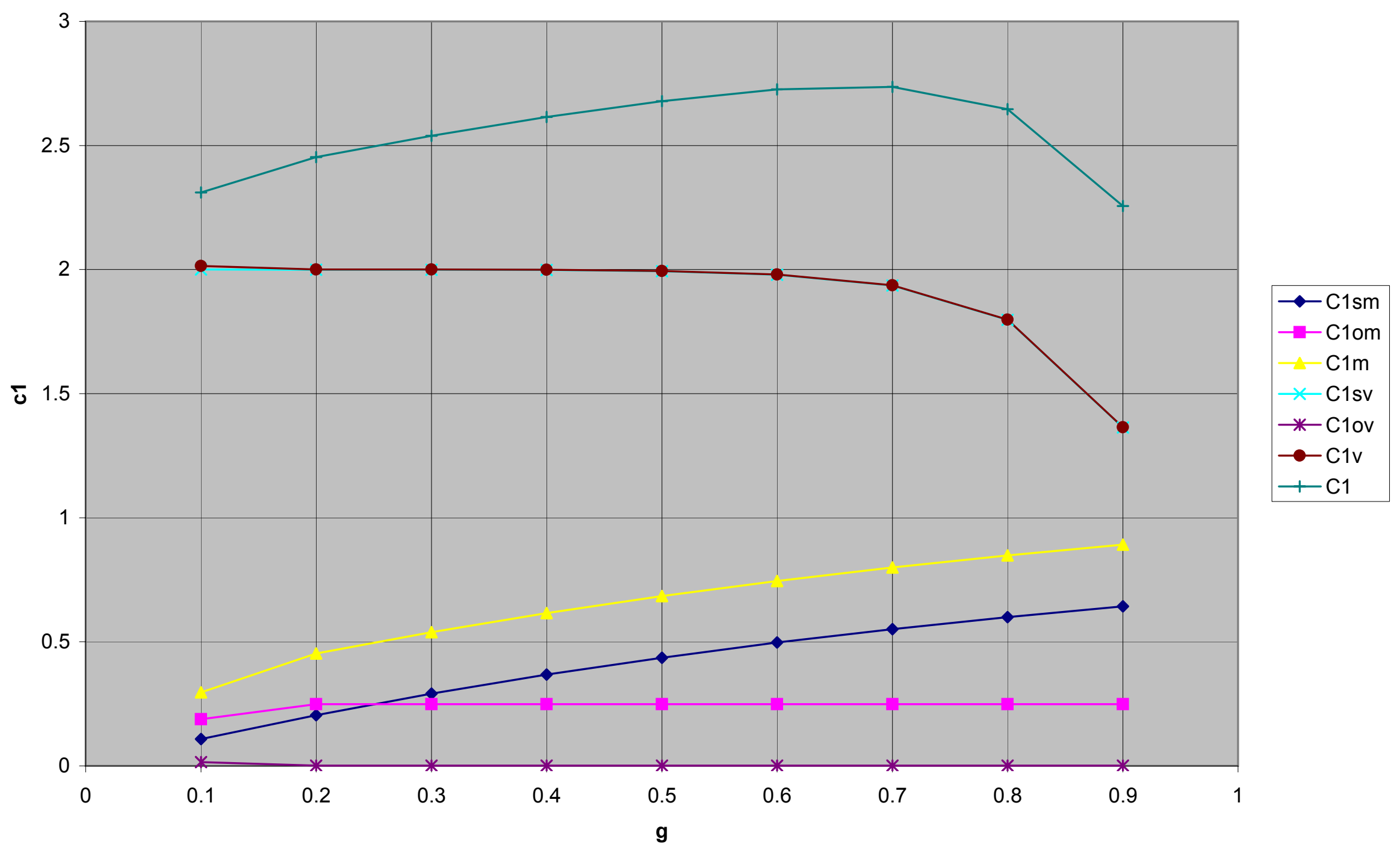


cost vs h

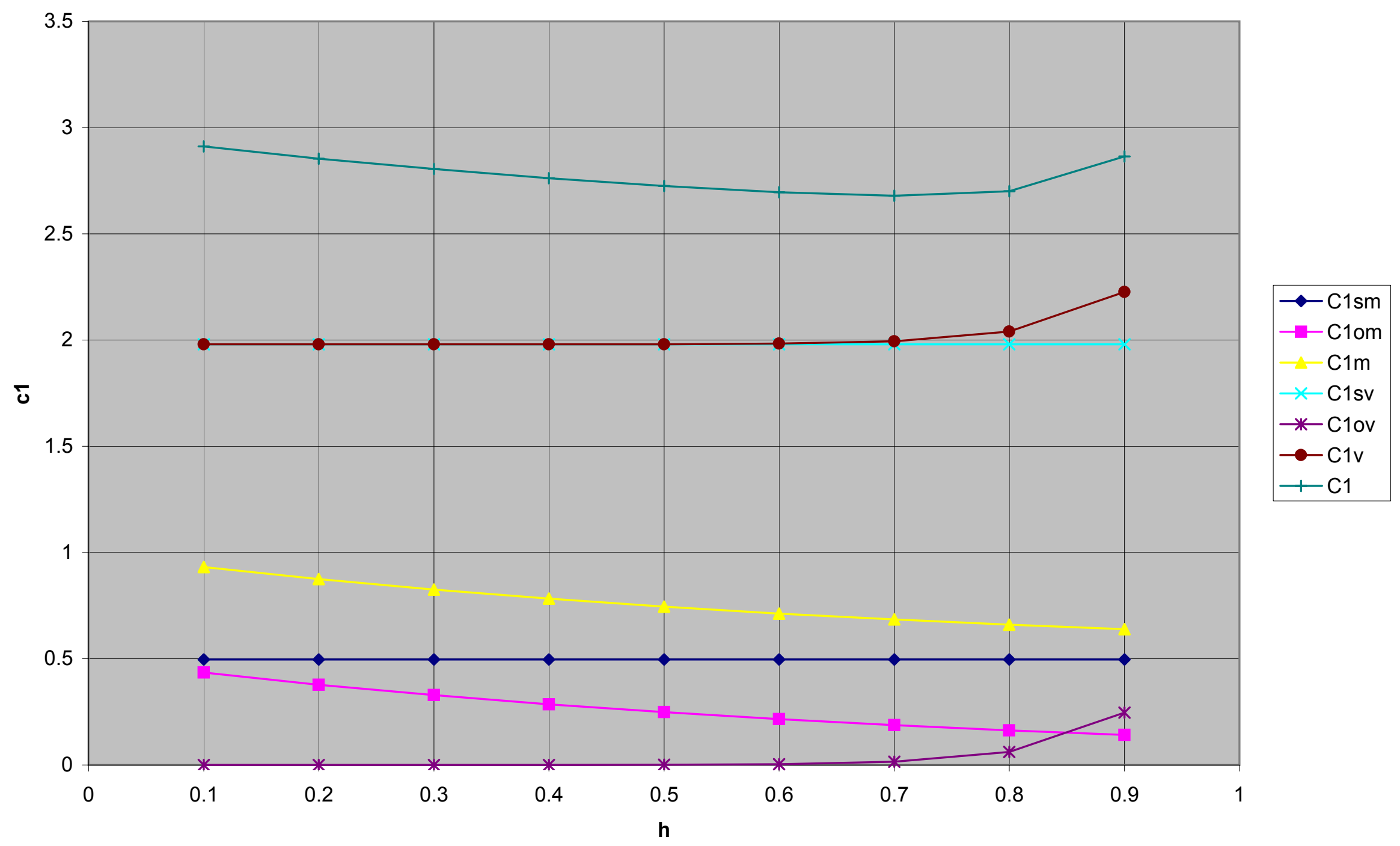




\begin{tabular}{|c|c|c|c|c|c|c|c|c|c|c|c|c|c|c|c|c|c|c|c|}
\hline & v & $p$ & q & L & K & V & M & $\mathrm{N}$ & W & f & g & $\mathrm{h}$ & $\mathrm{F}$ & Q & S & C1sm & C1om & $\mathrm{C} 1 \mathrm{~m}$ & C1sv C1 \\
\hline 0.001 & 0.01 & 0.8 & 0.2 & 0.5 & 2 & 1 & 500 & 500 & 2000 & 0.1 & 0.6 & 0.7 & 1800 & 0.53 & 525 & 0.6 & 42 & 0.741 & 2 \\
\hline 0.001 & 0.01 & 0.8 & 0.2 & 0.5 & 2 & 1 & 500 & 2 & 2000 & 0.2 & 0.6 & 0.7 & 1600 & 8 & 276 & & & & 1.99 \\
\hline 001 & 01 & 0.8 & 0.2 & 0.5 & 2 & 1 & 500 & 500 & 000 & 0.3 & 0.6 & 0.7 & 1400 & 0.14 & 45 & 497 & & 85 & .98 \\
\hline 0.001 & 01 & 0.8 & 0.2 & 0.5 & 2 & 1 & 500 & 500 & 2000 & 0.4 & 0.6 & 0.7 & 1200 & 0.08 & 1076 & 0.476 & & 0.692 & 1.97 \\
\hline 0.001 & .01 & 0.8 & 0.2 & 0.5 & 2 & 1 & 500 & 2 & 2000 & 0.5 & 0.6 & 0.7 & 1000 & 0.04 & 340 & 0.464 & & 0.712 & 1.97 \\
\hline 0.001 & 0.01 & 0.8 & 0.2 & 0.5 & 2 & 1 & 500 & 2 & 2000 & 0.6 & 0.6 & 0.7 & 800 & 0.02 & 1021 & 0.458 & & 0.744 & 1.97 \\
\hline 0.001 & 0.01 & 0.8 & 0.2 & 0.5 & 2 & 1 & 500 & 2 & 2000 & 0.7 & 0.6 & 0.7 & 600 & 0.01 & 1 & 0.455 & 329 & 0.783 & 1.96 \\
\hline 0.001 & 0.01 & 0.8 & 0.2 & 0.5 & 2 & 1 & 500 & 500 & 2000 & 0.8 & 0.6 & 0.7 & 400 & 0.01 & 1006 & 0.453 & & 0.831 & 1.96 \\
\hline 0.001 & 0.01 & 0.8 & 0.2 & 0.5 & 2 & 1 & 2500 & 500 & 2000 & 0.9 & 0.6 & 0.7 & 200 & U & 1003 & 0.452 & 435 & 0.887 & 1.96 \\
\hline k & v & $p$ & $q$ & L & $\mathrm{K} V$ & V & $\mathrm{m} \quad \mathrm{M}$ & $n \mathrm{~N}$ & W & $f$ & g & h & $\mathrm{F}$ & Q & $S$ & $\mathrm{C} 1 \mathrm{sm}$ & rlom & C1m & C1sv \\
\hline 0.001 & 0.01 & 0.8 & 0.2 & 0.5 & 2 & 1 & 2500 & 2500 & 2000 & 0.3 & 0.1 & 0.7 & 1400 & 0.14 & 1145 & 0.108 & 0.188 & 0.296 & 2 \\
\hline 0.001 & 0.01 & 0.8 & 0.2 & 0.5 & 2 & 1 & 2500 & 500 & 2000 & 0.3 & 0.2 & 0.5 & 1400 & 0.14 & 1145 & 0.205 & 0.248 & 0.453 & 2 \\
\hline 0.001 & 0.01 & 0.8 & 0.2 & 0.5 & 2 & 1 & 2500 & 500 & 2000 & 0.3 & 0.3 & 0.5 & 1400 & 0.14 & 1145 & 0.291 & .248 & 0.539 & 2 \\
\hline 0.001 & 0.01 & 0.8 & 0.2 & 0.5 & 2 & 1 & 2500 & 500 & 2000 & 0.3 & 0.4 & 0.5 & 1400 & 0.14 & 1145 & 0.367 & 248 & 0.616 & 2 \\
\hline 0.001 & 0.01 & 0.8 & 0.2 & 0.5 & 2 & 1 & 2500 & 500 & 2000 & 0.3 & 0.5 & 0.5 & 1400 & 0.14 & 1145 & 0.436 & 248 & 0.684 & 1.99 \\
\hline 0.001 & 0.01 & 0.8 & 0.2 & 0.5 & 2 & 1 & 2500 & 500 & 2000 & 0.3 & 0.6 & 0.5 & 1400 & 0.14 & 1145 & 0.497 & .248 & 0.745 & 1.98 \\
\hline 0.001 & 0.01 & 0.8 & 0.2 & 0.5 & 2 & 1 & 2500 & 500 & 2000 & 0.3 & 0.7 & 0.5 & 1400 & 0.14 & 1145 & 0.551 & .248 & 0.8 & 1.94 \\
\hline 0.001 & 0.01 & 0.8 & 0.2 & 0.5 & 2 & 1 & 2500 & 500 & 2000 & 0.3 & 0.8 & 0.5 & 1400 & 0.14 & 1145 & 0.6 & .248 & 0.848 & 1.8 \\
\hline 0.001 & 0.01 & 0.8 & 0.2 & 0.5 & 2 & 1 & 2500 & 2500 & 2000 & 0.3 & 0.9 & 0.5 & 1400 & 0.14 & 1145 & 0.643 & 0.248 & 0.891 & 1.36 \\
\hline k & V & $p$ & q & L & $\mathrm{K} V$ & J & $\mathrm{m} \quad \mathrm{M}$ & $n \quad N$ & W & 1 & g & h & $\mathrm{F}$ & $\mathrm{Q}$ & $S$ & C1sm & C1om & C1m & C1sv \\
\hline 0.001 & 0.01 & 0.8 & 0.2 & 0.5 & 2 & 1 & 2500 & 500 & & 0.3 & 0.6 & 0.1 & 1400 & 0.14 & 145 & 497 & 135 & 0.932 & 1.98 \\
\hline 0.001 & 0.01 & 0.8 & 0.2 & 0.5 & 2 & 1 & 2500 & 500 & 2000 & 0.3 & 0.6 & 0.2 & 1400 & 0.14 & 1145 & 0.497 & 378 & 0.875 & 1.98 \\
\hline 0.001 & 0.01 & 0.8 & 0.2 & 0.5 & 2 & 1 & 2500 & 500 & 2000 & 0.3 & 0.6 & 0.3 & 1400 & 0.14 & 1145 & 0.497 & 0.329 & 0.825 & 1.98 \\
\hline
\end{tabular}


f \& h vs g

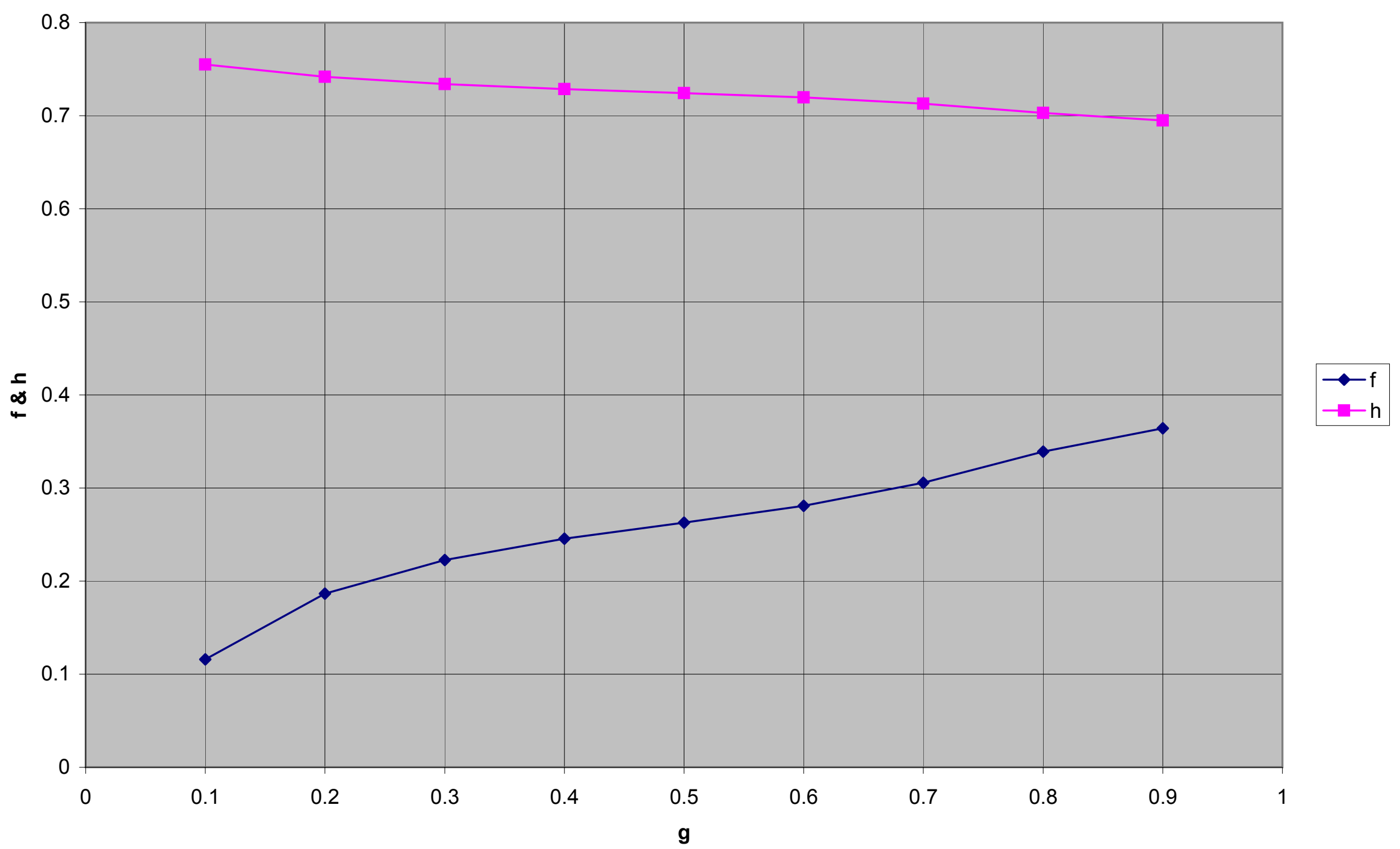


Fig. 1. costs vs 2 nd strike allocation, g

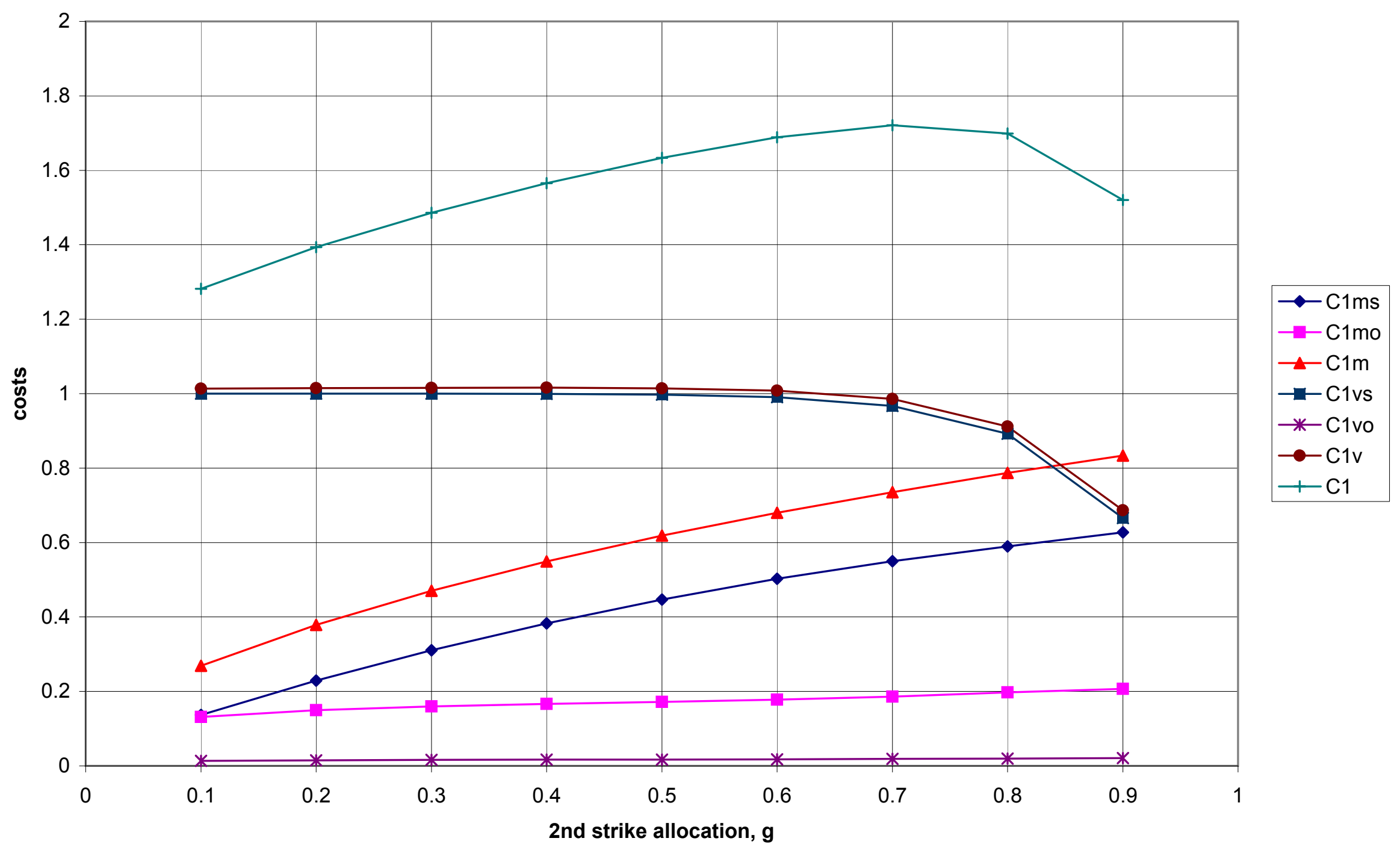




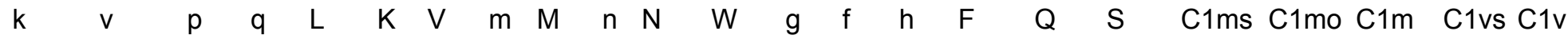
$\begin{array}{lllllllllllllllllllllll}0.001 & 0.01 & 0.8 & 0.2 & 0.5 & 1 & 1 & 2 & 500 & 2 & 500 & 2000 & 0.1 & 0.1 & 0.8 & 1768 & 0.47 & 1474 & 0.137 & 0.132 & 0.269 & 1 & 0.0\end{array}$ $\begin{array}{lllllllllllllllllllllllll}0.001 & 0.01 & 0.8 & 0.2 & 0.5 & 1 & 1 & 2 & 500 & 2 & 500 & 2000 & 0.2 & 0.2 & 0.7 & 1627 & 0.3 & 1301 & 0.229 & 0.15 & 0.379 & 1 & 0.0\end{array}$

$\begin{array}{lllllllllllllllllllllllll}0.001 & 0.01 & 0.8 & 0.2 & 0.5 & 1 & 1 & 2 & 500 & 2 & 500 & 2000 & 0.3 & 0.2 & 0.7 & 1555 & 0.24 & 1239 & 0.31 & 0.16 & 0.47 & 1 & 0.0\end{array}$

$\begin{array}{lllllllllllllllllllllllll}0.001 & 0.01 & 0.8 & 0.2 & 0.5 & 1 & 1 & 2 & 500 & 2 & 500 & 2000 & 0.4 & 0.2 & 0.7 & 1509 & 0.21 & 1206 & 0.383 & 0.167 & 0.549 & 1 & 0.0\end{array}$ 
g. f, \& h vs W

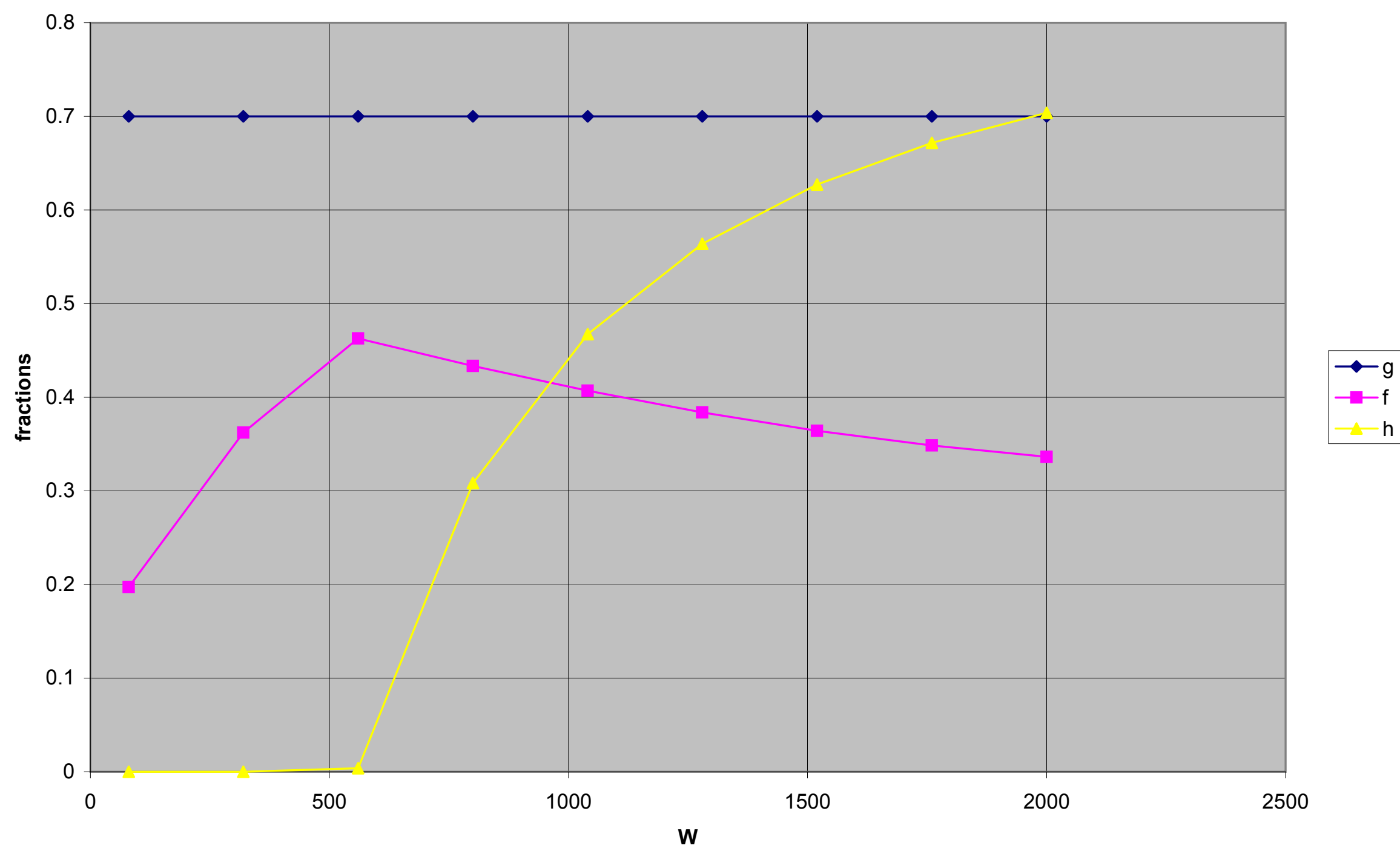


cost vs W

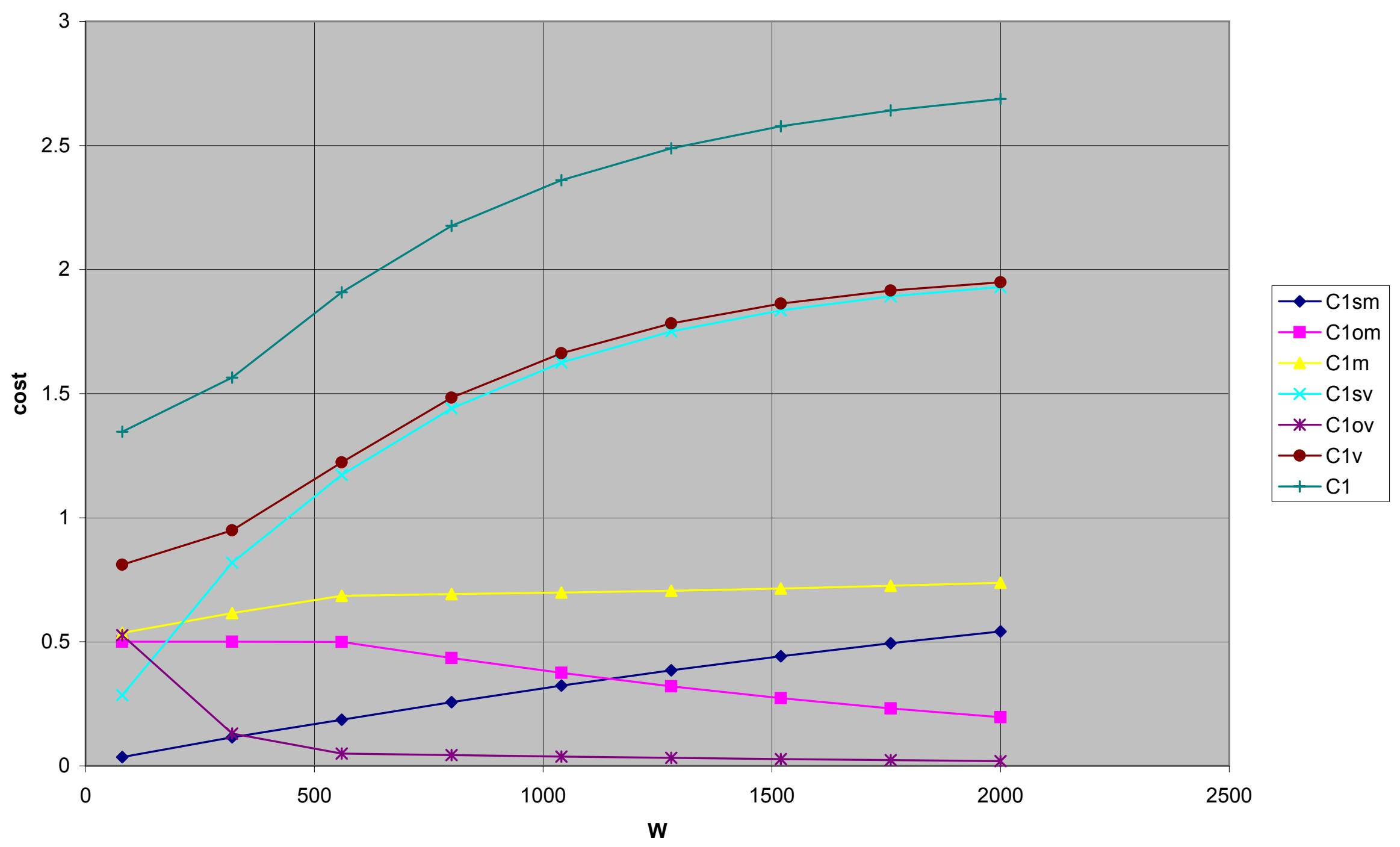




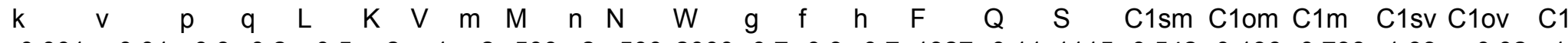

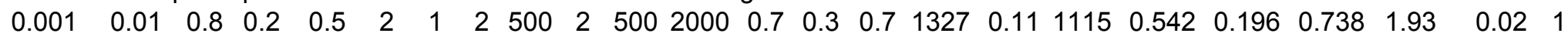
$\begin{array}{llllllllllllllllllllllllll}0.001 & 0.01 & 0.8 & 0.2 & 0.5 & 2 & 1 & 2 & 440 & 2 & 440 & 1760 & 0.7 & 0.3 & 0.7 & 1147 & 0.11 & 973 & 0.494 & 0.231 & 0.726 & 1.89 & 0.023 & 1\end{array}$ $\begin{array}{lllllllllllllllllllllllll}0.001 & 0.01 & 0.8 & 0.2 & 0.5 & 2 & 1 & 2 & 380 & 2 & 380 & 1520 & 0.7 & 0.4 & 0.6 & 966 & 0.1 & 833 & 0.442 & 0.273 & 0.715 & 1.84 & 0.027 & 1\end{array}$ $\begin{array}{lllllllllllllllllllllllll}0.001 & 0.01 & 0.8 & 0.2 & 0.5 & 2 & 1 & 2 & 320 & 2 & 320 & 1280 & 0.7 & 0.4 & 0.6 & 789 & 0.08 & 694 & 0.385 & 0.321 & 0.705 & 1.75 & 0.032 & 1\end{array}$ 
f \& h vs g

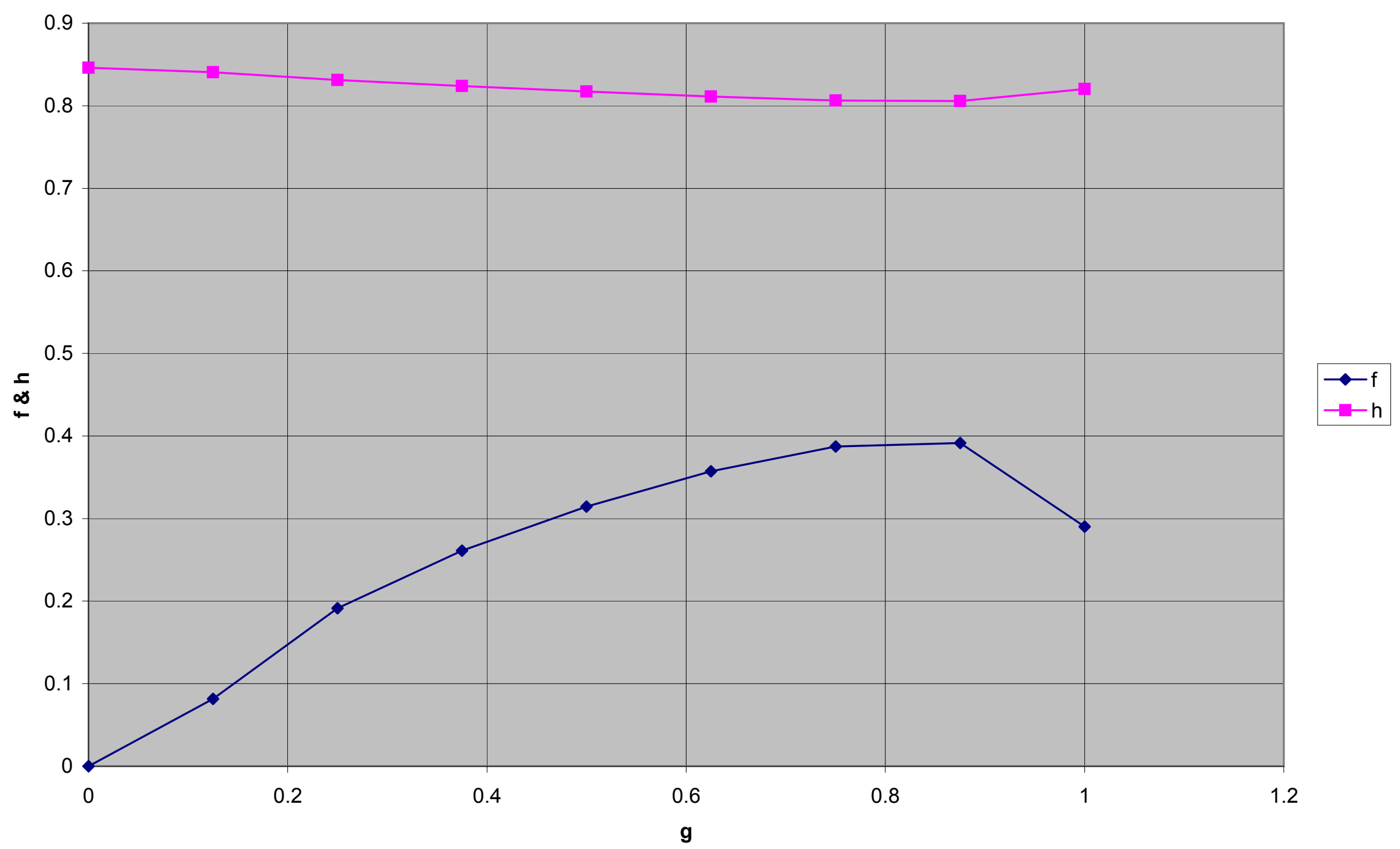


cost vs g

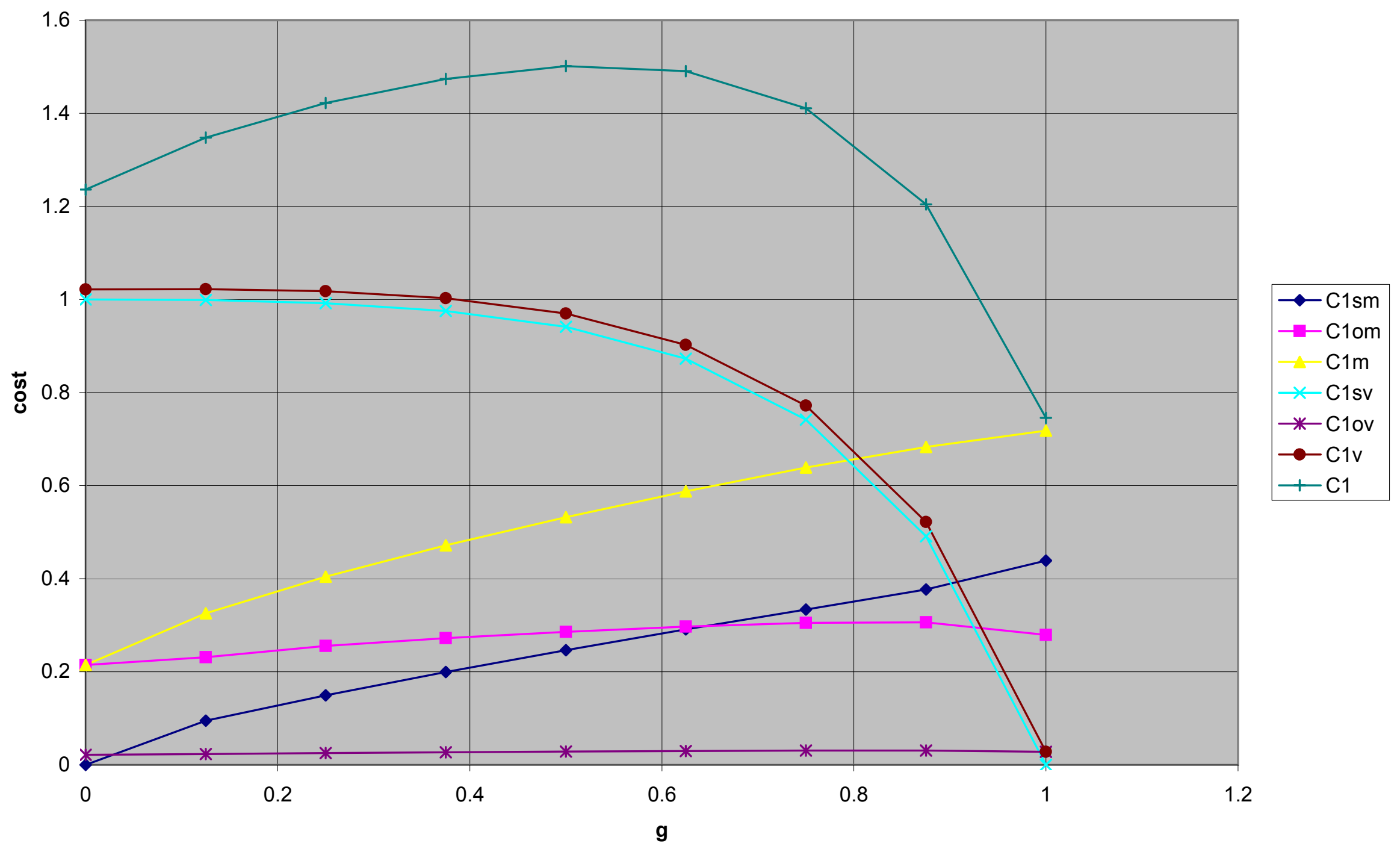


costs vs $P$ preference for attacking military value

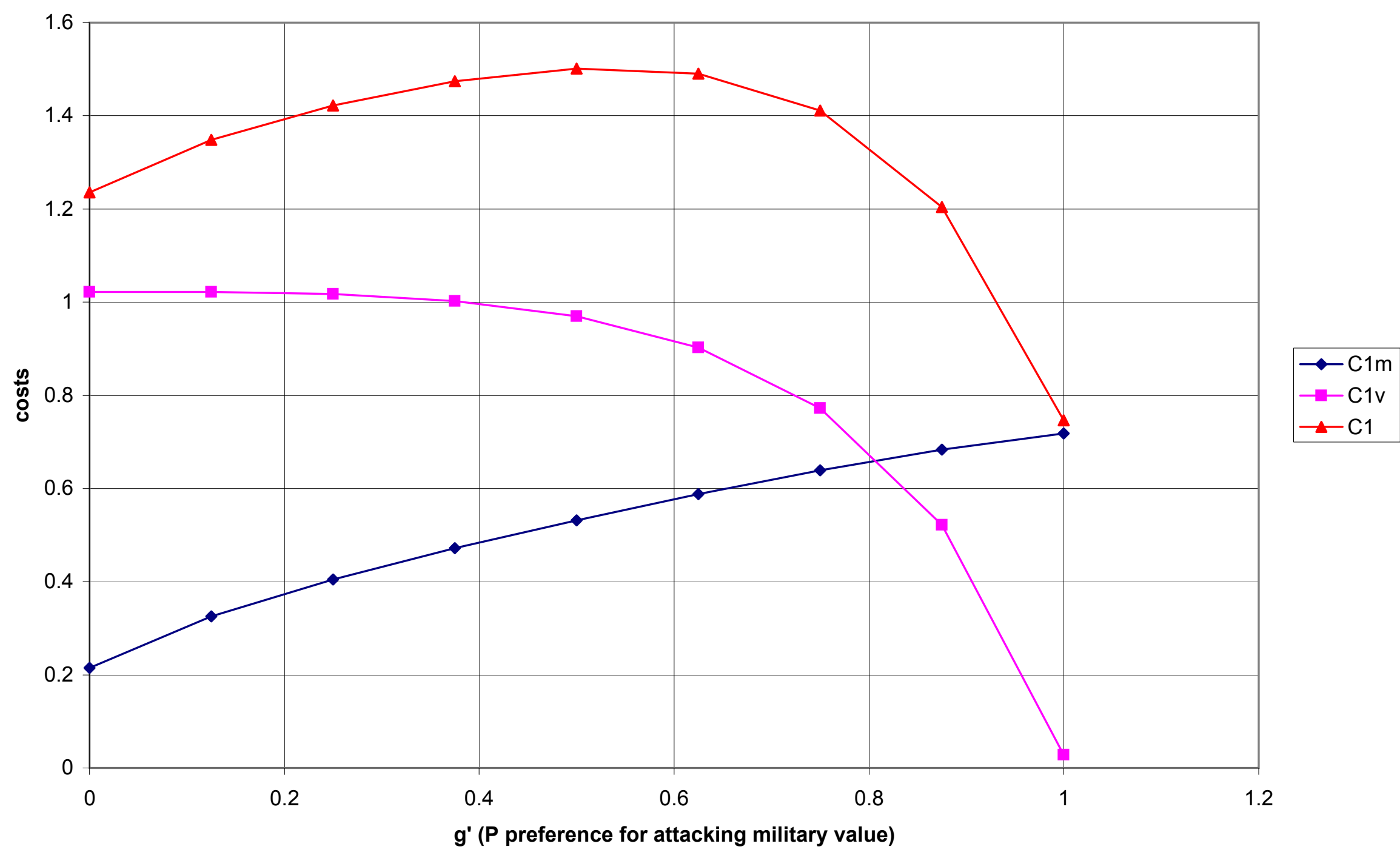




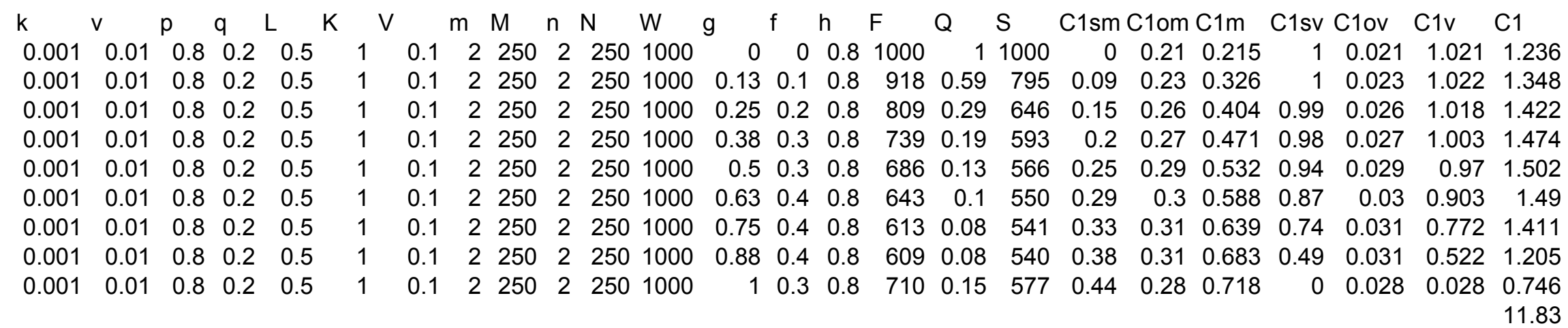


Fig 2. costs vs 2 ns strike allocation, $g$ 1,000 weapons

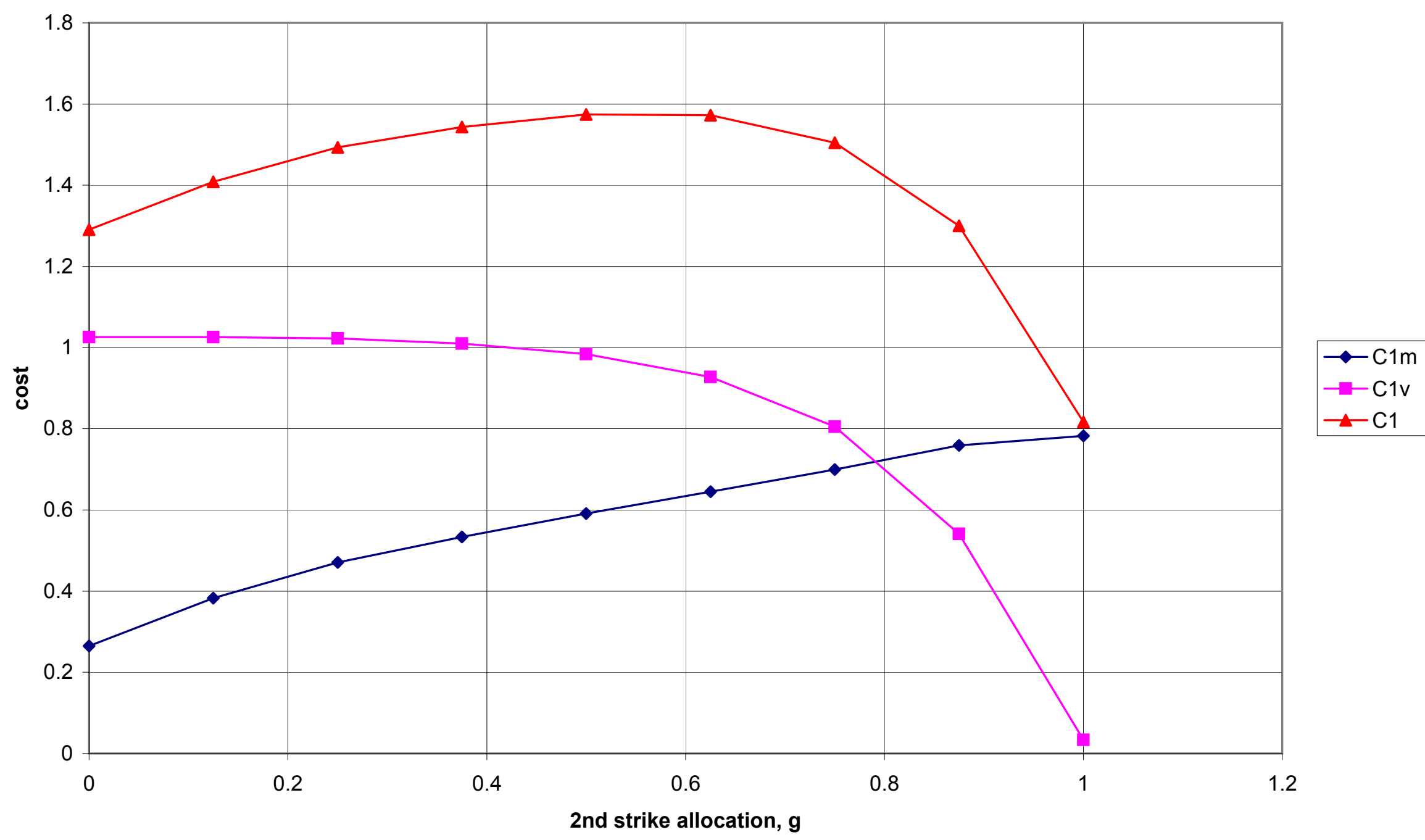




\begin{tabular}{|c|c|c|c|c|c|c|c|c|c|c|c|c|c|c|c|c|c|c|c|c|c|c|c|c|c|c|}
\hline & v & $p$ & $q$ & $\mathrm{~L}$ & V & & & M & $\mathrm{n}$ & $\mathrm{N}$ & W & g & f & $\mathrm{h}$ & $\mathrm{F}$ & $r$ & int $r$ & $Q$ & S & $\mathrm{C} 1 \mathrm{~ms}$ & & $1 \mathrm{~m}$ & C1vs & vo & C1v & C1 \\
\hline 0.001 & 0.01 & 0.8 & 0.2 & 0.5 & 1 & 1 & 2 & 250 & 2 & 250 & 1000 & 0 & 0 & 0.6 & 1000 & 0 & 0 & 1 & 1000 & 0 & 0.265 & 0.265 & 1 & 0.026 & 1.026 & 1.291 \\
\hline 0.001 & 0.01 & 0.8 & 0.2 & 0.5 & 1 & 1 & 2 & 250 & 2 & 250 & 1000 & 0.13 & 0 & 0.6 & 1000 & 0 & 0 & 1 & 1000 & 0.118 & 0.265 & 0.383 & 1 & & 1.026 & 1.408 \\
\hline 0.001 & 0.01 & 0.8 & 0.2 & 0.5 & 1 & 1 & 2 & 250 & 2 & 250 & 1000 & 0.25 & 0.2 & 0.5 & 750 & 1 & 0 & 0.2 & 600 & & & & 0.99 & & 023 & 193 \\
\hline 0.001 & 0.01 & 0.8 & 0.2 & 0.5 & 1 & & 2 & 250 & 2 & 250 & 1000 & 0.38 & 0.3 & 0.5 & 750 & & & 0.2 & 600 & & & & & & & .543 \\
\hline 001 & 0.01 & 0.8 & 0.2 & 0.5 & 1 & & 2 & 250 & 2 & 250 & 1000 & 0.5 & 0.3 & 0.5 & 750 & 1 & & 0.2 & 600 & & & & 0.95 & 34 & 984 & 575 \\
\hline .001 & 0.01 & 0.8 & 0.2 & 0.5 & 1 & 1 & 2 & 250 & 2 & 250 & 1000 & 0.63 & 0.3 & 0.5 & 746 & 1 & . & 0.2 & 599 & 0.312 & 0.333 & 0.645 & 0.89 & 0.034 & 0.928 & 1.573 \\
\hline 0.001 & 0.01 & 0.8 & 0.2 & 0.5 & 1 & 1 & 2 & 250 & 2 & 250 & 1000 & 0.75 & 0.3 & 0.5 & 721 & 1.1 & 1 & 0.18 & 591 & 0.358 & 0.341 & 0.699 & 0.77 & 0.034 & 0.805 & 1.505 \\
\hline 0.001 & 0.01 & 0.8 & 0.2 & 0.5 & 1 & 1 & 2 & 250 & 2 & 250 & 1000 & 0.88 & 0.4 & 0.5 & 633 & 1.5 & & 0.12 & 562 & 0.389 & 0.37 & 0.759 & 0.5 & 0.036 & 0.541 & 1.3 \\
\hline 0.001 & 0.01 & 0.8 & 0.2 & 0.5 & 1 & 1 & 2 & 250 & 2 & 250 & 1000 & 1 & 0.3 & 0.5 & 750 & 1 & 1 & 0.2 & 600 & 0.451 & 0.332 & 0.783 & 0 & 0.034 & 0.034 & 0.816 \\
\hline
\end{tabular}


cost vs g var Int

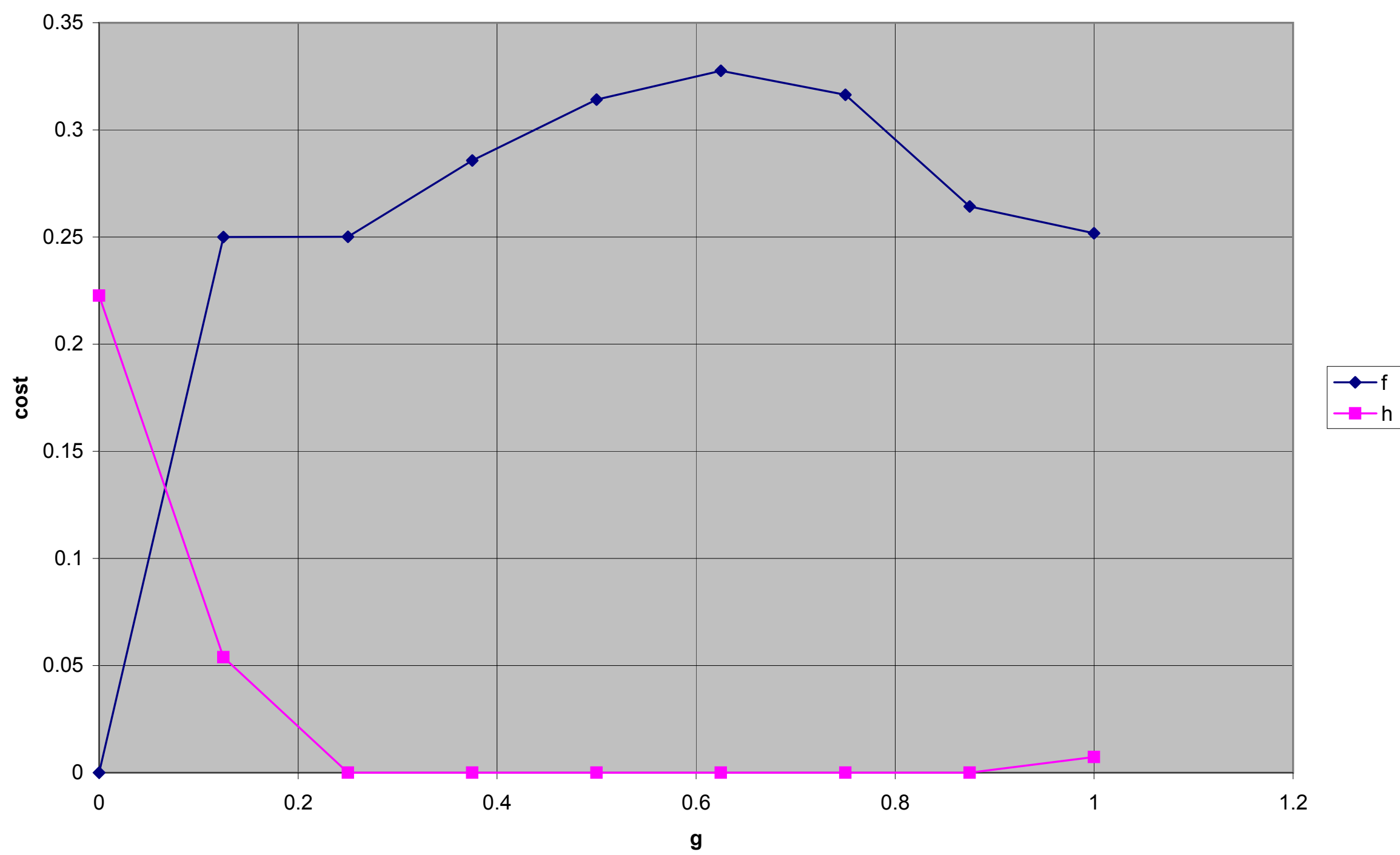


cost vs g w/l

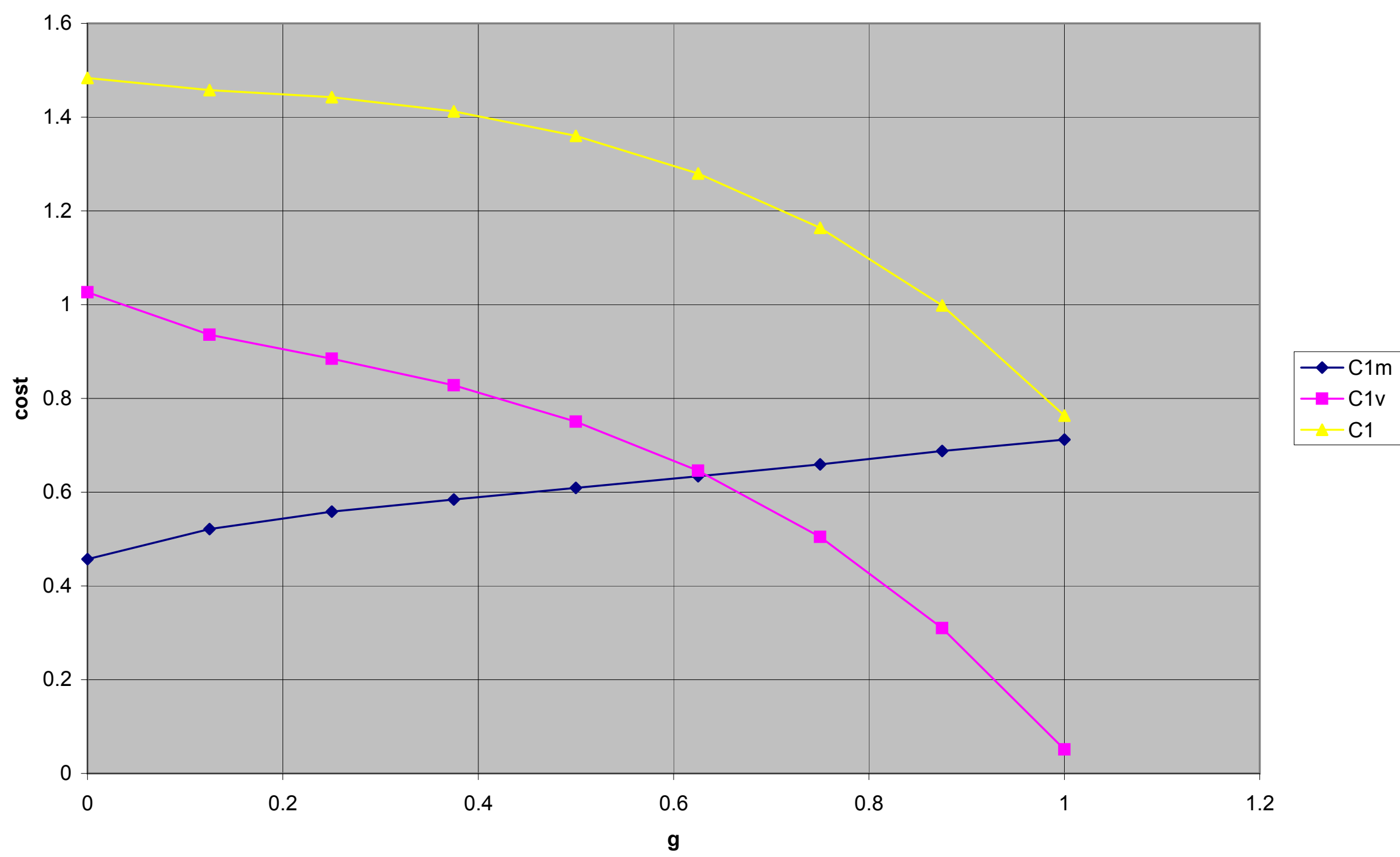


cost vs $\mathrm{g}$

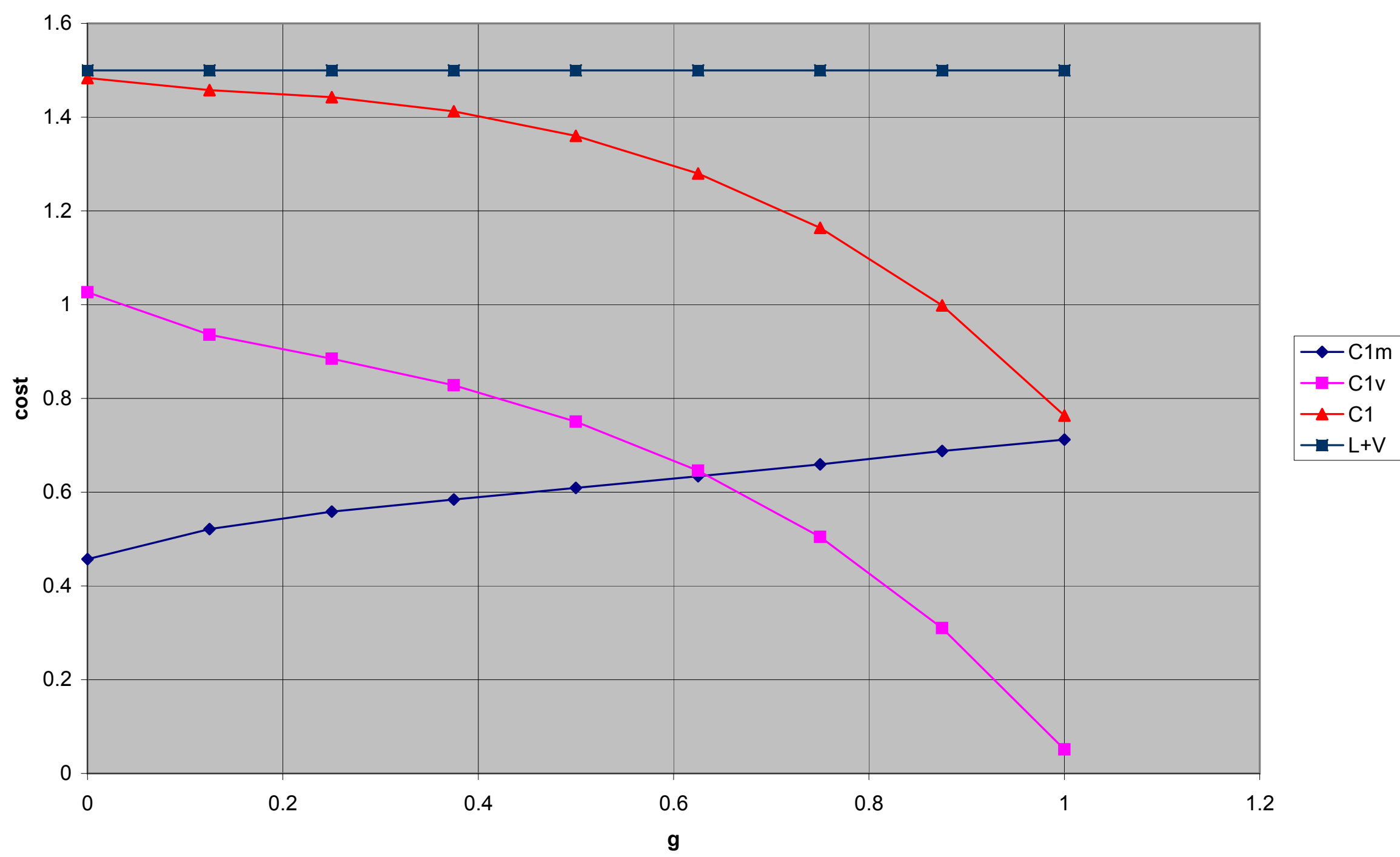




\begin{tabular}{|c|c|c|c|c|c|c|c|c|c|c|c|}
\hline & v & $p$ & $q$ & L & K & V & $\mathrm{m}$ & M & $\mathrm{n}$ & $\mathrm{N}$ & W \\
\hline 0.001 & 0.01 & 0.8 & 0.2 & 0.5 & 1 & 1 & 12 & 100 & 2 & 100 & 400 \\
\hline 0.001 & 0.01 & 0.8 & 0.2 & 0.5 & 1 & 1 & 2 & 100 & 2 & 100 & 400 \\
\hline 0.001 & 0.01 & 0.8 & 0.2 & 0.5 & 1 & 1 & 2 & 100 & 2 & 100 & 400 \\
\hline 0.001 & 0.01 & 0.8 & 0.2 & 0.5 & 1 & 1 & 2 & 100 & 2 & 100 & 400 \\
\hline 0.001 & 0.01 & 0.8 & 0.2 & 0.5 & 1 & 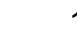 & 2 & 100 & 2 & 100 & 400 \\
\hline 0.001 & 0.01 & 0.8 & 0.2 & 0.5 & 1 & 1 & 2 & 100 & 2 & 100 & 400 \\
\hline .001 & 0.01 & 0.8 & 0.2 & 0.5 & 1 & 1 & 2 & 100 & 2 & 100 & 400 \\
\hline 0.001 & 0.01 & 0.8 & 0.2 & 0.5 & 1 & 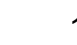 & 2 & 100 & 2 & 100 & 400 \\
\hline 0.001 & 0.01 & 0.8 & 0.2 & 0.5 & 1 & 1 & 2 & 100 & 2 & 100 & 400 \\
\hline
\end{tabular}

\begin{tabular}{|c|c|c|c|c|c|c|c|c|c|c|c|c|c|c|c|c|}
\hline & 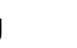 & $f$ & $\mathrm{~h}$ & $F$ & r & int $r$ & Q & 5 & C1sm & C1om & C1m & C1sv & C1ov & C1v & C1 & $L+V$ \\
\hline & 0 & 0 & 0.2 & 400 & 0 & 0 & 1 & 400 & 0 & 0.457 & 0.46 & 0.98 & 0.045 & 1.03 & 1.48 & \\
\hline & 0.13 & 0.3 & 0.1 & 300 & 1 & 1 & 0.2 & 240 & 0.03 & 0.492 & 0.52 & 0.8 & 0.059 & 0.94 & 1.46 & \\
\hline & 0.25 & 0.3 & 0 & 00 & 1 & 1 & 0.2 & 240 & 0.0 & .5 & 56 & & & & & \\
\hline & 0.38 & 0.3 & 0 & 286 & 1.1 & 1 & 0.18 & 235 & 0.085 & 0.5 & 0.58 & & 0.057 & 0.83 & & .5 \\
\hline & 0.5 & 0.3 & 0 & 274 & 1.3 & 1 & 0.16 & 232 & 0.1 & 0.5 & 0.61 & & 0.064 & 0.75 & 1.3 & \\
\hline & 63 & 0.3 & 0 & 269 & 1.3 & 1 & 0.15 & 230 & 0.134 & & 0.6 & & & 0.65 & 1.28 & \\
\hline & 0.75 & 0.3 & 0 & 273 & 1.3 & 1 & 0.16 & 232 & 0.159 & 0.5 & 0.6 & 0.4 & & 0.5 & 1.16 & \\
\hline & 0.88 & 0.3 & 0 & 294 & 1.1 & 1 & 0.19 & 238 & 0.188 & 0.5 & 0.69 & 0.26 & 0.053 & 0.31 & 1 & .5 \\
\hline & 1 & 0.3 & 0 & 299 & 1 & 1 & 0.2 & 240 & 0.213 & 0.499 & 0.71 & 0 & 0.051 & 0.05 & 0.76 & 1.5 \\
\hline
\end{tabular}


C1sm C1om C1m C1sv C1ov C1v C1

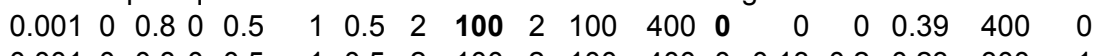

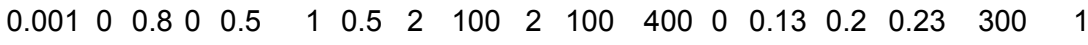

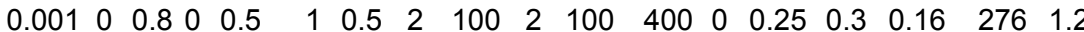

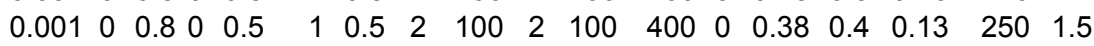

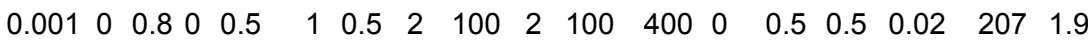

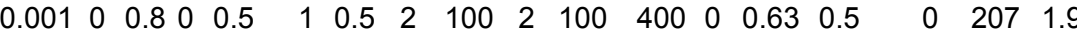

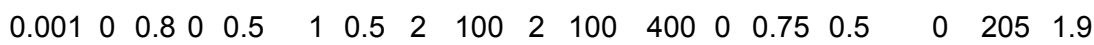

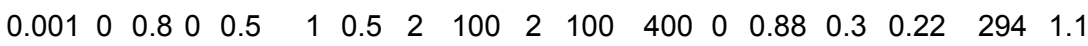
$\begin{array}{llllll}0.001 & 0 & 0.8 & 0 & 0.5\end{array}$

$\begin{array}{llllllllll}1 & 0.5 & 2 & 100 & 2 & 100 & 400 & 0\end{array}$

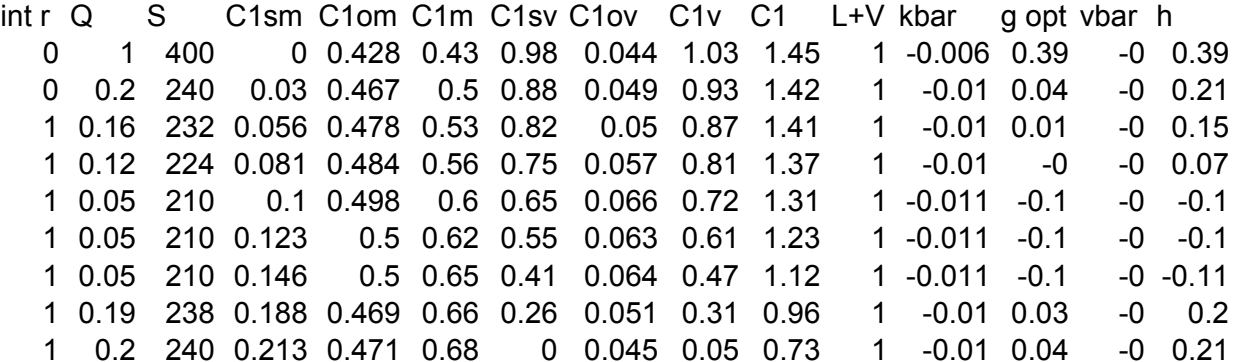


Fig. 3. Allocations $\mathrm{f}, \mathrm{g}, \boldsymbol{\&} \mathrm{h}$ vs total forces, $\mathrm{W}$

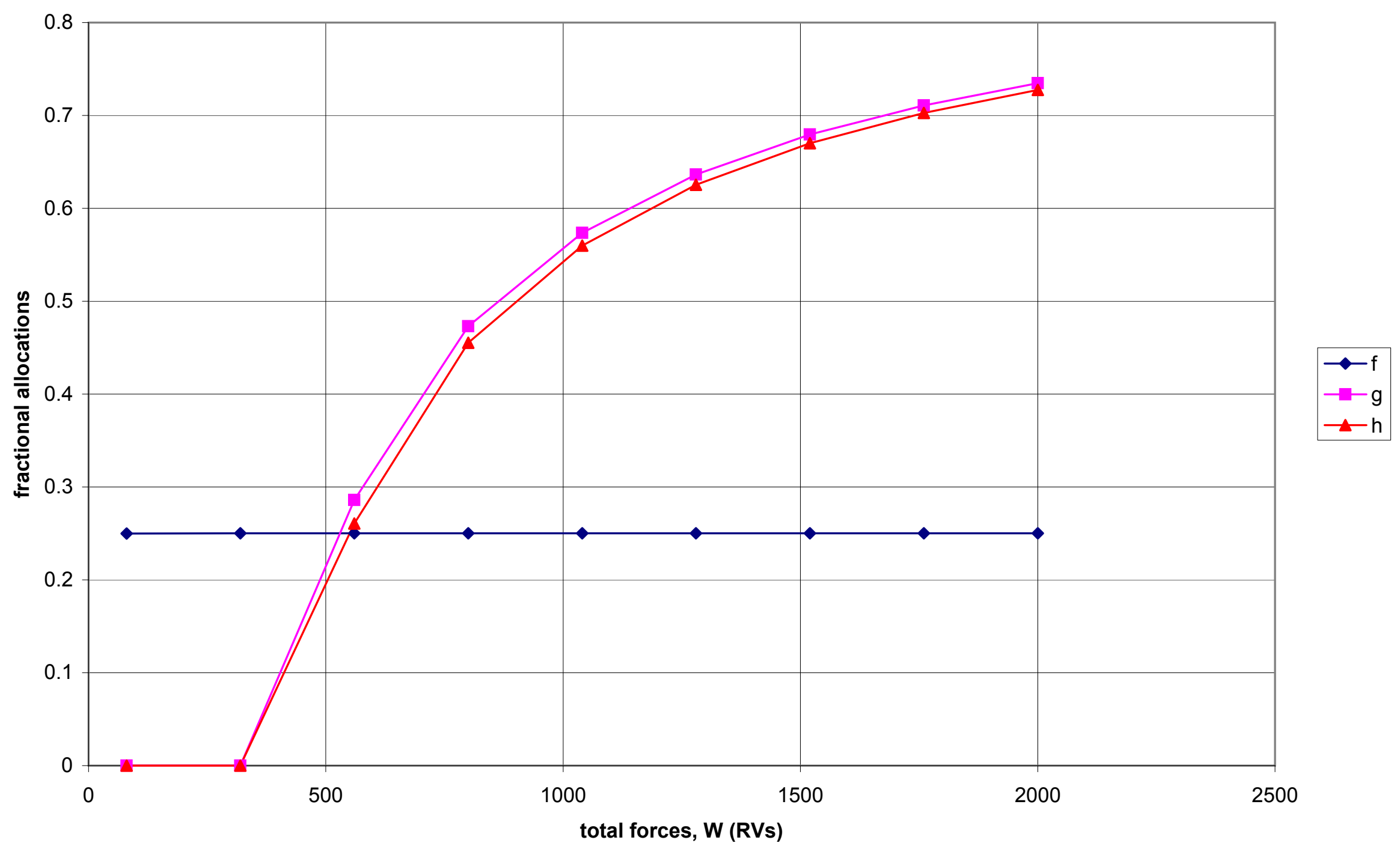


Fig. 4. weapons on high value targets vs total forces

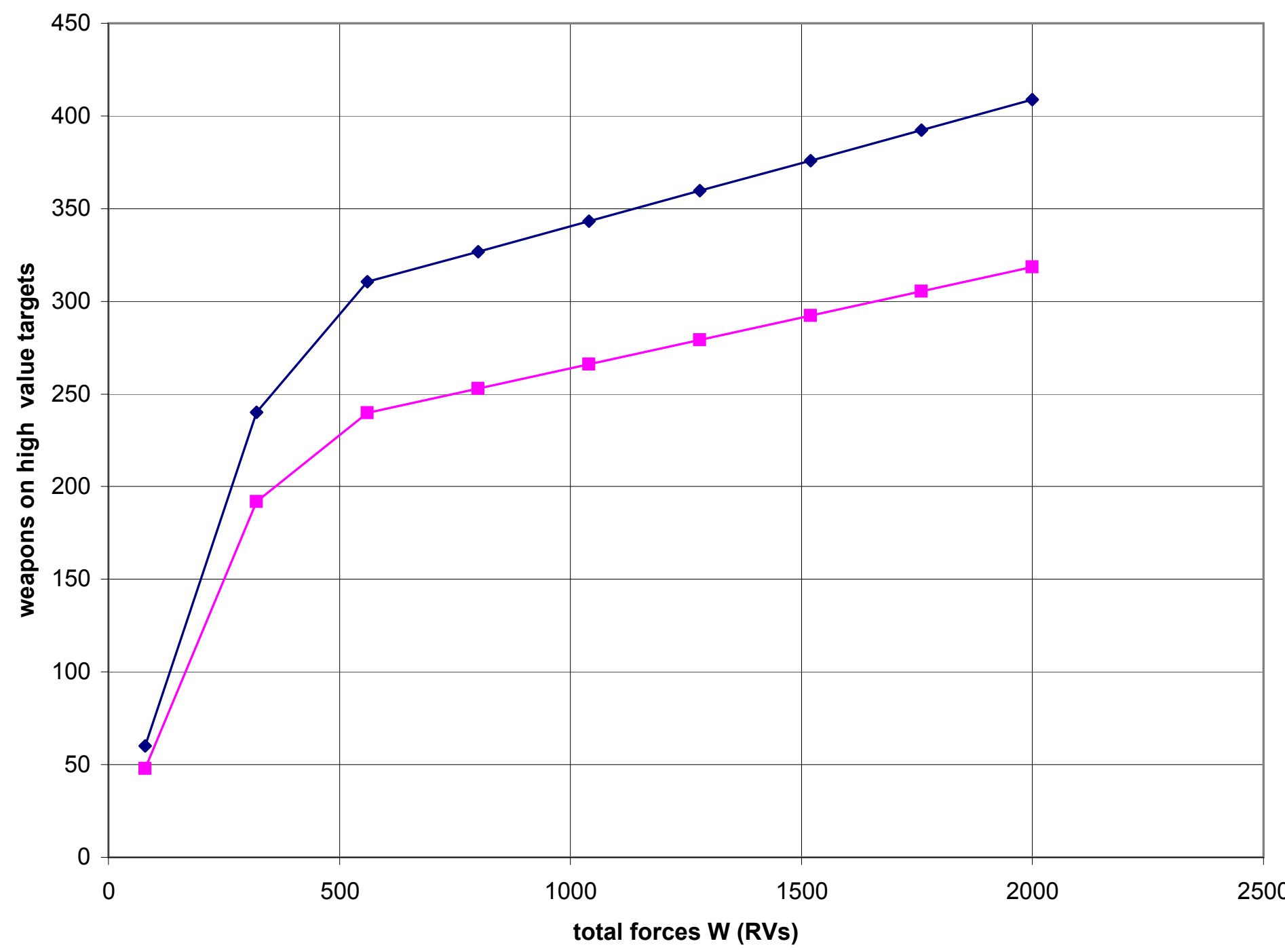


Fig. 5. costs vs total forces W

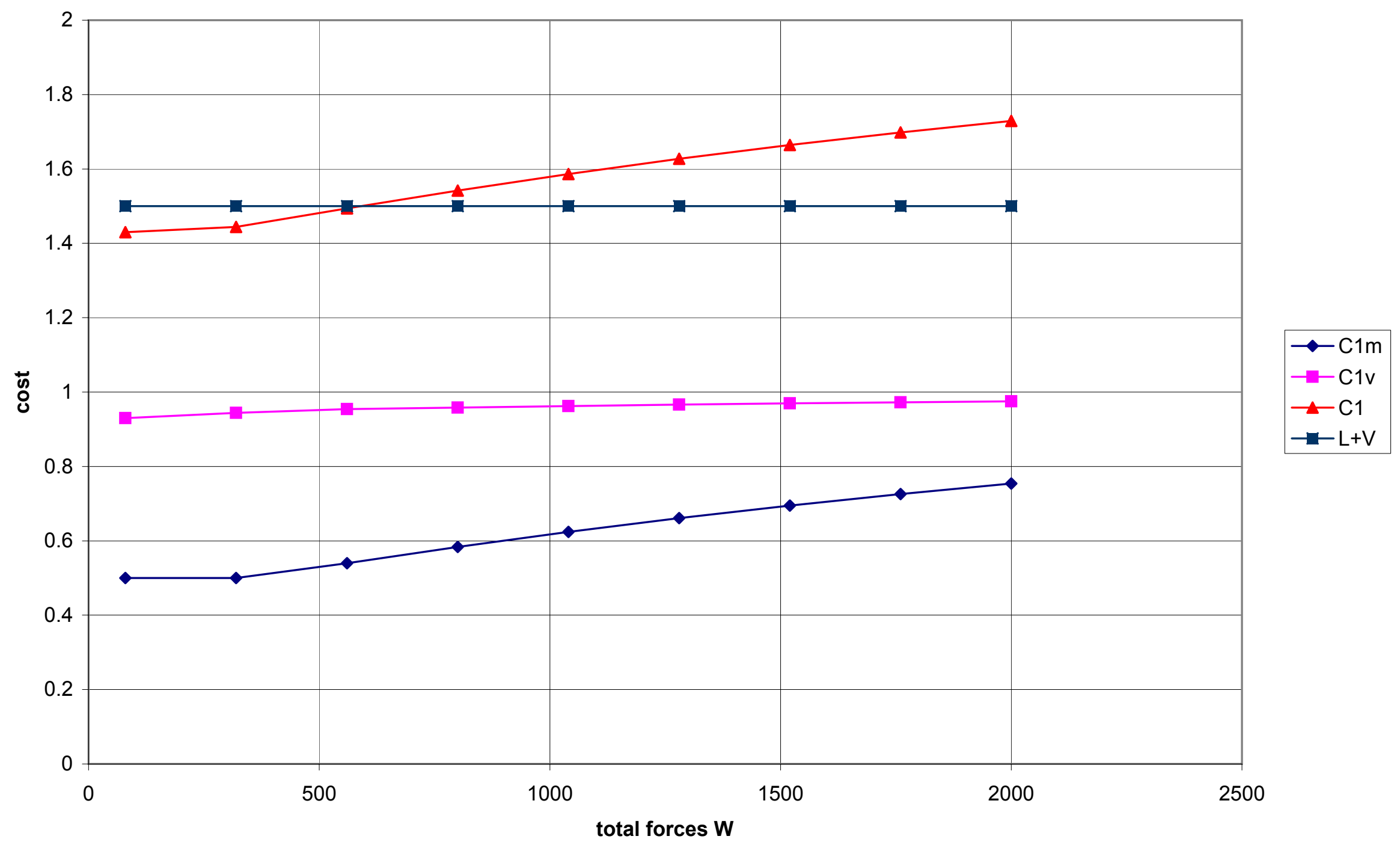


Fig. 6. costs vs W

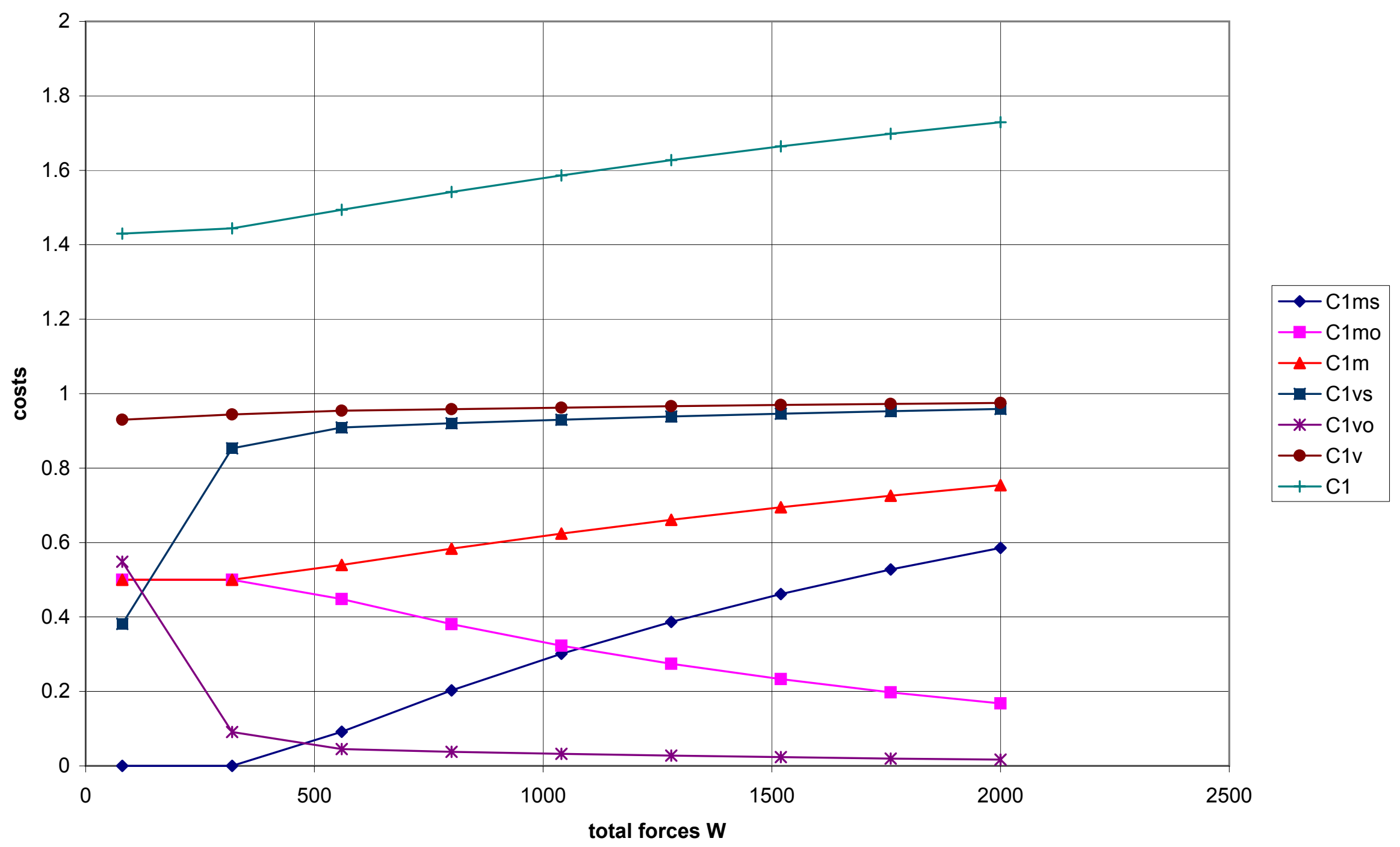


$\begin{array}{llllllllllllllllllllllllllllllllll}0.001 & 0 & 0.8 & 0 & 0.5 & 1 & 1 & 2 & 440 & 2 & 440 & 1760 & 0 & 0.3 & -0.002 & 0.71 & -0.002 & 0.7 & 1320 & 1 & 1 & 0.2 & 1056 & 0.53 & 0.2 & 0.73 & 0.95 & 0.02 & 0.97 & 1.7 & 1.5 & 392.3 & 305\end{array}$ $\begin{array}{lllllllllllllllllllllllllllllllllllll}0.001 & 0 & 0.8 & 0 & 0.5 & 1 & 1 & 2 & 380 & 2 & 380 & 1520 & 0 & 0.3 & -0.003 & 0.68 & -0.003 & 0.67 & 1140 & 1 & 1 & 0.2 & 912 & 0.46 & 0.23 & 0.69 & 0.95 & 0.02 & 0.97 & 1.66 & 1.5 & 376 & 292\end{array}$

$\begin{array}{rllllllllllllllllllllllllllllllllllllll}0.001 & 0 & 0.8 & 0 & 0.5 & 1 & 1 & 2 & 320 & 2 & 320 & 1280 & 0 & 0.3 & -0.003 & 0.64 & -0.003 & 0.63 & 960 & 1 & 1 & 0.2 & 768 & 0.39 & 0.27 & 0.66 & 0.94 & 0.03 & 0.97 & 1.63 & 1.5 & 359.6 & 279\end{array}$

$\begin{array}{lllllllllllllllllllllllllllllllllll}0.001 & 0 & 0.8 & 0 & 0.5 & 1 & 1 & 2 & 260 & 2 & 260 & 1040 & 0 & 0.3 & -0.004 & 0.57 & -0.004 & 0.56 & 780 & 1 & 1 & 0.2 & 624 & 0.3 & 0.32 & 0.62 & 0.93 & 0.03 & 0.96 & 1.59 & 1.5 & 343.2 & 266\end{array}$

$\begin{array}{lllllllllllllllllllllllllllllllllllllll}0.001 & 0 & 0.8 & 0 & 0.5 & 1 & 1 & 2 & 200 & 2 & 200 & 800 & 0 & 0.3 & -0.005 & 0.47 & -0.005 & 0.46 & 600 & 1 & 1 & 0.2 & 480 & 0.2 & 0.38 & 0.58 & 0.92 & 0.04 & 0.96 & 1.54 & 1.5 & 326.9 & 253\end{array}$

$\begin{array}{llllllllllllllllllllllllllllllllll}0.001 & 0 & 0.8 & 0 & 0.5 & 1 & 1 & 2 & 140 & 2 & 140 & 560 & 0 & 0.3 & -0.007 & 0.29 & -0.007 & 0.26 & 420 & 1 & 1 & 0.2 & 336 & 0.09 & 0.45 & 0.54 & 0.91 & 0.04 & 0.95 & 1.49 & 1.5 & 310.5 & 240\end{array}$

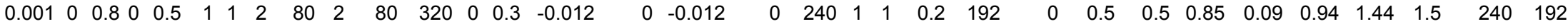

$\begin{array}{llllllllll}0 & 0.5 & 0.5 & 0.85 & 0.09 & 0.94 & 1.44 & 1.5 & 0.5 \\ 0 & 0.5 & 0.5 & 0.38 & 0.55 & 0.93 & 1.43 & 1.5\end{array}$

$\begin{array}{lllllllllllllll}0.001 & 0 & 0.8 & 0 & 0.5 & 1 & 1 & 2 & 20 & 2 & 20 & 80 & 0 & 0.2 & -0.048\end{array}$

0.0 .05

$\begin{array}{llllll}0 & 60 & 1 & 0 & 0.2 & 48\end{array}$

14.2 
fract vs V

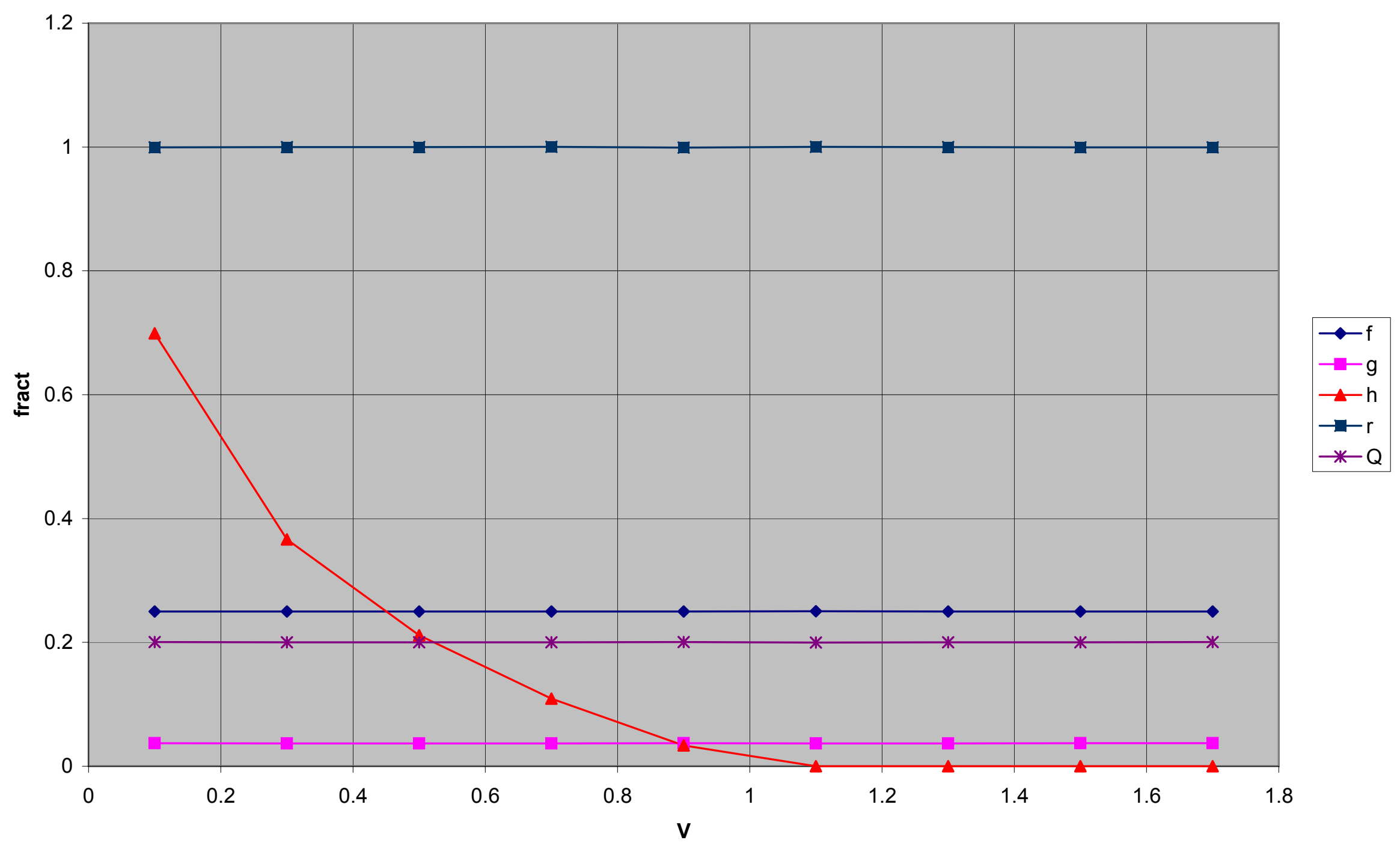


Fig. . costs vs first strike high value preference V

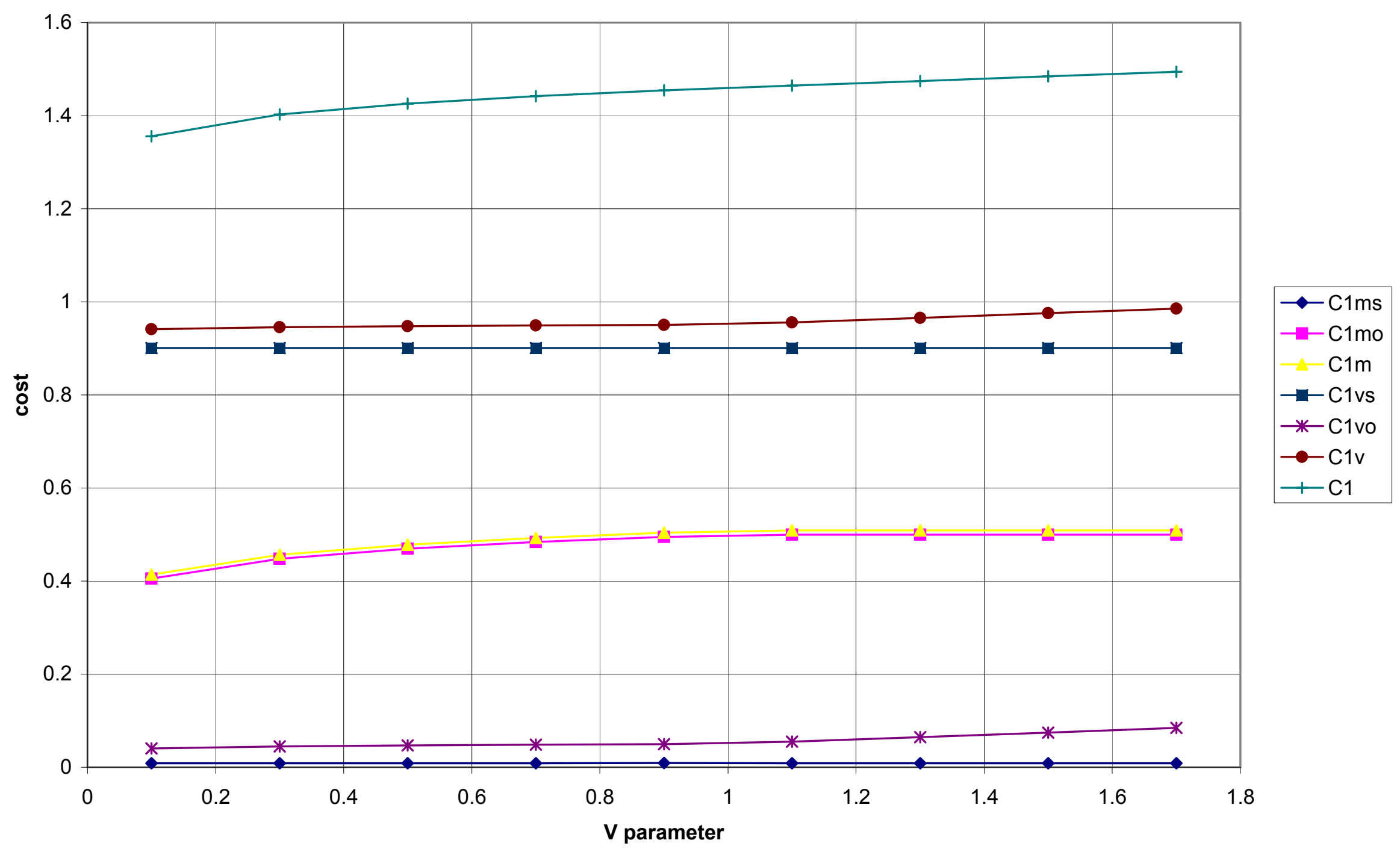


Fig.7. costs vs 1 st strike high value parameter $V$

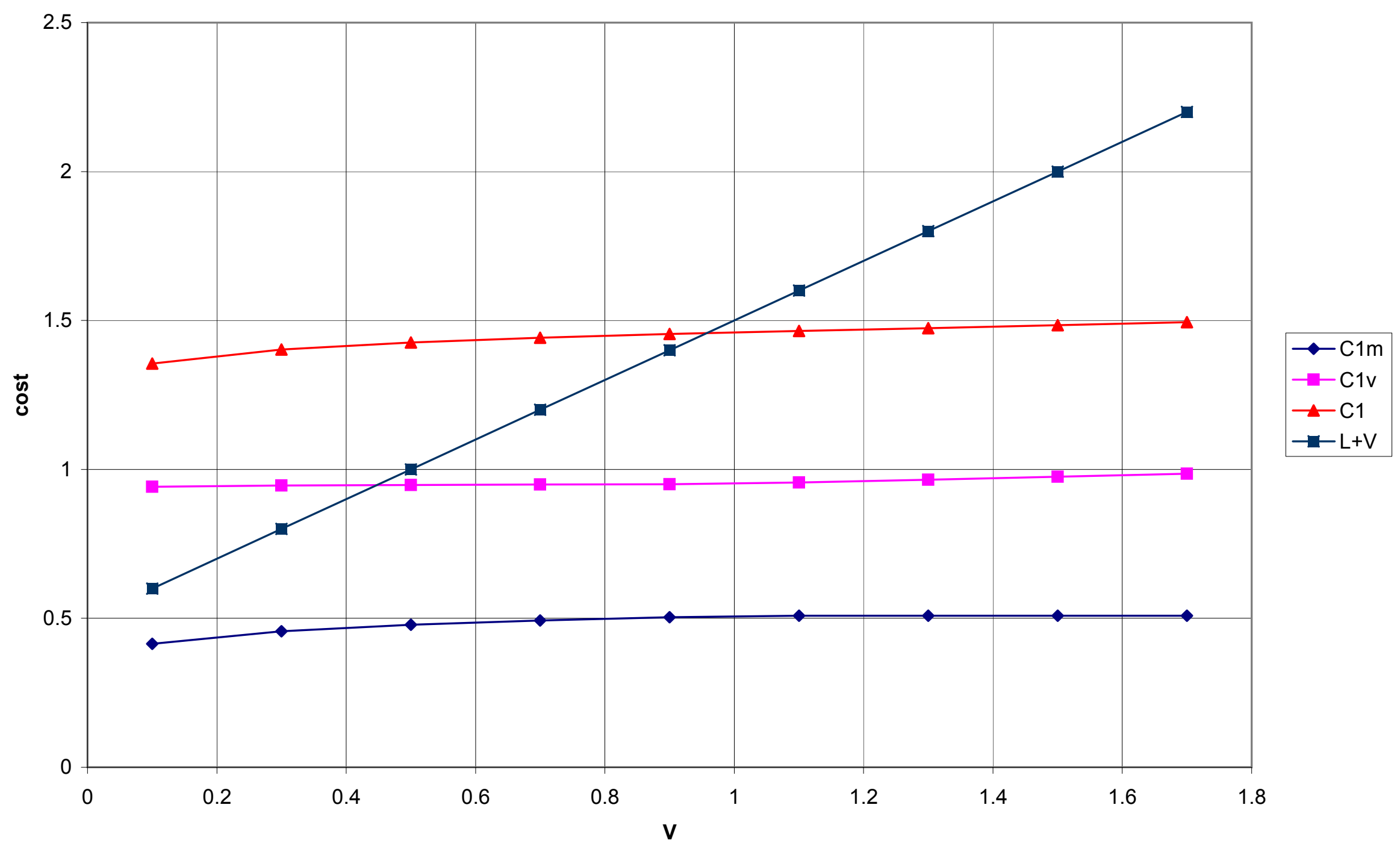




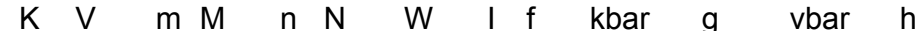
$\begin{array}{llllllllllllllllll}0.001 & 0.01 & 0.8 & 0 & 0.5 & 1 & 0.1 & 2 & 100 & 2 & 100 & 400 & 0 & 0.2 & -0.01 & 0.04 & -0.002 & 0.7 \\ 0.001 & 0.01 & 0.8 & 0 & 0.5 & 1 & 0.3 & 2 & 100 & 2 & 100 & 400 & 0 & 0.2 & -0.01 & 0.04 & -0.006 & 0.37\end{array}$ $\begin{array}{lllllll}0.3 & 2 & 100 & 2 & 100 & 400 & 0\end{array}$

$\begin{array}{lllll}0.001 & 0.01 & 0.8 & 0 & 0.5\end{array}$

$\begin{array}{lllll}0.001 & 0.01 & 0.8 & 0 & 0.5\end{array}$ $\begin{array}{llllllll}0.5 & 2 & 100 & 2 & 100 & 400 & 0 & 0.2\end{array}$

$\begin{array}{lllllllll}1 & 0.7 & 2 & 100 & 2 & 100 & 400 & 0 & 0.3\end{array}$

$\begin{array}{llllllllllllll}0.001 & 0.01 & 0.8 & 0 & 0.5 & 1 & 1.3 & 2 & 100 & 2 & 100 & 400 & 0 & 0.2\end{array}$

0.800 .5

$\begin{array}{lllllllll}1.5 & 2 & 100 & 2 & 100 & 400 & 0 & 0.2\end{array}$

$\begin{array}{llllllll}1.7 & 2 & 100 & 2 & 100 & 400 & 0 & 0.2\end{array}$ $\begin{array}{llllll}-0.01 & 0.04 & -0.008 & 0.21 & 300 & 1\end{array}$

$\begin{array}{llllll}-0.01 & 0.04 & -0.009 & 0.11 & 300 & 1\end{array}$

$\begin{array}{lllllll}-0.01 & 0.04 & -0.01 & 0.03 & 300 & 1\end{array}$

$\begin{array}{llllll}-0.01 & 0.04 & -0.01 & 0 & 300 & 1\end{array}$

$\begin{array}{lll}-0.01 & 0.04 & -0.011\end{array}$

$\begin{array}{llll}-0.01 & 0.04 & -0.011\end{array}$

$\begin{array}{lll}-0.01 & 0.04 & -0.012\end{array}$
$0 \quad 300 \quad 1$

$0 \quad 300 \quad 1$

$0 \quad 3001$
$\mathrm{S}$

C1ms C1moC1m C1vs C1vo C1v C1 L+V $\begin{array}{lllllllllll}0 & 0.2 & 240 & 0.01 & 0.41 & 0.41 & 0.9 & 0.04 & 0.94 & 1.36 & 0.6\end{array}$ $\begin{array}{llllllllllll}0 & 0.2 & 240 & 0.01 & 0.45 & 0.46 & 0.9 & 0.04 & 0.95 & 1.4 & 0.8\end{array}$ $\begin{array}{lllllllllll}0 & 0.2 & 240 & 0.01 & 0.47 & 0.48 & 0.9 & 0.05 & 0.95 & 1.43 & 1\end{array}$

$\begin{array}{lllllllllll}1 & 0.2 & 240 & 0.01 & 0.48 & 0.49 & 0.9 & 0.05 & 0.95 & 1.44 & 1.2\end{array}$

$\begin{array}{lllllllllll}0 & 0.2 & 240 & 0.01 & 0.5 & 0.5 & 0.9 & 0.05 & 0.95 & 1.45 & 1.4\end{array}$

$\begin{array}{lllllllllll}1 & 0.2 & 240 & 0.01 & 0.5 & 0.51 & 0.9 & 0.05 & 0.96 & 1.46 & 1.6\end{array}$

$\begin{array}{lllllllllll}0 & 0.2 & 240 & 0.01 & 0.5 & 0.51 & 0.9 & 0.06 & 0.97 & 1.47 & 1.8\end{array}$

$\begin{array}{llllllllllll}0 & 0.2 & 240 & 0.01 & 0.5 & 0.51 & 0.9 & 0.07 & 0.98 & 1.48 & 2\end{array}$

$\begin{array}{lllllllllll}0 & 0.2 & 240 & 0.01 & 0.5 & 0.51 & 0.9 & 0.08 & 0.99 & 1.49 & 2.2\end{array}$ 
Fig. 8. Fractional allocations vs 2 nd strike high value parameter $K$ $W=1,000$ weapons

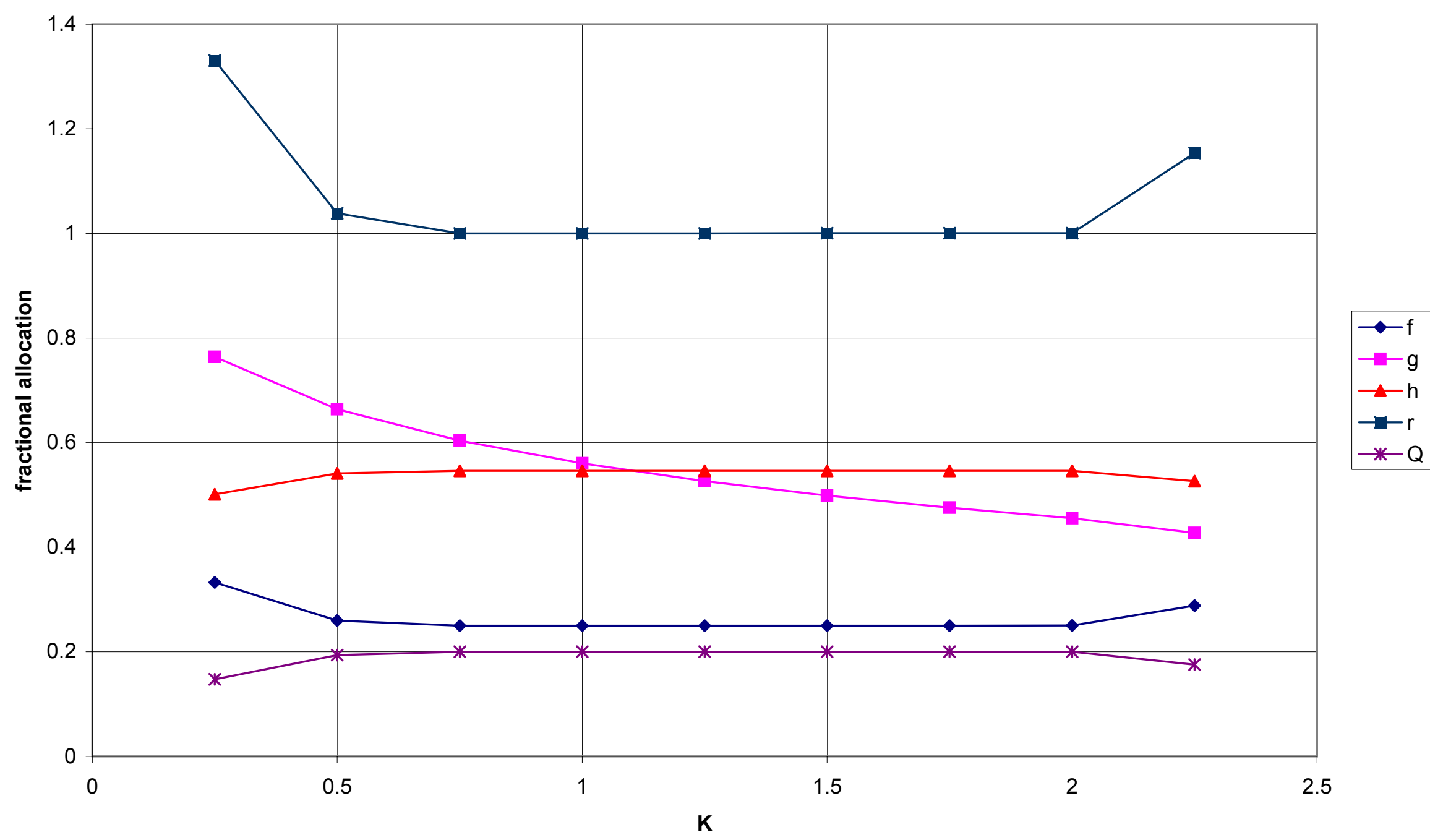


Fig. 9. cost vs 2 nd strike high value parameter $K$

$W=1,000$ weapons

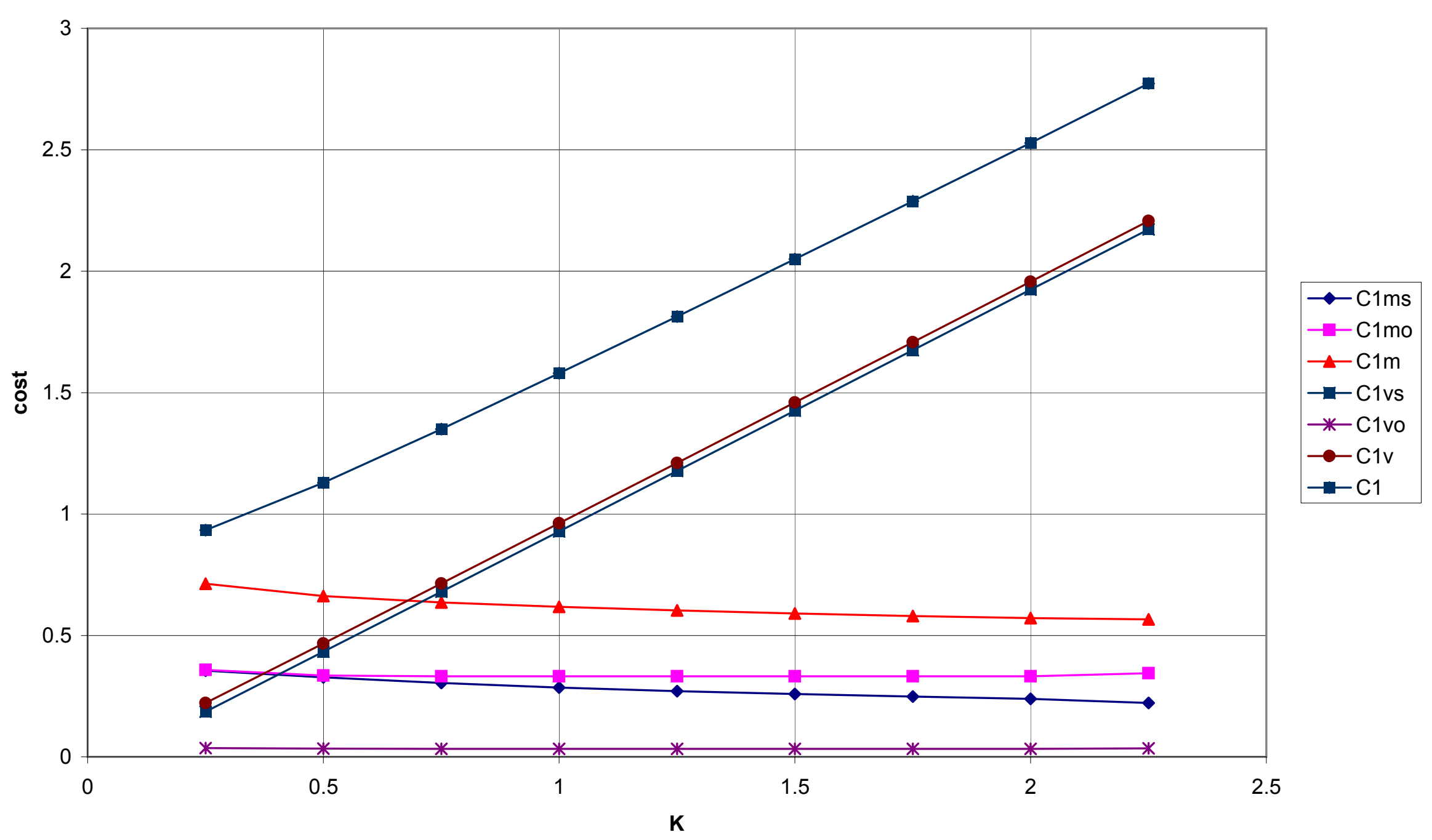




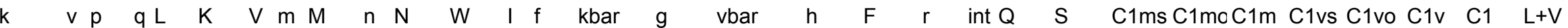

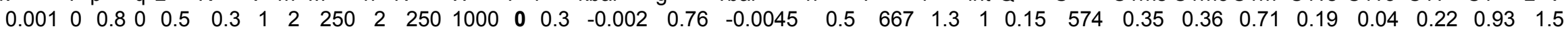
$\begin{array}{lllllllllllllllllllllllllllllllllll}0.001 & 0 & 0.8 & 0 & 0.5 & 0.5 & 1 & 2 & 250 & 2 & 250 & 1000 & 0 & 0.3 & -0.003 & 0.66 & -0.004 & 0.54 & 740 & 1 & 1 & 0.19 & 597 & 0.33 & 0.33 & 0.66 & 0.43 & 0.03 & 0.47 & 1.13 & 1.5\end{array}$ $\begin{array}{lllllllllllllllllllllllllllllll}0.001 & 0 & 0.8 & 0 & 0.5 & 0.8 & 1 & 2 & 250 & 2 & 250 & 1000 & 0 & 0.2 & -0.003 & 0.6 & -0.004 & 0.55 & 750 & 1 & 0 & 0.2 & 600 & 0.3 & 0.33 & 0.64 & 0.68 & 0.03 & 0.71 & 1.35 & 1.5\end{array}$ $\begin{array}{llllllllllllllllllllllllllllllll}0.001 & 0 & 0.8 & 0 & 0.5 & 1 & 1 & 2 & 250 & 2 & 250 & 1000 & 0 & 0.3 & -0.004 & 0.56 & -0.004 & 0.55 & 750 & 1 & 1 & 0.2 & 600 & 0.29 & 0.33 & 0.62 & 0.93 & 0.03 & 0.96 & 1.58 & 1.5\end{array}$ $\begin{array}{llllllllllllllllllllllllllllllllll}0.001 & 0 & 0.8 & 0 & 0.5 & 1.3 & 1 & 2 & 250 & 2 & 250 & 1000 & 0 & 0.3 & -0.004 & 0.53 & -0.004 & 0.55 & 750 & 1 & 1 & 0.2 & 600 & 0.27 & 0.33 & 0.6 & 1.18 & 0.03 & 1.21 & 1.81 & 1.5\end{array}$ $\begin{array}{lllllllllllllllllllllllllllllll}0.001 & 0 & 0.8 & 0 & 0.5 & 1.5 & 1 & 2 & 250 & 2 & 250 & 1000 & 0 & 0.3 & -0.005 & 0.5 & -0.004 & 0.55 & 750 & 1 & 1 & 0.2 & 600 & 0.26 & 0.33 & 0.59 & 1.43 & 0.03 & 1.46 & 2.05 & 1.5\end{array}$ $\begin{array}{llllllllllllllllllllllllllllllllll}0.001 & 0 & 0.8 & 0 & 0.5 & 1.8 & 1 & 2 & 250 & 2 & 250 & 1000 & 0 & 0.3 & -0.005 & 0.48 & -0.004 & 0.55 & 750 & 1 & 1 & 0.2 & 600 & 0.25 & 0.33 & 0.58 & 1.67 & 0.03 & 1.71 & 2.29 & 1.5\end{array}$ $\begin{array}{lllllllllllllllllllllllllllllll}0.001 & 0 & 0.8 & 0 & 0.5 & 2 & 1 & 2 & 250 & 2 & 250 & 1000 & 0 & 0.3 & -0.005 & 0.46 & -0.004 & 0.55 & 750 & 1 & 1 & 0.2 & 600 & 0.24 & 0.33 & 0.57 & 1.92 & 0.03 & 1.96 & 2.53 & 1.5\end{array}$ $\begin{array}{llllllllllllllllllllllllllllllll}0.001 & 0 & 0.8 & 0 & 0.5 & 2.3 & 1 & 2 & 250 & 2 & 250 & 1000 & 0 & 0.3 & -0.005 & 0.43 & -0.0042 & 0.53 & 712 & 1.2 & 1 & 0.18 & 588 & 0.22 & 0.34 & 0.57 & 2.17 & 0.03 & 2.21 & 2.77 & 1.5\end{array}$ 
Fig. 10. allocations vs interceptors

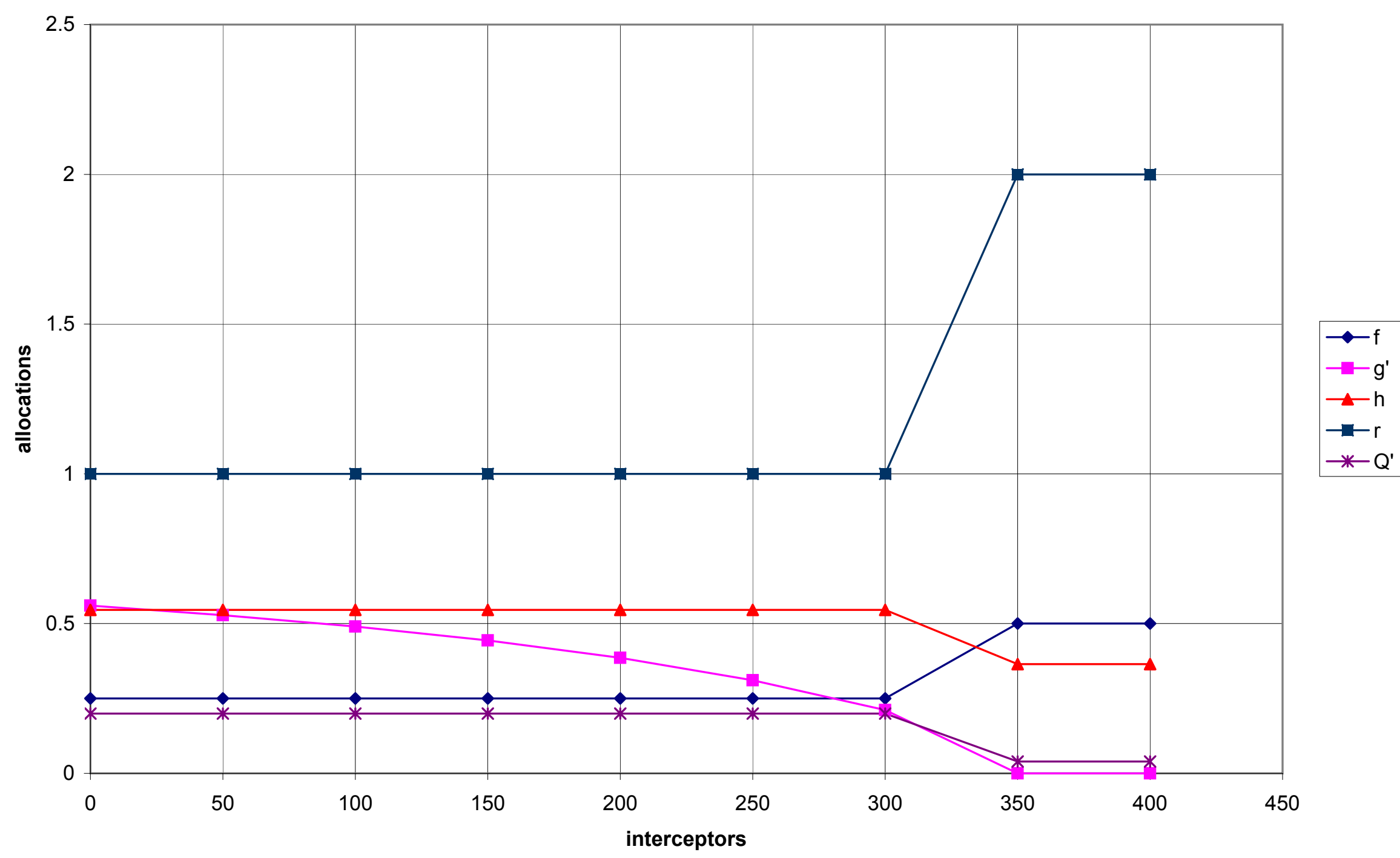


Fig. 11. costs vs Interceptors

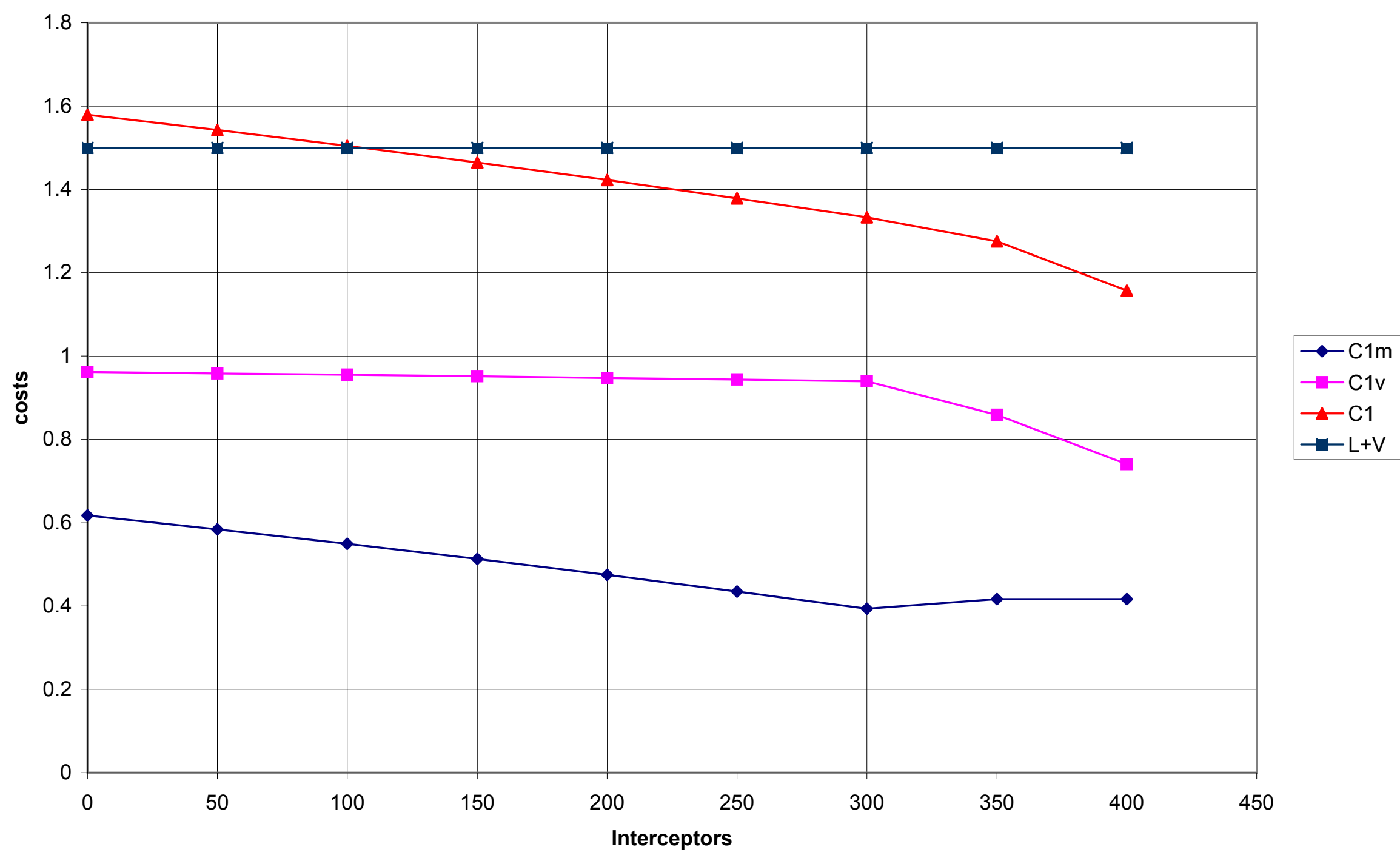


Fig. 12. strikes on high value targets vs interceptors

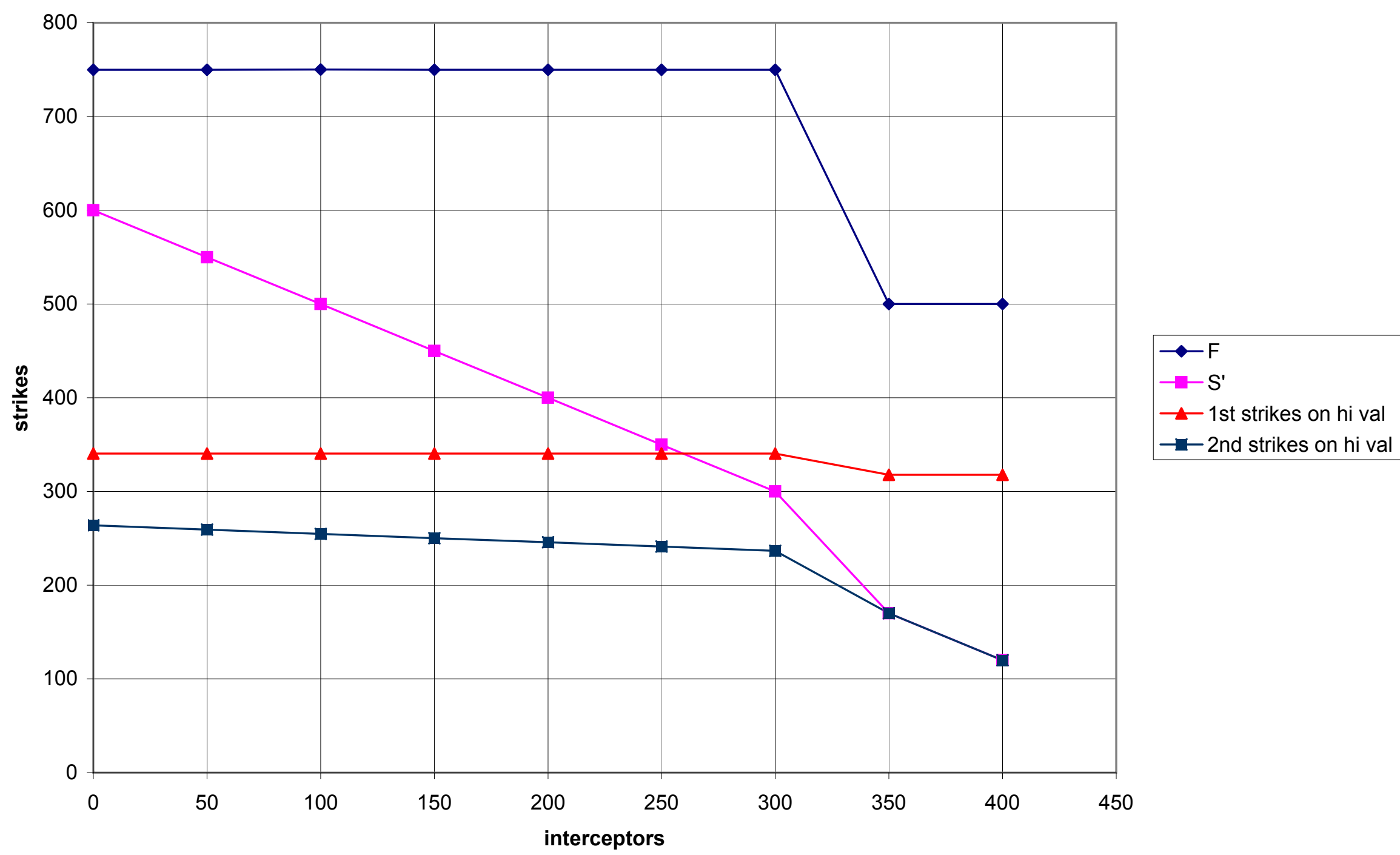


all costs vs Int

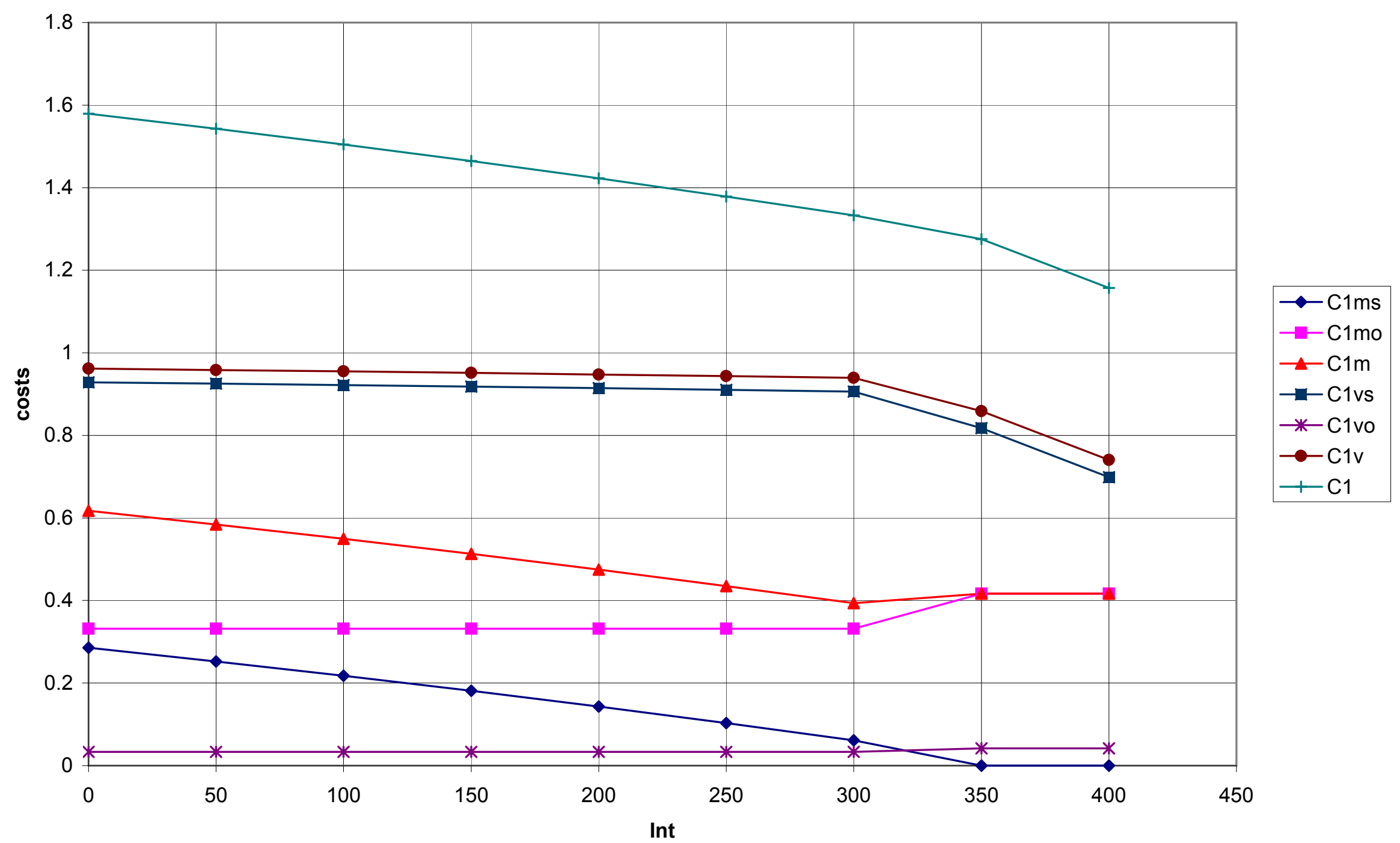




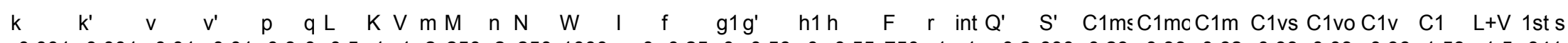

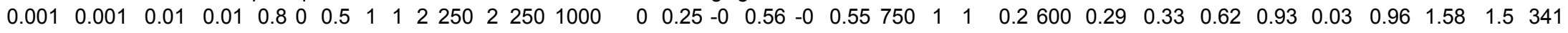
$\begin{array}{llllllllllllllllllllllllllllllllllll}0.001 & 0.001 & 0.01 & 0.01 & 0.8 & 0 & 0.5 & 1 & 1 & 2 & 250 & 2 & 250 & 1000 & 50 & 0.25 & -0 & 0.53 & -0 & 0.55 & 750 & 1 & 1 & 0.2 & 550 & 0.25 & 0.33 & 0.58 & 0.93 & 0.03 & 0.96 & 1.54 & 1.5 & 341\end{array}$ $\begin{array}{llllllllllllllllllllllllllllllllllll}0.001 & 0.001 & 0.01 & 0.01 & 0.8 & 0 & 0.5 & 1 & 1 & 2 & 250 & 2 & 250 & 1000 & 100 & 0.25 & -0 & 0.49 & -0 & 0.55 & 750 & 1 & 0 & 0.2 & 500 & 0.22 & 0.33 & 0.55 & 0.92 & 0.03 & 0.95 & 1.5 & 1.5 & 341\end{array}$ $\begin{array}{llllllllllllllllllllllllllllllllllll}0.001 & 0.001 & 0.01 & 0.01 & 0.8 & 0 & 0.5 & 1 & 1 & 2 & 250 & 2 & 250 & 1000 & 150 & 0.25 & -0 & 0.44 & -0 & 0.55 & 750 & 1 & 1 & 0.2 & 450 & 0.18 & 0.33 & 0.51 & 0.92 & 0.03 & 0.95 & 1.46 & 1.5 & 341\end{array}$ $\begin{array}{lllllllllllllllllllllllllllllllllll}0.001 & 0.001 & 0.01 & 0.01 & 0.8 & 0 & 0.5 & 1 & 1 & 2 & 250 & 2 & 250 & 1000 & 200 & 0.25 & -0 & 0.39 & -0 & 0.55 & 750 & 1 & 1 & 0.2 & 400 & 0.14 & 0.33 & 0.47 & 0.91 & 0.03 & 0.95 & 1.42 & 1.5 & 341\end{array}$ $\begin{array}{llllllllllllllllllllllllllllllllllll}0.001 & 0.001 & 0.01 & 0.01 & 0.8 & 0 & 0.5 & 1 & 1 & 2 & 250 & 2 & 250 & 1000 & 250 & 0.25 & -0 & 0.31 & -0 & 0.55 & 750 & 1 & 1 & 0.2 & 350 & 0.1 & 0.33 & 0.44 & 0.91 & 0.03 & 0.94 & 1.38 & 1.5 & 341\end{array}$ $\begin{array}{llllllllllllllllllllllllllllllllllllll}0.001 & 0.001 & 0.01 & 0.01 & 0.8 & 0 & 0.5 & 1 & 1 & 2 & 250 & 250 & 1000 & 300 & 0.25 & -0 & 0.21 & -0 & 0.55 & 750 & 1 & 1 & 0.2 & 300 & 0.06 & 0.33 & 0.39 & 0.91 & 0.03 & 0.94 & 1.33 & 1.5 & 341\end{array}$

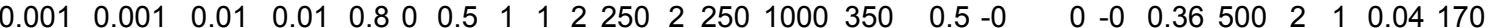
$\begin{array}{llllllllll}0 & 0.42 & 0.42 & 0.82 & 0.04 & 0.86 & 1.28 & 1.5 & 318\end{array}$

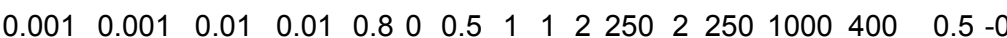




\section{F \& S vs W}

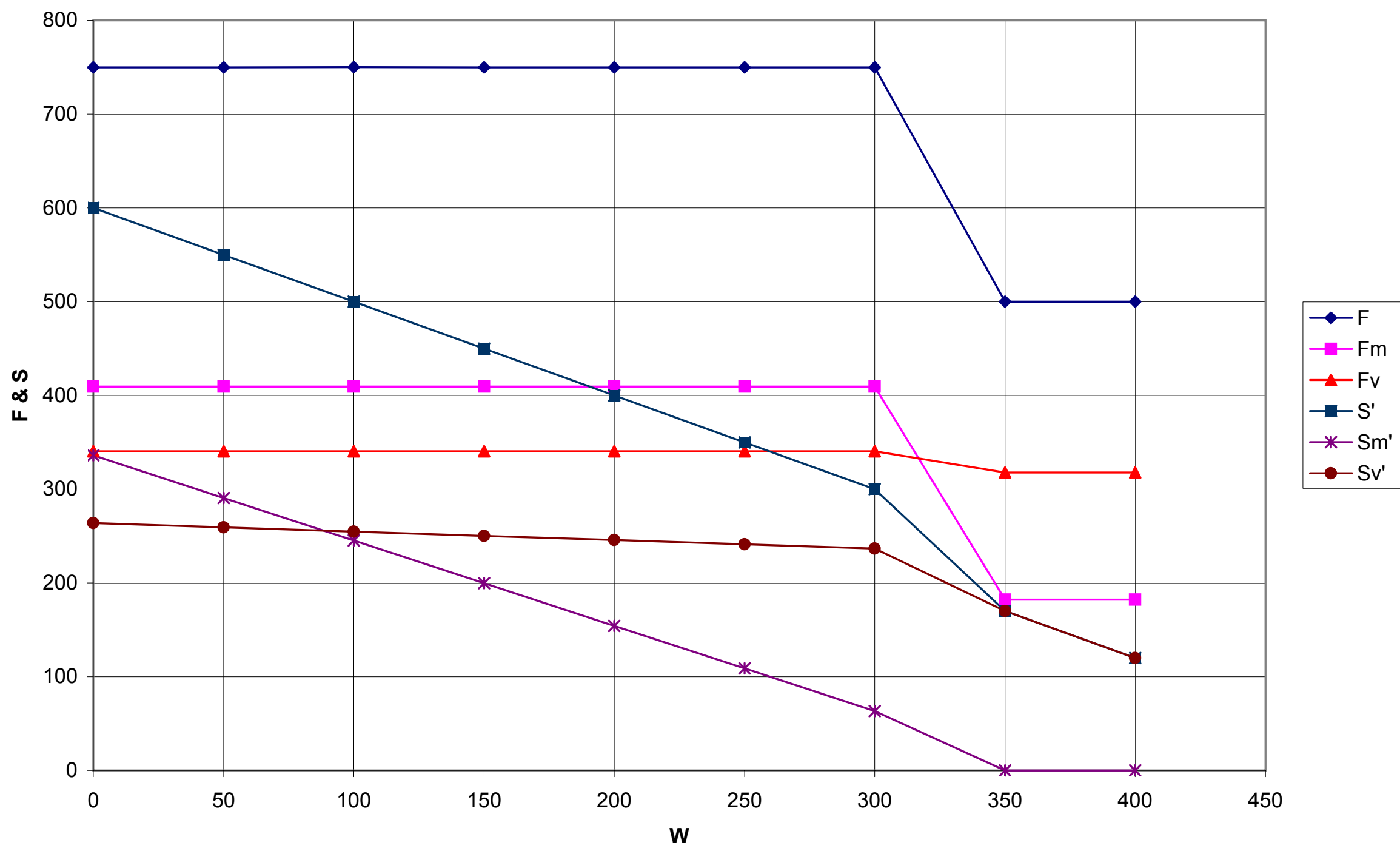




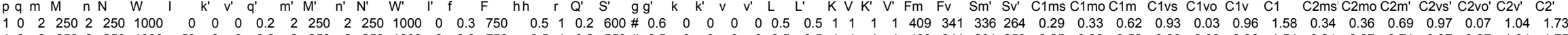

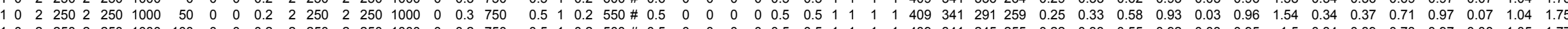

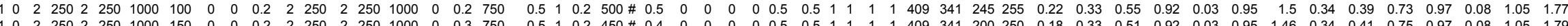

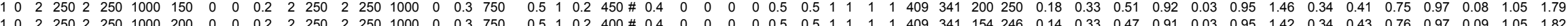

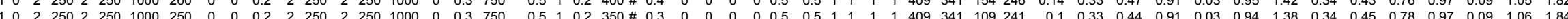

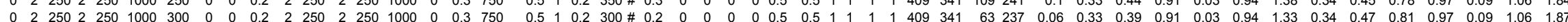

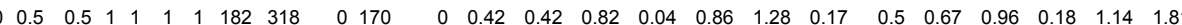
$\begin{array}{lllllllllllllllllllllllllllllllllllllllllllllllllllllll}10 & 2 & 250 & 250 & 1000 & 400 & 0 & 0 & 0.2 & 2 & 250 & 2 & 250 & 1000 & 0 & 0.5 & 500 & 0.4 & 2 & 0 & 120 & \# & 0 & 0 & 0 & 0 & 0 & 0.5 & 0.5 & 1 & 1 & 1 & 1 & 182 & 318 & 0 & 120 & 0 & 0.42 & 0.42 & 0.7 & 0.04 & 0.74 & 1.16 & 0.17 & 0.5 & 0.67 & 0.96 & 0.3 & 1.26 & 1.93\end{array}$ 
allocations

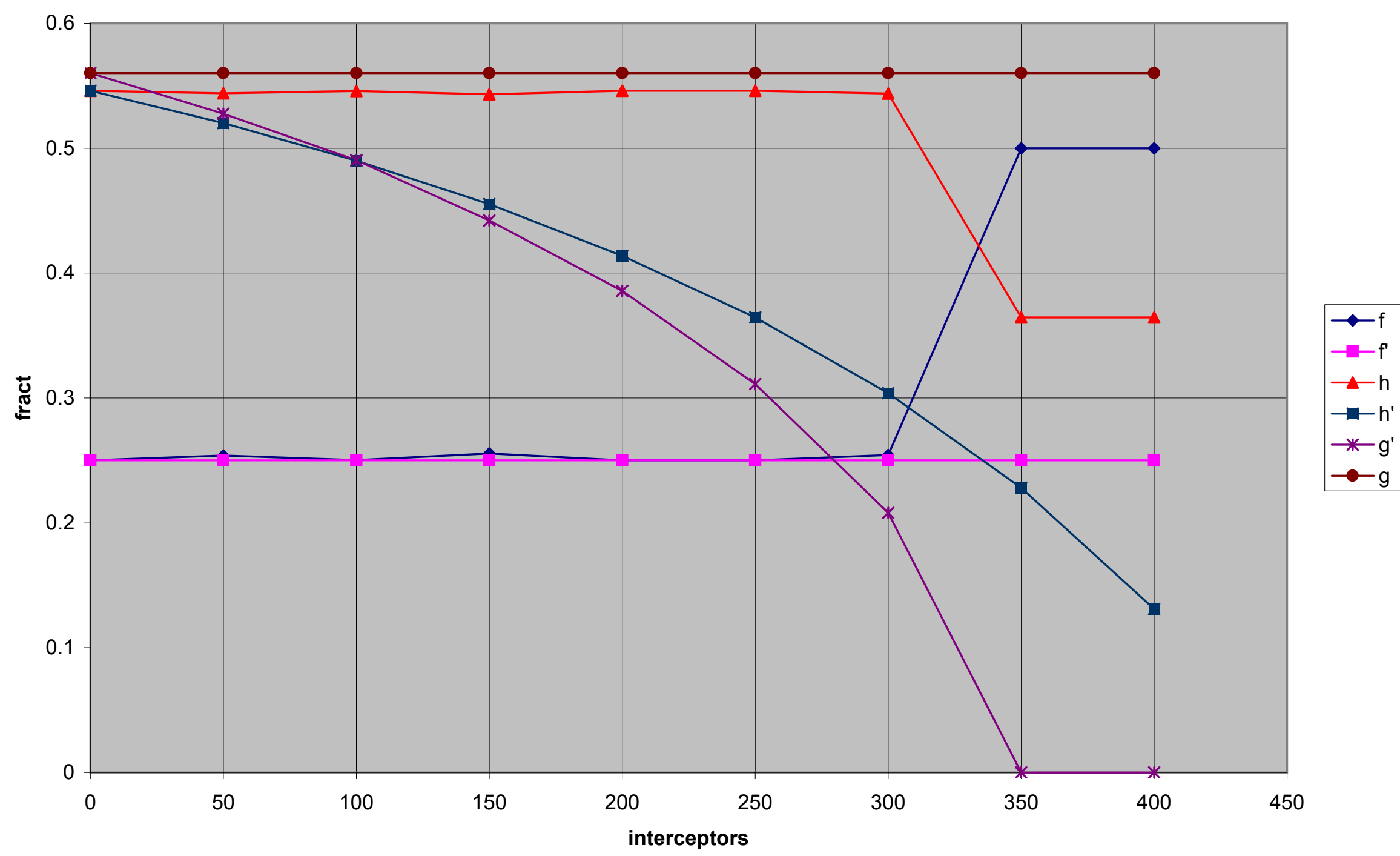


$F \& S$

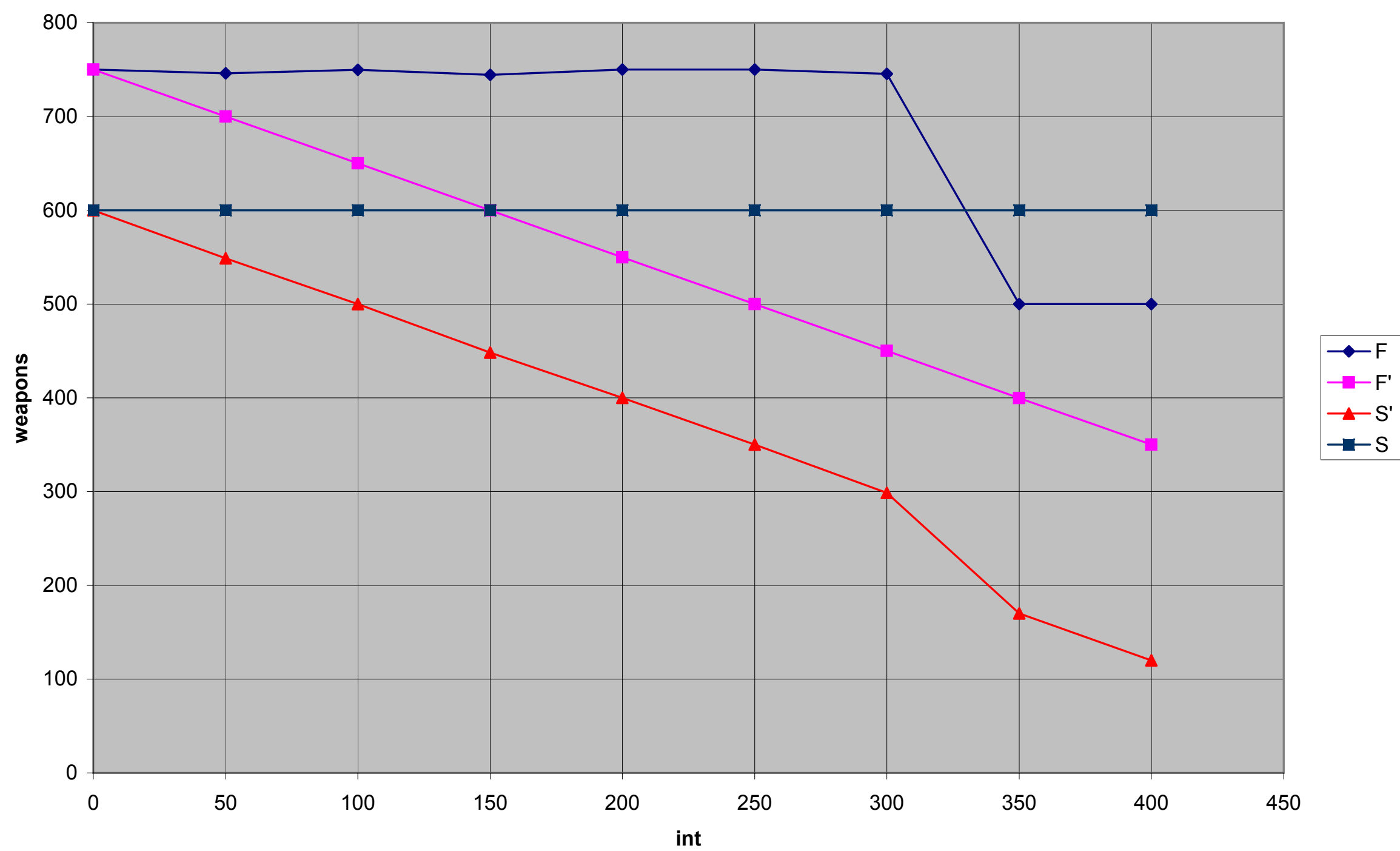


strikes

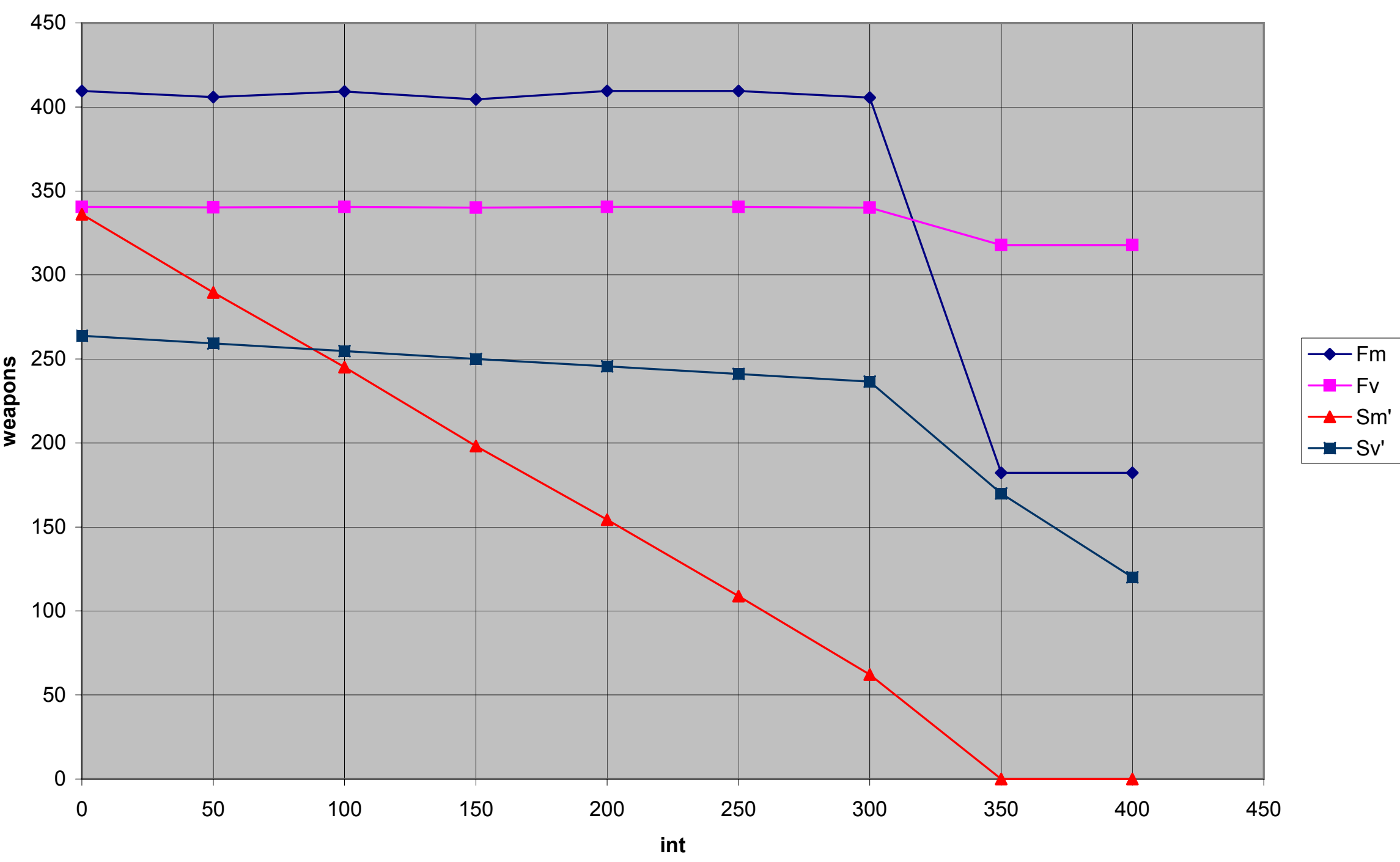


strikes

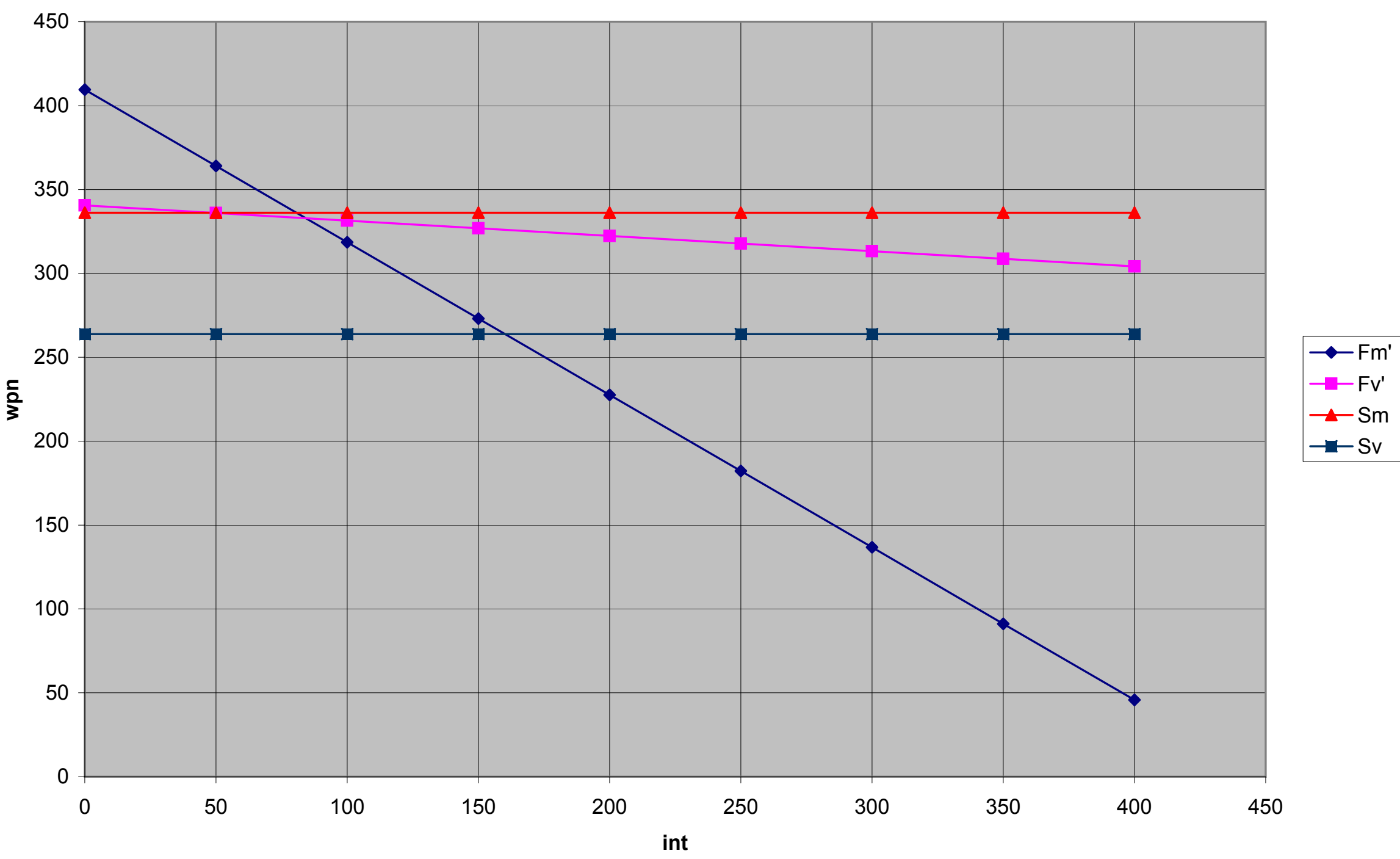




\section{C1}

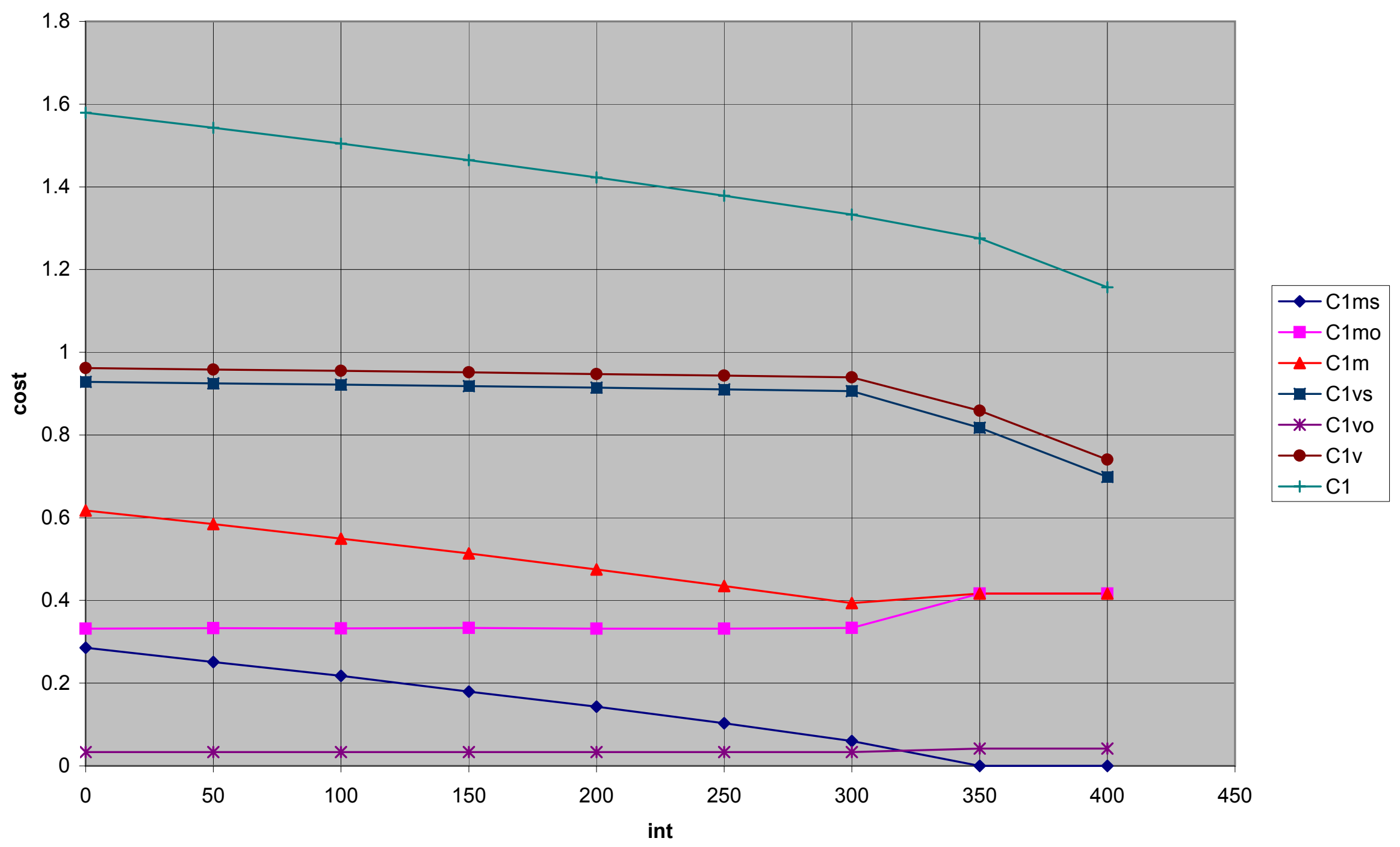




\section{C1'}

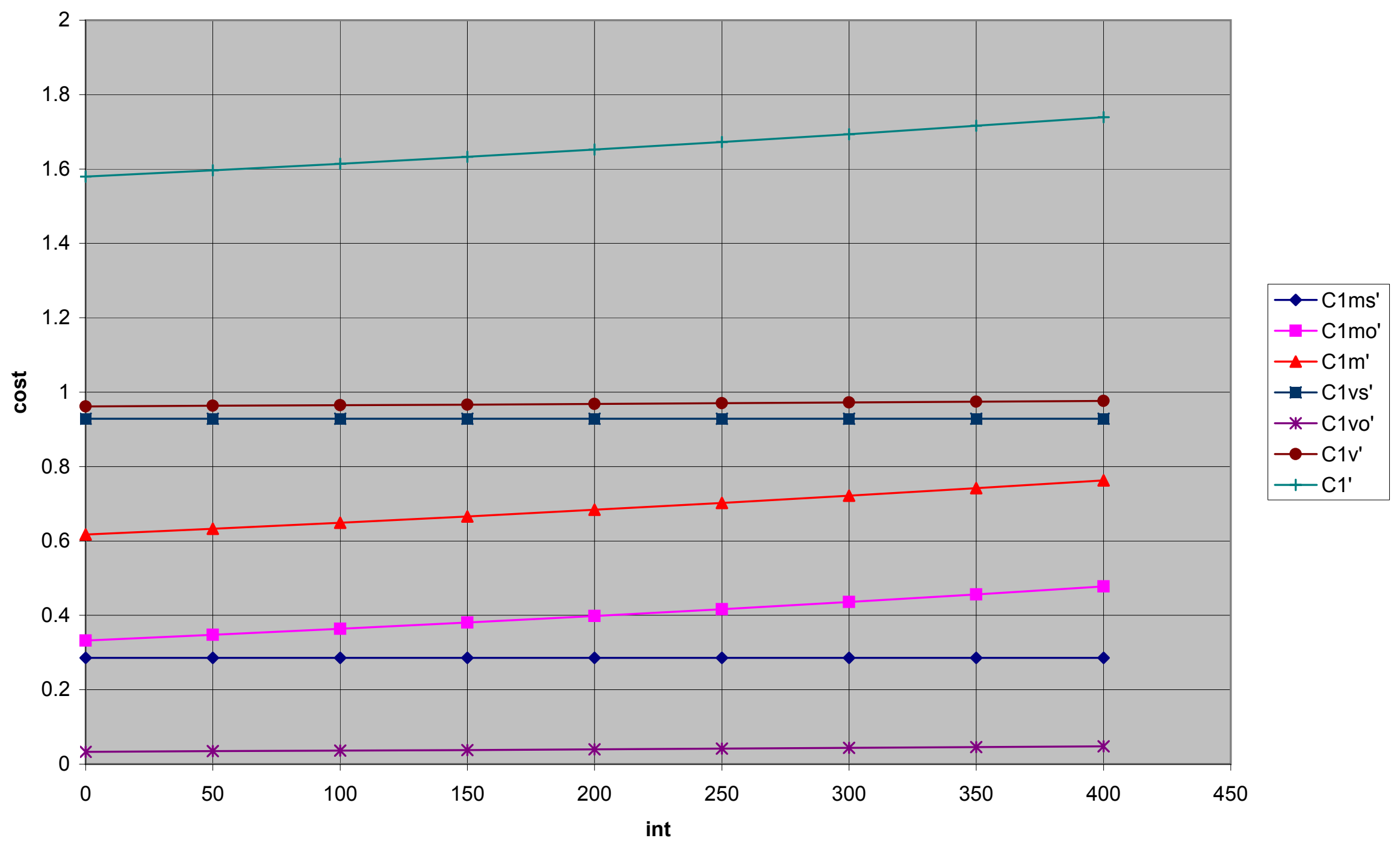


node 1 \& 2

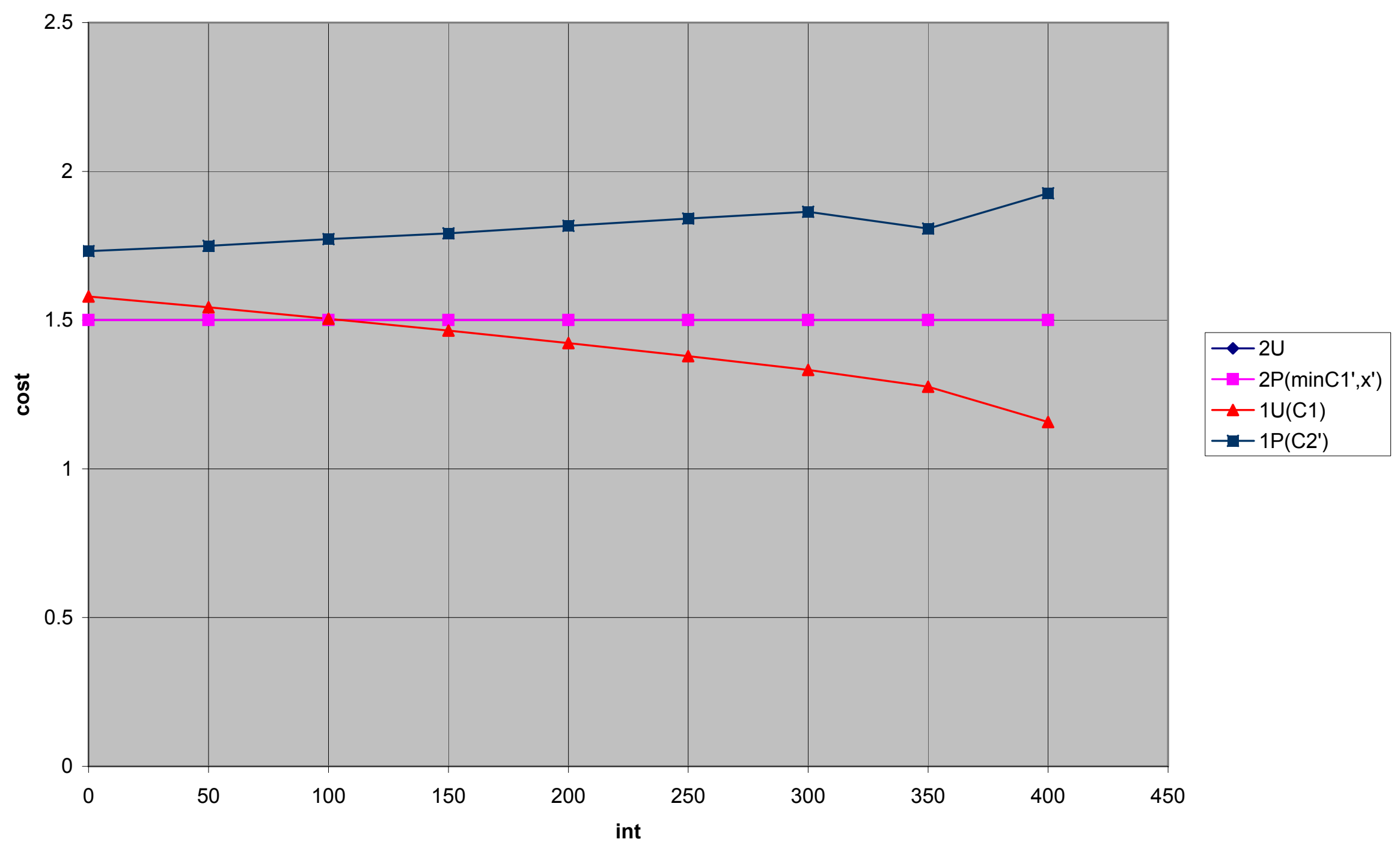


node 5

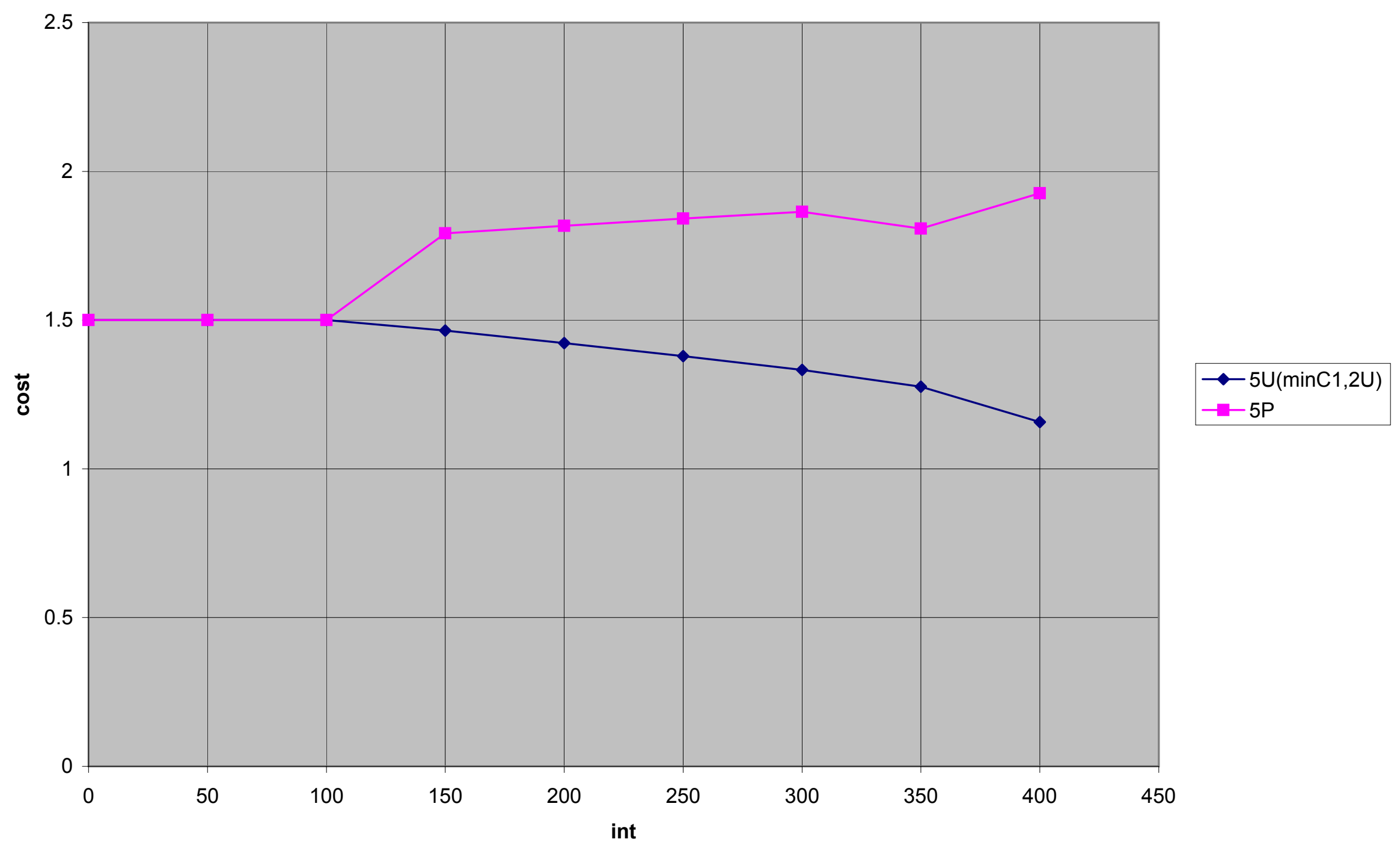


nodes 3 \& 4

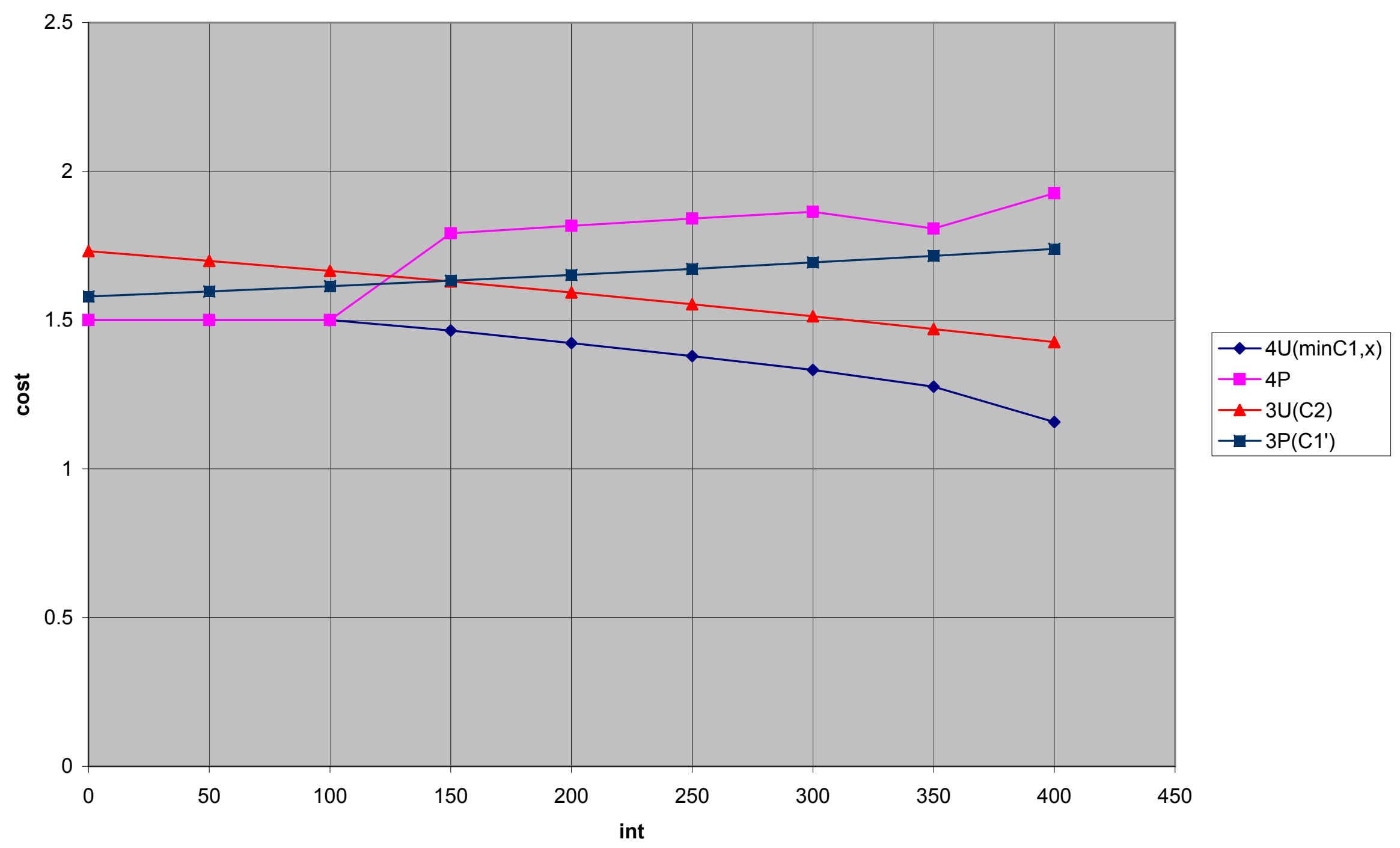


node 6

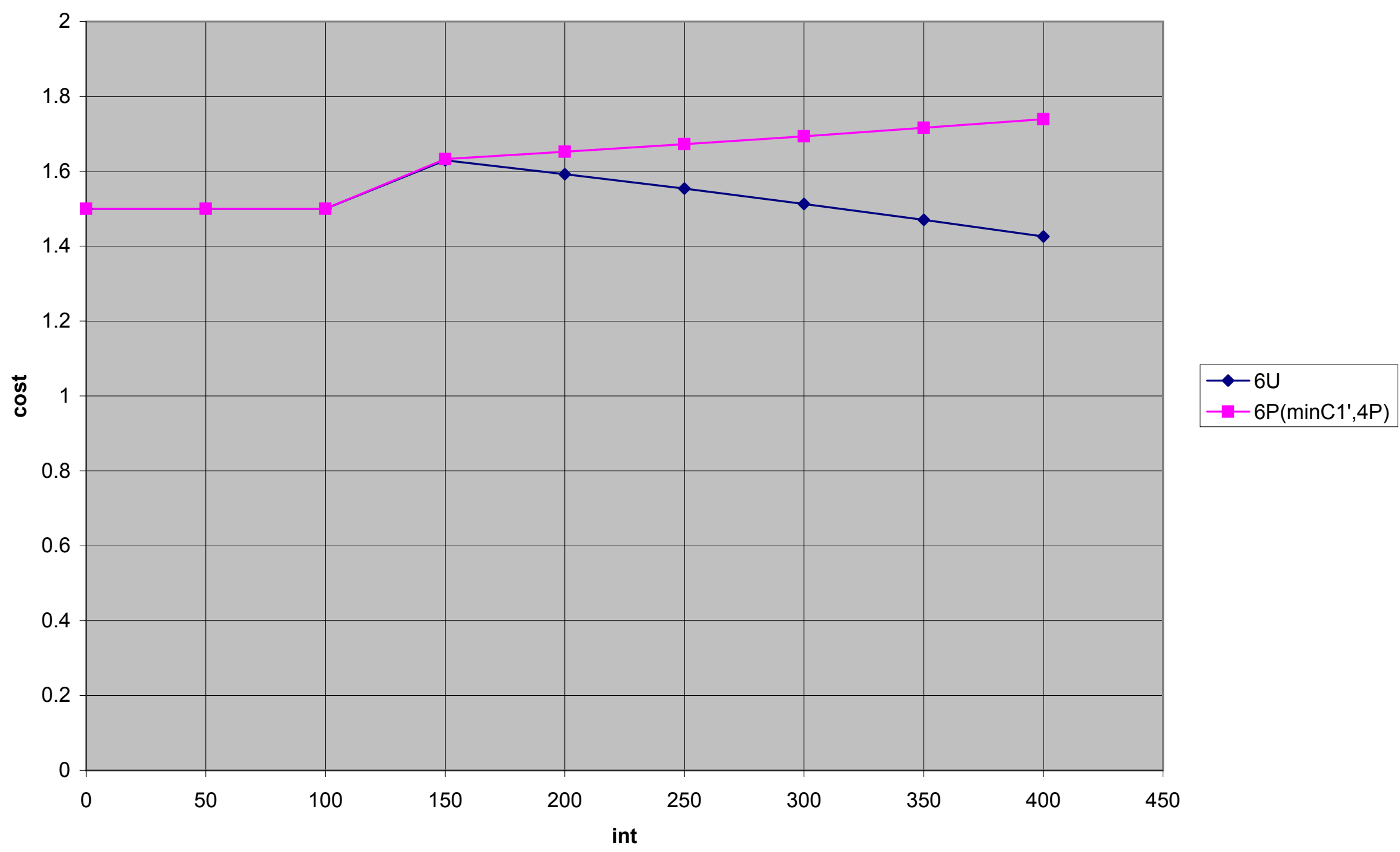


node 7

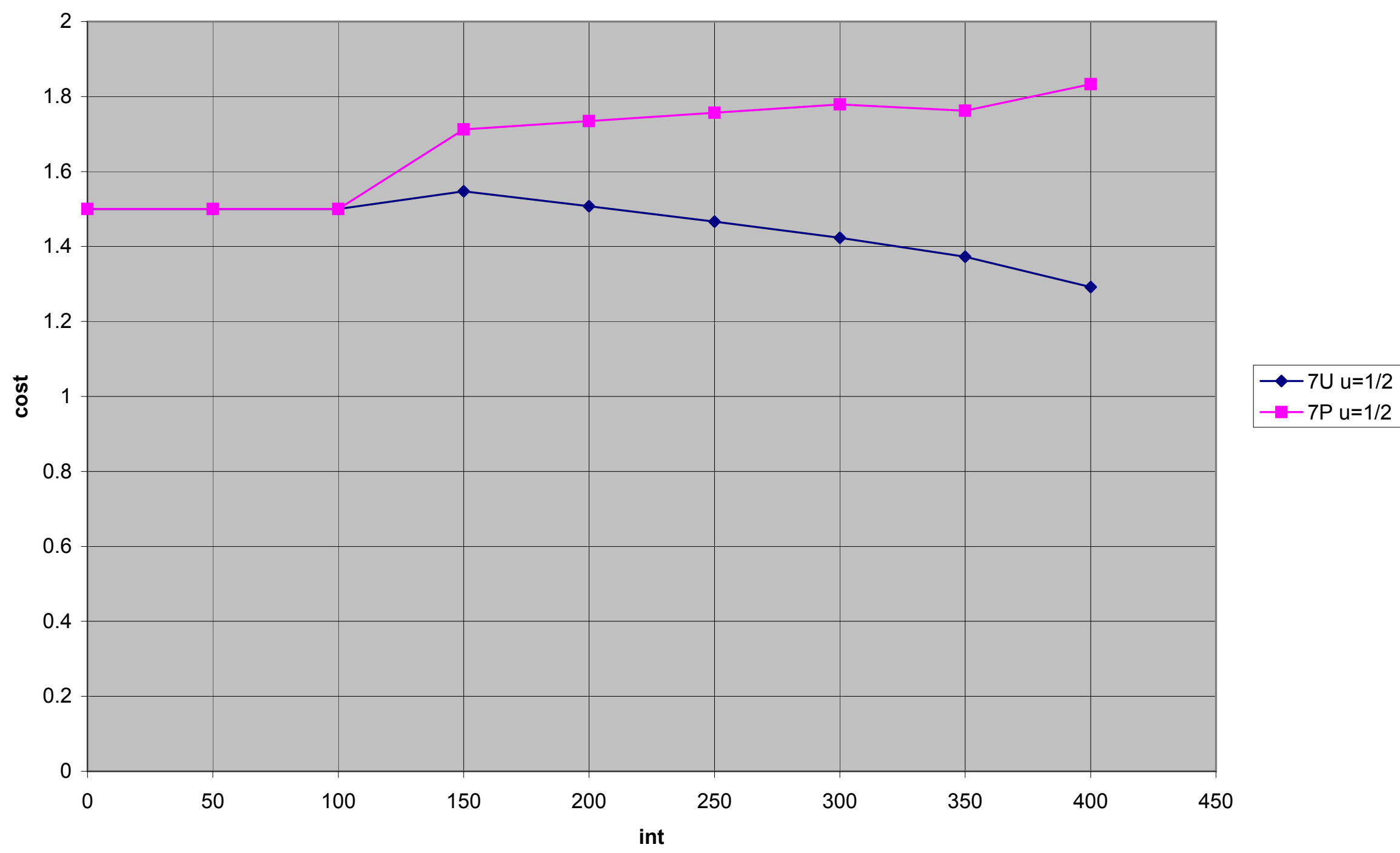




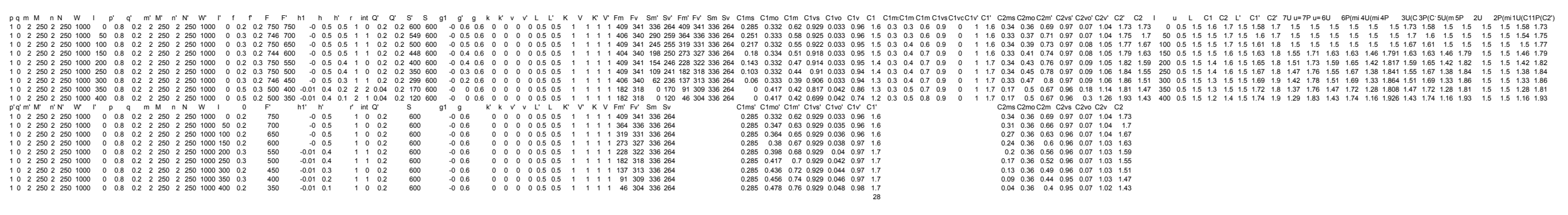


u $\quad$ L/L+1C1 $\quad$ C2 $\quad L^{\prime} / L^{\prime}+C 1^{\prime} \quad C^{\prime} \quad 7 \mathrm{U} 157 \mathrm{P} 156 \mathrm{U} \quad 6 \mathrm{P}\left(\mathrm{m} 4 \mathrm{U}\left(\mathrm{m} 4 \mathrm{P} \quad 3 \mathrm{U}\left(\mathrm{C} 3 \mathrm{P}\left(\mathrm{C} 5 \mathrm{U}\left(\mathrm{m} 5 \mathrm{P} \quad 2 \mathrm{U} \quad 2 \mathrm{P}\left(\mathrm{m} 1 \mathrm{U}\left(\mathrm{C} 1 \mathrm{P}\left(\mathrm{C} 2^{\prime}\right)\right.\right.\right.\right.\right.\right.\right.$

$\begin{array}{lllllllllllllllllllll}0.5 & 0.5 & 0.1 & 0.5 & 0.5 & 0.5 & 0.5 & 0.1 & 0.5 & 0.1 & 0.5 & 0.1 & 0.5 & 0.5 & 0.5 & 0.1 & 0.5 & 0.5 & 0.5 & 0.1 & 0.5\end{array}$

$\begin{array}{lllllllllllllllllllll}0.5 & 0.5 & 0.2 & 0.5 & 0.5 & 0.5 & 0.5 & 0.2 & 0.5 & 0.2 & 0.5 & 0.2 & 0.5 & 0.5 & 0.5 & 0.2 & 0.5 & 0.5 & 0.5 & 0.2 & 0.5\end{array}$

$\begin{array}{lllllllllllllllllllll}0.5 & 0.5 & 0.3 & 0.5 & 0.5 & 0.5 & 0.5 & 0.3 & 0.5 & 0.3 & 0.5 & 0.3 & 0.5 & 0.5 & 0.5 & 0.3 & 0.5 & 0.5 & 0.5 & 0.3 & 0.5\end{array}$

$0.5 \begin{array}{lllllllllllllllllllll}0.5 & 0.4 & 0.5 & 0.5 & 0.5 & 0.5 & 0.4 & 0.5 & 0.4 & 0.5 & 0.4 & 0.5 & 0.5 & 0.5 & 0.4 & 0.5 & 0.5 & 0.5 & 0.4 & 0.5\end{array}$

$0.5 \begin{array}{lllllllllllllllllllll}0.5 & 0.5 & 0.5 & 0.5 & 0.5 & 0.5 & 0.5 & 0.5 & 0.5 & 0.5 & 0.5 & 0.5 & 0.5 & 0.5 & 0.5 & 0.5 & 0.5 & 0.5 & 0.5 & 0.5\end{array}$

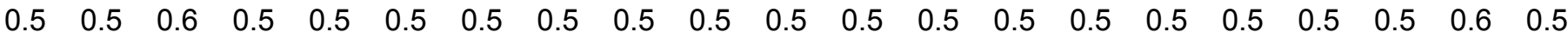

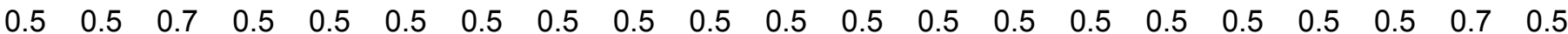

$\begin{array}{lllllllllllllllllllll}0.5 & 0.5 & 0.8 & 0.5 & 0.5 & 0.5 & 0.5 & 0.5 & 0.5 & 0.5 & 0.5 & 0.5 & 0.5 & 0.5 & 0.5 & 0.5 & 0.5 & 0.5 & 0.5 & 0.8 & 0.5\end{array}$

$\begin{array}{lllllllllllllllllllll}0.5 & 0.5 & 0.9 & 0.5 & 0.5 & 0.5 & 0.5 & 0.5 & 0.5 & 0.5 & 0.5 & 0.5 & 0.5 & 0.5 & 0.5 & 0.5 & 0.5 & 0.5 & 0.5 & 0.9 & 0.5\end{array}$ 